Portland State University

PDXScholar

6-10-2019

\title{
Teacher Learning in the Context of Students' Mathematical Thinking
}

Mary Sherrett Duden

Portland State University

Follow this and additional works at: https://pdxscholar.library.pdx.edu/open_access_etds

Part of the Curriculum and Instruction Commons, and the Science and Mathematics Education Commons

Let us know how access to this document benefits you.

\section{Recommended Citation}

Duden, Mary Sherrett, "Teacher Learning in the Context of Students' Mathematical Thinking" (2019). Dissertations and Theses. Paper 5493.

https://doi.org/10.15760/etd.7367

This Dissertation is brought to you for free and open access. It has been accepted for inclusion in Dissertations and Theses by an authorized administrator of PDXScholar. Please contact us if we can make this document more accessible: pdxscholar@pdx.edu. 
Teacher Learning in the Context of Students' Mathematical Thinking

\author{
by \\ Mary Sherrett Duden \\ A dissertation submitted in partial fulfillment of the \\ requirements of the degree of \\ Doctor of Education \\ in \\ Educational Leadership: Curriculum and Instruction
}

Dissertation Committee:

Nicole Rigelman, Chair

Amanda Sugimoto

Swapna Mukhopadhyay

Paul Latiolais

Portland State University

2019 


\begin{abstract}
Currently mathematics education is undergoing substantial changes so that students may experience mathematics in intellectually engaging, equitable, and relevant ways. More specifically, I am referring to a teacher stance of centering student thinking and allowing students to make sense of mathematical ideas. Proponents of reform efforts in mathematics argue that this is the path to helping elementary students develop a deep and conceptually sound understanding of mathematics. This is critical because a strong mathematical foundation has increasingly become a gateway for access to many career opportunities and citizenship in the United States (Moses \& Cobb, 2001).

Unfortunately, these ambitious changes present a challenge for teachers who may themselves have learned mathematics under a transmission model of teaching in which efficient, procedural understanding was the goal. The purpose of this case study was to explore and describe how three teachers involved in one professional development project, the East Metro Mathematics Leadership (EaMML) Partnership Grant, responded to a 3-year professional learning experience grounded in children's authentic ways of thinking about mathematics.
\end{abstract}

Results from the study provide descriptive evidence about how the teacher participants articulate and enact changes in their beliefs and instructional methods. In addition, the provide illustrations of the teacher noticing of students' mathematical thinking. These illustrations of practice can support the field of mathematics professional 
development to further conceptualize the practice of teacher noticing and how teacher noticing provides evidence of shifts in teachers' beliefs and instruction. 


\section{Dedication}

This paper is dedicated to my two children, Pearson Duden and Olivia Duden, and my husband Andrew Duden, who have patiently waited while "mommy finishes her paper." 


\section{Acknowledgements}

In every big adventure in my life, I have experienced a moment of trepidation. When I first became a teacher, I remember the excitement of setting up my first classroom and then realizing I had only just begun to understand the complexities this job would entail. I remember being struck by the feeling that my colleagues, administrators, and classroom parents were entrusting me with such an awesome responsibility, and I had only scratched the surface of what it meant to be a teacher. In 20 years of practice, I have felt the continued support of those around me in the education field who allowed,

encouraged, and challenged me to take new steps and try new things in the field of education. Now I have a deep understanding of the classroom world and of what I did not know in those early days. Yet now I have the wisdom to know that not knowing in a complex job such as teaching is an ever- present phenomenon.

Early in the first year of the doctoral studies, I felt trepidation again. This time it was related to the endeavor of scholarship and research. I had the familiar feeling that I was really just scratching the surface of the academic and research world. Again, I feel fortunate that I was able to draw upon my experience of teaching to recognize that early feeling of not knowing and keep it in its place as a part of a process of continued learning. I know that, just like in teaching, I am surrounded by the grace of so many people who are allowing, encouraging, and challenging me to take these first timid steps. I acknowledge Dr. Swapna Mukhopadhyay and Dr. Sue Lenski for guiding me through 
the coursework and helping to instill in me a growing identity as an educational leader and a researcher. The agency and identity assignments that pushed us to present at conferences and step into our leadership were invaluable. The assignments provided a forum to help build my confidence in this new role as a leader and a scholar. I acknowledge Dr. Swapna Mukhopadhyay for all her time and encouragement through the first hurdle of the CORE paper.

I would like to thank Dr. Moti Hara for allowing me a glimpse into the world of quantitative methods. Although there is so much more to learn in this field, he skillfully provided the first taste of the complexity of quantitative methods and made reading the literature so much easier.

I would like to acknowledge Dr. Dot McElhone for laying the foundations of a paradigmatic view of research and giving me a stronger base from which to build my first research platform.

I would also like to acknowledge Dr. Christine Chaille for introducing me to the idea of "the vision of the Utopia." This idea resonated so clearly with me as an educator who is constantly learning and evolving. Although I had not consciously realized it, as an educator, I was always in search of books and experiences that provide this "vision of the Utopia" in the classroom because when I see it, I know I can reproduce it. It is this idea that informs my decision to use a descriptive case study approach.

I would also like to acknowledge Dr. Nicole Rigelman, who has been a mentor to me for many years before I entered the doctoral studies program. From our early work 
together 15 years ago, when she taught a geometry lesson in my classroom, to her incredible work as a math instructor who has helped me to deepen my understanding of math content and how to use sensemaking practices in the classroom. Most importantly, I would like to acknowledge her tireless efforts to help me realize my value as a professional development provider and leader as a mathematics teacher, and to keep me moving forward in the process of completing this dissertation paper.

I would also like to acknowledge my colleague, Karen Prigodich, for struggling alongside me as we test out our new role of scholars.

Lastly, I would like to acknowledge my committee members, Dr. Nicole Rigelman, Dr. Swapna Mukhopadhyay, Dr. Amanda Sugimoto, and Dr. Paul Latiolais, who patiently waited for me to complete this work. I appreciate your support to me as a beginning researcher. 


\section{Table of Contents}

$\begin{array}{ll}\text { Abstract } & \text { i }\end{array}$

Dedication $\quad$ iii

Acknowledgements $\quad$ iv

List of Tables $\quad$ xi

List of Figures $\quad$ xii

Chapter 1

Problem of Practice 1

Statement of the Research Problem 2

Background of the Problem $\quad 2$

$\begin{array}{ll}\text { Significance of the Problem } & 6\end{array}$

$\begin{array}{ll}\text { Research Questions and Research Methods } & 10\end{array}$

Research questions 11

Research methods $\quad 12$

$\begin{array}{ll}\text { Definition of Terms } & 12\end{array}$

Students' mathematical thinking $\quad 12$

Conceptual understanding 13

Pedagogical content knowledge (PCK) 14

Chapter 2

Literature Review 16

$\begin{array}{ll}\text { Organization of the Literature Review } & 18\end{array}$

$\begin{array}{ll}\text { Theoretical Framework } & 18\end{array}$

Learning in and from practice $\quad 19$

Pedagogical content knowledge $\quad 19$

Teacher noticing $\quad 22$

Background Professional Development Literature 25

Beyond training and activity PD 25

Mathematical content knowledge and PCK 26

Using student thinking $\quad 28$

Impact of PD on teacher noticing $\quad 32$

Using classroom artifacts $\quad 34$

Case Studies Measuring the Impact of PD 37

$\begin{array}{ll}\text { Case study as a support to a larger study } & 37\end{array}$

$\begin{array}{ll}\text { Case studies to illustrate propositions } & 38\end{array}$ 


\section{Chapter 3}

Methods

Research Methods $\quad 42$

Research Paradigm $\quad 43$

Justification of the research paradigm 43

Justification of case study within the social 43 constructivist paradigm

Case Study Embedded in a Larger EaMML Project $\quad 44$

Justification of a case study design $\quad 44$

Limitation of a case study design $\quad 45$

Participants 46

Context and participants of the EaMML project 46

Context of the case study $\quad 46$

Context of the EaMML PD project 46

Case study participants $\quad 48$

$\begin{array}{ll}\text { Procedures } & 49\end{array}$

Phases of case study research design $\quad 49$

Phase 1: Recruitment of the participants $\quad 50$

Phase 2: Collection of data 50

Phase 3: Transcribing, coding and analyzing the data 53

$\begin{array}{ll}\text { Instruments and measures } & 53\end{array}$

EaMML instruments and measures $\quad 53$

EaMML instruments and measures utilized in the case study 53

Classroom observation data $\quad 54$

Teacher survey data $\quad 55$

Case study instruments and measures $\quad 56$

MIL coursework documents $\quad 56$

Participant interview 58

Classroom lessons and SR participant interview $\quad 58$

Limitations of the SR approach $\quad 59$

Targeted interview questions $\quad 60$

Rationale for one interview 61

Limitation of the interview 61

Limitation of the Data Sources $\quad 61$

Case study context shift $\quad 62$

Participant and researcher time limitations $\quad 62$

Maintaining Data

63

Positionality of the Researcher $\quad 63$

$\begin{array}{lr}\text { Analysis of the Data } & 68\end{array}$

$\begin{array}{ll}\text { Coding data } & 68\end{array}$

Using thematic networks analysis to develop themes 69 
Learning to notice framework $\quad 70$

Validity

\section{Chapter 4}

Analysis and Findings $\quad 74$

$\begin{array}{ll}\text { Introduction } & 74\end{array}$

$\begin{array}{ll}\text { Presentation of the Data } & 74\end{array}$

EaMML Data and Context Case Study Participants 76

Context and EaMML findings for Ms. Jones $\quad 78$

Context and EaMML findings for Mr. Wells 81

Context and EaMML findings for Mr. Nelson 83

Impact of the PD on Ms. Jones' Beliefs and Instruction 85

Sensemaking as an adult learner $\quad 86$

Tools for sensemaking as an adult learner $\quad 88$

Using tools for sensemaking in the classroom during $\begin{array}{ll}\text { rehearsals teacher noticing } & 89\end{array}$

$\begin{array}{lr}\text { Ms. Jones' Teacher Noticing } & 90\end{array}$

Activities of teaching as sources for teacher noticing 94

Example of Ms. Jones' teacher noticing 96

Summary of Impact for Ms. Jones 98

The Impact of the PD on Mr. Wells' Beliefs and Instruction 99

Sensemaking as an adult learner $\quad 99$

Case studies provide a picture of student sensemaking $\quad 100$

$\begin{array}{ll}\text { Limited expectations of students } & 101\end{array}$

Learning situated in practice 103

Posing purposeful questions and increasing student talk $\quad 104$

$\begin{array}{lr}\text { Mr. Wells' Teacher Noticing } & 110\end{array}$

Example of Mr. Wells' teacher noticing 112

Activities of Teaching as sources of rehearsals of teacher noticing 114

$\begin{array}{ll}\text { Summary of Impact for Mr. Wells } & 116\end{array}$

The Impact of the PD on Mr. Nelson's Beliefs and Instruction 116

$\begin{array}{ll}\text { Sensemaking as an adult learner } & 118\end{array}$

Inspiration from cases of students' mathematical thinking $\quad 119$

The context of Mr. Nelson's student thinking rehearsals 121

$\begin{array}{ll}\text { Search for structures and routines } & 123\end{array}$

Tasks with potential. 123

$\begin{array}{ll}\text { Mr. Nelson's Teacher Noticing } & 126\end{array}$

Activities of teaching as a source for teacher noticing 128

Example of Mr. Nelson's teacher noticing $\quad 130$

$\begin{array}{ll}\text { Summary of EaMML Impact for Mr. Nelson } & 134\end{array}$

$\begin{array}{ll}\text { Limitations of the Study } & 135\end{array}$ 


\section{Chapter 5}

Discussion and Conclusion $\quad 137$

$\begin{array}{ll}\text { Research Problem } & 137\end{array}$

$\begin{array}{ll}\text { Purpose of the Study } & 137\end{array}$

$\begin{array}{ll}\text { Research Questions and Methods } & 138\end{array}$

$\begin{array}{lr}\text { Summary of Findings } & 139\end{array}$

$\begin{array}{ll}\text { Situated in the Larger Context } & 140\end{array}$

Learning in and from practice. $\quad 140$

Pedagogical content knowledge (PCK). 142

Teacher noticing 143

Limitations of the study from an equity-based lens $\quad 146$

$\begin{array}{ll}\text { Implications } & 148\end{array}$

$\begin{array}{ll}\text { Further research possibilities } & 148\end{array}$

Implications for PD facilitators $\quad 149$

References

Implications for teaching community $\quad 150$

Appendices

Appendix A East Metro Mathematics Leadership Project Model 166

Appendix B Dissertation Recruitment Presentation 167

Appendix C Initial Recruitment Survey 169

Appendix D Research Participant Information and Informed Consent $\quad 170$

$\begin{array}{ll}\text { Appendix E Parent Permission to Videotape } & 175\end{array}$

Appendix F Portfolio Reflection Assignment 177

Appendix G Example of Student Thinking Assignment 178

Appendix H Focus Questions for Written Episodes of Students'

$\begin{array}{ll}\text { Mathematical Thinking } & 179\end{array}$

$\begin{array}{lr}\text { Appendix I Example of MIL Mathematics Activity } & 180\end{array}$

Appendix J Case Study Participant Interview 181

Appendix K Instructional Quality Assessment Observation Tool (IQA) 182

Appendix L Learning to Notice Framework 196

Appendix M Permission to Adapt and Reprint the Learning to Notice Framework 198 


\section{List of Tables}

Table 3.1 EaMML Data Collection Measures and Instruments 54

Table 3.2 Research Questions Connected to Data Sources 56

Table 3.3 Frameworks for Reflecting on Teaching Practices and Equity-Based Practices

Table 3.4 Adapted Learning to Notice Framework

Table 4.1 Research Questions and Global Themes

Table 4.2 EaMML Findings for Ms. Jones' Classroom Observation

Table 4.3 EaMML Findings for Ms. Jones' Teacher Survey

Table 4.4 EaMML Findings for Mr. Wells' Classroom Observations 82

Table 4.5 EaMML Mr. Wells' Findings for Teacher Survey 83

Table 4.6 EaMML Mr. Nelson's Findings for Classroom Observation 84

Table 4.7 EaMML Mr. Nelson's Findings for Teacher Survey 85

Table 4.8 Comparative Samples of Mr. Wells' Questioning Patterns 106 


\section{List of Figures}

Figure 2.1 Network Model of Pedagogical Content Knowledge 21

Figure 3.1 Course titles for the EaMML pedagogical-focused content courses 47

Figure 3.2 Phases of the case study research design spanning spring 2016 to $\begin{array}{lr}\text { spring, } 2019 & 50\end{array}$

Figure 3.3 List of rubrics used to measure classroom instruction in the EaMML 55 project

Figure 3.4 Process of the thematic network analysis data reduction protocol $\quad 70$

Figure 3.5 Thematic networks analysis of case study data 72

Figure 4.1 EaMML classroom observation data using the IQA observation tool

Figure 4.2 Ms. Jones' graph of teacher noticing from the student thinking $\quad 78$ assignments as the part of the MIL courses $\quad 92$

Figure 4.3 Sources of Mr. Wells' teacher noticing 95

Figure 4.4 Student work sample from Ms. Jones' student thinking assignment 97

Figure 4.5 Mr. Wells' graph of teacher noticing from the student thinking $\begin{array}{ll}\text { assignments as the part of the MIL courses } & 111\end{array}$

Figure 4.6 Sources of Mr. Wells' teacher noticing 115

Figure 4.7 Odd and evens task from Mr. Nelson's student thinking assignment 125

$\begin{array}{lr}\text { Figure 4.8 Mr. Nelson's teacher noticing graph } & 127\end{array}$

$\begin{array}{lr}\text { Figure 4.9 Sources of Mr. Nelson's teacher noticing } & 130\end{array}$

Figure 4.10 Linear function task from Mr. Nelson's student thinking assignment 130

Figure 5.1 Interpretive framework illustrating the intersection between the theoretical framework, EaMML project PD elements and the case study

research findings 


\section{Chapter 1: Problem of Practice}

Several years ago, I was coaching a teacher, Sally, to support her in learning to teach mathematics conceptually to her students. Sally and I were rehearsing the practice of conferring with student mathematicians to understand what they understand about the mathematics. The student solved the problem with manipulatives using a unique strategy that did not match the strategies in the curriculum materials. The teacher was unsure how to respond to her student and later admitted she did not understand how the student was solving the problem. We spent the rest of our coaching session making sense of the student's strategy by solving new problems the way her student would have solved it. What stood out to me about this experience was how surprised Sally was to encounter a solution path from a student that she herself could not understand. She expressed to me feeling excited about learning that her student could think in such a sophisticated way, but also a little nervous that new solutions will come up that she does not understand.

This experience was one experience among several with teachers who are learning how to promote authentic reasoning in their classrooms. At the time, I myself had experienced extensive professional development myself and was leading professional development for teachers. I had personally experienced the powerful ways in which children were able to reason about mathematical ideas and I wanted to share this with others. However, sharing resources and ideas about how students could reason about mathematically did not seem to go far enough. It seemed disconnected from actual practice. Some colleagues were doubtful of their students' capacity to reason mathematically, others asked for resources but were discouraged when their students did 
not seem to be doing what I had suggested was possible and others were convinced that all students needed was the modeling of how to solve problems. I began to wonder in what ways math professional development, in teachers' own contexts, could support teachers in changing their stance from one of teaching problems to one of eliciting and using student thinking already available? How do teachers draw from the funds of knowledge and intuition that children already possess? What does learning to listen to students' mathematical thinking afford teachers in terms of their own growth as a teacher?

\section{Statement of the Research Problem}

Children come to school with rich mathematical ideas (Carpenter, Fennema, Peterson, Chiang, \& Loef, 1989; Ginsburg, 1989). Utilizing the knowledge that students bring to the classroom has been linked to conceptual understanding and mathematical sensemaking (Fennema, Carpenter, Franke, Levi, Jacobs \& Empson, 1996); greater intellectual engagement and autonomy (Polya, 1947); classrooms inclusive of the diversity of voices (Yackel \& Cobb, 1996); and equity of participation (Wager, 2014). Elementary classroom teachers, however, have struggled to shift instructional practices toward positioning children's mathematical thinking at the core of their instruction. Instead classrooms continue to be centered in large part on heteronomous learning experiences (Kamii, 1984; Kamii \& Housemann, 2000).

\section{Background of the Problem}

Spillane (1999) makes a distinction between procedural knowledge, which is characteristic of heteronomous learning environments, and principled knowledge of 
mathematical concepts that can be used to develop procedures, which is supportive of a more autonomous learning environment. The teacher in a heteronomous learning environment is the mathematics authority who transmits rules and procedures to solve mathematical problems. Students defer to the feedback of the teacher rather than relying on internal sensemaking capabilities to determine whether they are correctly solving problems.

Heteronomous learning environments and procedural dominance represent what is referred to as a transmission model of teaching. Schoenfeld (2004) explains that elementary mathematics instruction was governed historically by a theory of social efficiency. Students were to learn the basics as was needed for carrying predetermined roles in society such as clerking in shops. Only a small percentage of elite students went on to high school to continue their mathematical studies (Schoenfeld, 2004). The predominance of a behaviorist model of learning stratified elementary students into those that understood mathematics and those that did not (Ellis \& Berry, 2005). This legacy has been reified by generations of adults who were products of a stratified system and continue the myth that mathematics ability is genetically predisposed, and some children just are not inclined toward mathematics (Boaler, 2009).

The impetus for changes toward more autonomous elementary mathematics classrooms stems from a parallel focus of equity in mathematics instruction and concern for the poor math skills of U.S. students in comparison to those of other countries (National Commission on Excellence in Education, 1983). The Nation at Risk report laid the groundwork for reformers such as National Council of Teachers of Mathematics 
(NCTM) to reimagine a more active, principled, and student-centered mathematics classroom $(1989,2000)$.

More than thirty years after the report was published, a robust body of research reveals that students have formed mathematical ideas before they enter school and are capable of reasoning about mathematical concepts prior to instruction (Kamii \& Houseman, 2000). Often these mathematical ideas are beyond the grade level standards used in elementary schools (Carpenter et al., 1989; Fuson, Smith, \& Lo Cicero, 1997). Students invent their own strategies for operations that develop from place value understanding (Fuson, Smith, \& Lo Cicero, 1997; Kamii \& Houseman, 2000) and are able to conjecture and generalize about algebraic ideas (Fennema, et al., 1996) before entering an algebra classroom. However, elementary mathematics teaching approaches have not kept pace with this research (Battista et al., 2007).

The factors that mediate how elementary teachers learn to teach mathematics for principled understanding are complex. Many teachers learned mathematics under a procedure-based mathematics paradigm themselves, pointing to a need to support teachers with time and resources to relearn their craft (Stein, Smith, \& Silver, 1999). In addition, teachers continue to hold beliefs about teaching as telling students the procedures and rules to follow and students performing those procedures and rules (Battista, 1994).

Teachers' beliefs connect to their expectation that they will be able to bring about student learning, or teacher efficacy (Ross, 1998). According to Ross \& Bruce (2010), teachers who have low teacher efficacy are less likely to try new teaching techniques, 
particularly when it means sharing control with students, and less likely to promote student autonomy. This suggests a need for redefinition of what success in terms of student learning looks like in mathematics classrooms (Smith, 2000).

Teachers also wrestle with what it means to teach for understanding (Ball \& Cohen, 1999; Hiebert et al., 1997). Simply employing new teaching strategies such as giving students manipulatives, putting students into cooperative groups and asking better questions does not by itself yield mathematical understanding (Franke, Kazemi \& Battey, 2007).

The literature about mathematics teaching suggests that attending to the development of teachers' mathematical knowledge, their beliefs, and their instructional stance is the most effective way to change the experience of mathematics learning in the U.S. (Darling-Hammond \& McLaughlin, 1995). Centering students' mathematical thinking in the mathematics classroom requires of teachers not only the belief that students have the ability to make sense of mathematics prior to teacher instruction, but also the ability to listen closely to the thinking of their students. It also assumes a developed sense of the mathematics content they teach so that it is possible to recognize how student thinking ties into the landscape of mathematical ideas (An, Kulm, \& Wu, 2004; Ball, Thames, \& Phelps, 2008; NCTM, 2013; Shulman, 1986). Lampert, Beasley, Ghousseini, Kazemi, and Franke (2010) refer to the instructional method of centering student thinking as ambitious mathematics teaching. These authors suggest that what is required of teachers to engage students in important and rigorous mathematical ideas is an ability to manage the interactions of students, while understanding varying levels of 
competence and engagement. Ambitious teaching requires one to listen and understand how students are making sense of content and then to work with student thinking drawing out big mathematical ideas for the whole class. Different authors have referred to similar practices as high-leverage practices (Boerst, et al., 2011) and practices that support the developments of students' mathematical dispositions (NRC, 2001). For the purposes of this study, these practices are referred to as Mathematics Teaching Practices (NCTM, 2014). I describe these practices more fully in chapter 2.

Attending to what teachers need to learn and how teachers learn, challenges traditional notions of professional development (PD) (Ball \& Cohen, 1999; Borko, 2004; Darling-Hammond, Wei, Andree, Richardson, \& Orphanos, 2009; Desimone, 2009; Hill, 2009; Little, 1993). Traditional forms of PD such as the district-mandated workshops designed to brief and train teachers, are inadequate to support sustained change in classroom instruction (Little, 1993; Borko, 2004). These experiences do not respect the intellect of teachers and often result in teachers assimilating new ideas into old belief structures (Cohen \& Ball, 1999; Little, 1993). Yet according to a 2003-2004 Schools and Staffing Survey, $92 \%$ of public and private teachers reported that the PD they experienced could be characterized as trainings, workshops, or conferences (NCTM, 2014). If the training model represents that majority of teacher's PD experiences, it is likely that mathematics instruction will not move beyond heteronomous models that currently dominate US classrooms.

\section{Significance of the Problem}


The complexity of the type of change that is necessary for teachers to enact an engaging and principled mathematics environment coupled with a dearth of opportunities to learn significant mathematics for teaching in substantive ways are significant issues in elementary mathematics education. In Principles to Actions, the National Council of Teachers of Mathematics reports that fourth-grade students' achievement in math has risen from $13 \%$ in 1990 to $42 \%$ in 2013 , however, only $44 \%$ of students graduating from college were considered ready for college mathematics as measured by 2013 ACT and SAT (NCTM, 2014).

The need for better support of elementary teachers to make changes in their mathematics instructional practices is further heightened by the adoption of the Common Core State Standards for Mathematics (CCSS-M) in 2009. The CCSS-M calls for a focus on fewer topics, coherence and connections between topics and rigor. Rigor is defined as conceptual understanding, procedural fluency and application, suggesting that the shifts in mathematics instruction are not a move away from traditional procedures and computational fluency, rather procedural fluency ought to be undergirded by conceptual understanding. The CCSS-M also make an explicit charge to engage students in active mathematical habits such as modeling with mathematics, making sense of problems and persevering in solving them, reasoning abstractly and quantitatively, and constructing viable arguments and critiquing the reasoning of others (NGA, 2010). The Standards for Mathematical Practice represent a marked shift from the transmission style teaching common in heteronomous classrooms. 
The intent of these standards is to raise the mathematical expectations of all students and support students in developing a more conceptual understanding of mathematics rather than simply following procedures. As well, the CCSS-M standards serve as a guide for teachers defining the depth of mathematical concepts being taught.

Regardless of efforts to raise standards for mathematics teaching, the focus of elementary mathematics curriculum is persistently lower-level procedural skills that are prioritized in many accountability assessments (NCTM, 2014). Perhaps more troubling is that elementary mathematics in the U.S. continues to be marked by a narrative that stratifies students, particularly with respect to achievement of marginalized students (Gutierrez, 2007; Ladson-Billings, 2009; Wager, 2014).

The tenacious cultural belief in the U.S. that mathematics is comprised of computation skills, sets of procedures and rules coupled with the genetic argument that some students are just good at math and others are not, continue to serve as an excuse for students' poor mathematics achievement, rather than an opportunity to inquire into other methods of mathematics instruction. Moses and Cobb (2001) raise a crucial argument that mathematics is increasingly becoming a gateway for students' future opportunities. Wager (2014) argues that in order to create a system that affords all students opportunities to deeply understand mathematics, teachers must learn to notice and increase participation of marginalized students in mathematics. Gutstein, Lipman, Hernanadez \& de los Reyes (1997) argue that centering students' thinking in mathematics and positioning students as mathematical authorities empowers them with the critical thinking skills necessary for college and career readiness. These arguments raise 
considerable concern for a new and more equitable view of children as capable learners who make sense of mathematical ideas in elementary mathematics instruction.

Additionally, students themselves express boredom, demonstrate anxiety, and complain about the lack of relevance of mathematics to their lives (Boaler, 2009). These attitudes toward mathematics learning, unfortunately, are often accepted as examples of the social myth that understanding math is a genetic predisposition and that math is meant to be boring and complicated (Boaler, 2009).

As a contrast, the work of mathematicians can be characterized as an intellectually engaging venture of seeking patterns and relationships among ideas. It is a process of solving complicated problems creatively and extending problems in new directions (Boaler, 2009). Polya (1945) describes the value of challenging students intellectually this way:

The problem may be modest; but if it challenges your curiosity and brings into play your inventive faculties, you may experience the tension and enjoy the triumph of discovery. Such experiences at a susceptible age may create a taste for mental work and leave their imprint on mind and character for a lifetime. (Polya, 1945, p. VI)

The significance of this problem of practice has been the impetus for the field of math professional development to reimagine professional development to better meet the needs of mathematics teachers. Policy mandates alone reduce teachers to passive receptacles of new instructional methods and do little to inspire innovation and spark creativity (Spillane, 1999), the CCSS-M has been criticized for being a policy change that lacks attention to actual pedagogical strategies, and teacher incentives in the form of accountability practices have been shown to have little effect in changing elementary 
math instructional practices (Boston, 2012). To support teachers to teach more autonomously with greater attention to students and how they make sense of principled mathematics content, it is critical that PD be designed to help teachers make better sense of mathematics conceptually themselves. Further, teachers need opportunities to learn more about students' interactions with conceptual mathematics and what pedagogical strategies will draw out productive interactions.

\section{Research Questions and Research Methods}

My study is embedded in the context of the East Metro Mathematics Leadership (EaMML) project, a three-year grant funded project designed to grow math leaders who will support principled mathematics instruction in their own classrooms as well as their school buildings and the larger district context.

The professional learning elements of the larger EaMML project, attend to Desimone's (2009) core features of effective PD: (a) situated in the work of teaching (b) focused on content (c) longer in duration (d) coherent (e) collective focus and (f) includes active learning. More specifically, elements of the EaMML project was enacted in the context of teachers' schools and classrooms, focused developing content and pedagogical knowledge, including 6 mathematical content-focused pedagogy courses and 2 leadership

courses over three years. The course content was aligned with the Common Core State Standards for Mathematics (CCSS-M), including both the Mathematical Content Standards and the Standards for Mathematical Practices (SMP) and focused on building the capacity of teacher leaders for supporting other teachers. In addition, the EaMML 
project engaged teachers in collaborative teams and focused on enactment of the eight mathematics teaching practices defined by NCTM (2014).

Research questions. The larger EaMML study addressed many components of both student and teacher learning. My study, however, focused on the particular aspect of teacher articulation and enactment of teaching practices and productive beliefs about students' learning. In addition, this study described the ways in which teachers noticed and used students' mathematical thinking. By teacher noticing, I am referring to the ways teachers notice how their students are making sense of mathematical ideas; how they are interpreting those ideas and placing them in the context of the larger mathematical trajectory; and how they use those ideas to further the mathematical goals of individual students and the class as a whole. I argue that in order for substantive changes in mathematics to take on the instructional form conceptualized in the mathematics reform movement and the CCSS-M initiatives teachers have to move toward student autonomous instruction by releasing control to students to make sense of mathematical ideas. This release of responsibility rests on a change in the stance teachers take in the classroom from the transmission of knowledge to noticing, using and building upon the thinking of their students. For this reason, this study illustrated the ways in which the EaMML PD model impacted this change in teacher stance.

I addressed three questions in my study. First, in what ways does being involved in a reform-oriented PD project that is focused on integrated mathematics content and pedagogy development and students' mathematical thinking impact teachers' a) instruction and b) beliefs about mathematics teaching or c) perceptions of themselves as 
teachers of mathematics? Second, which activities, tools or frameworks from the PD do teachers point to as the most impactful in terms of their work in the classroom? Finally, in which tasks of teaching is teacher noticing and using of students' mathematical thinking-whether strong or weak — most apparent?

Research methods. I conducted a case study analysis of three teachers involved in the EaMML project. I used document analysis of teachers' reflections, student thinking assignments, and mathematics research reviews over the course of their engagement in the content-focused pedagogy courses. Additionally, I observed several course sessions as well as cycles of lesson study.

I interviewed the three participants in the spring of 2017. Interviews were two part. The first part was a stimulated recall (SR) interview using two video recorded mathematics lessons and the second part included open-ended questions designed to capture participant views of their learning and changes in practice with respect to the PD experience.

I coded these documents, observations, and interviews to capture the nature of (a) teacher response to student thinking and (b) the mathematical practices and routines articulated and enacted in the classroom that center student thinking.

In chapter 3, I expand on my methodological approach and frameworks for analysis.

\section{Definition of Terms}

Students' mathematical thinking. Students' mathematical thinking is central to my work, and it refers to ideas that come from students' conceptualization of a 
mathematical phenomenon. Students' mathematical thinking draws upon a student's prior knowledge or schema about the mathematical task at hand and stems from a desire to make sense of a new idea or mathematical situation. Adults and peers may elicit the mathematical thinking, or the thinking may be volunteered by the student.

When I refer to students' mathematical thinking, I am referring to (a) the strategies and ideas students use when solving a problem, (b) the patterns students notice and subsequent conjectures about the nature of those patterns, (c) the way students make sense of a mathematical point with another student, (d) the connections students make from one math idea or pattern to another, and (e) the questions or statements from students. This list is not exhaustive, but it captures the major types of characteristics that are referred to as students' mathematical thinking in this study.

Conceptual understanding. In order to distinguish between narrow procedural practices in math education and practices that build on children's mathematical thinking, I also define conceptual understanding. Conceptual understanding is characterized by an ability to use mathematical knowledge fluidly in any mathematical problem-solving situation. Children who have conceptual understanding reason about mathematical ideas, make arguments, justify that the thinking is mathematically supported, and communicate mathematical ideas with peers (NCTM, 2000). This definition contrasts with the more limited view of mathematics as a practice of rote memorization of facts and procedures that, when done correctly, results in one correct answer, which is ultimately the only desired end. 
A child with conceptual understanding will not only know how to apply mathematical ideas to solve problems but also will be able to communicate or justify why the mathematical ideas work. Conceptual understanding is also characterized by the connection or relationships between mathematical ideas. For example, conceptual understanding of multiplication involves the ability to efficiently calculate numbers in groups or sets and understand that those groups or sets are added repeatedly. In this way, students understand the relationship of multiplication to addition.

Other authors have used different terms in reference to teaching that focuses on conceptual understanding. Spillane (1999) refers to this type of knowledge as principled knowledge. An, Kulm, and $\mathrm{Wu}$ (2004) use the term convergent teaching—or knowing student thinking - to mean teaching for conceptual understanding. In the view of these researchers, there are four building blocks to develop conceptual understanding: (a) building on students' mathematical ideas, (b) addressing misconceptions, (c) engaging students in mathematics learning, and (d) promoting students' thinking mathematically.

Pedagogical content knowledge (PCK). Teaching elementary mathematics requires an understanding of relevant mathematical content. It also requires knowledge of pedagogical practices best suited to connecting student thinking to the mathematical concepts and strategies. Shulman calls this pedagogical content knowledge. Shulman (1986) defines PCK as

... the most useful forms of representation of those ideas, the most powerful analogies, illustrations, examples, explanations, and demonstrations - in a word, the most useful ways of representing and formulating the subject that make it comprehensible to others....Pedagogical content knowledge also includes an understanding of what makes the learning of specific topics easy or difficult: the 
conceptions and preconceptions that students of different ages and backgrounds bring with them to the learning of those most frequently taught topics and lessons. (Shulman, p.7) 


\section{Chapter 2: Literature Review}

In this study, I take the stance that centering classroom instruction on students' mathematical thinking is a productive means of changing instructional practice toward an equitable and engaging mathematics classroom. Centering student thinking has also been cited as a productive component of PD in teachers' own classrooms (Sherin, Jacobs, \& Philipp, 2011) as well as a site for practical inquiry into one's practice, which has been theorized to lead to a self-sustained generative change (Franke, Carpenter, Fennema, Ansell, \& Behrend, 1998; Kazemi \& Franke, 2004). In recent studies, teacher noticing of student thinking is demonstrated as a "core" practice in developing teachers" skills for teaching and assessing mathematics conceptually (Whitcomb, Borko, \& Liston, 2008). But centering student thinking in mathematics has merit beyond a vehicle for professional development for teachers in that students offer reasoning or ideas that have potential for learning for their students. Centering student thinking in classrooms has been noted to be a powerful tool to support the learning of other students if it is taken up and made the object of discussion (Schoenfeld 2008; Thames \& Ball, 2014; Peterson, Stockero \& Van Zoest, 2015). Another line of research suggests that centering the attention on students' reasonings promote equitable participation practices in mathematics (Featherstone, Crespo, Jilk, Oslund, Parks \& Wood, 2011; Moschovich, 2013; Wager, 2014) and translate critical math thinking to more broadly viewing the world critically (Gutstein, 1997). 


\section{Organization of the Literature Review}

In the first section, I describe the theoretical framework that guides this study. This work is guided by a belief that centering students' mathematical thinking is necessary in order to intellectually engage students and support growth in their conceptual understanding. Key to this instructional shift is quality professional development (Darling-Hammond \& McLaughlin, 1995).

I launch the theoretical framework discussion with a review of the literature that characterizes promising mathematics PD with Ball and Cohen's learning in and from practice. I look most closely at both qualitative and quantitative studies that incorporate teachers' efforts to learn to notice students' mathematical thinking.

Next, I focus on one aspect of this framework and argue the importance of supporting teachers' development of what Shulman (1986) refers to as pedagogical content knowledge (PCK). One critical aspect of PCK, on which my argument rests emerges from An, Kulm \& Wu's conceptualization of PCK is the importance of teacher knowledge of student's thinking.

Thus, I culminate the theoretical discussion with the framework of teacher noticing of students' mathematical thinking.

After presenting the theoretical framework, I delve more deeply into PD models that center around these theoretical principles and lend to their importance in supporting teachers to shift instructional practices in mathematics teaching.

In the final section, I review studies that provide insight into a case study methodology. I look at the characteristics of those studies that justify the use of the case 
study method to add knowledge to the field of mathematics PD and that are focused on developing teachers' noticing skills as a crucial aspect of PCK.

\section{Theoretical Framework}

Three theoretical positions anchor the study of mathematics PD reported in my case study: (a) opportunities for teachers to learn in and from practice, (b) teachers' development of PCK, and (c) the notion of teacher noticing of students' mathematical thinking.

Learning in and from practice. Ball and Cohen's (1999) seminal work on teacher professional learning describes a type of learning that treats teachers as intellectuals and attends to teacher learning in the situated context of their workplace. The authors claim that given the complexity of the teaching environment learning opportunities for teachers must be centered in the critical activities of the profession.

If teachers are to make the types of changes that are needed to their math instruction, they need to (a) take an inquiry stance into their students and teaching, (b) use knowledge they learn to improve practice, (c) operate experimentally to anticipate students' thinking and misconceptions, (d) use tools of analysis that promote a culture of investigation, and (e) create communities of practice around improvement of practice. In order to do accomplish the above, the authors argue for teacher learning that is centered in practice and is thoughtful (Ball \& Cohen, 1999). Ball and Cohen recognize that the pace of the classroom does not always allow for this type of thoughtfulness in the moment, so they suggest that centered in practice is used broadly to mean working with documents of practice that allow teachers to rehearse their anticipation and analysis 
skills. To be clear, the term practice is used in this framework to mean the work of teaching. Documents of practice include student work, videos of classroom practice, mathematical interviews, classroom planning, etc. (Ball \& Cohen, 1999).

Pedagogical content knowledge (PCK). One of the core features of Ball and Cohen's situated learning is inquiry into students' mathematical thinking. In order to equip teachers with the investigative tools to inquire into student thinking, teachers need content knowledge specific to the work of teaching. Shulman (1986) calls this type of knowledge pedagogical content knowledge (PCK). He suggests that teaching elementary mathematics requires an understanding of relevant mathematical content as well as knowledge of the pedagogy best suited to teaching content that connects to children's mathematical thinking and how children develop mathematical ideas.

Ball, Thames, and Phelps (2008) further conceptualized PCK in a longitudinal study observing math classrooms to distill the work involved in elementary mathematics instruction. From this study, the authors found that the knowledge teachers need to have to teach in principled way encompasses several features including:

Subject matter knowledge.

1. Common Content Knowledge (CCK), which refers to mathematical knowledge and skills used in domains in and beyond teaching;

2. Specialized content knowledge (SCK), in which teachers need to recognize patterns in student errors, determine whether non-routine approaches would work in general, and understand different interpretations of operations; and

3. Horizon Knowledge, or awareness of how mathematical contexts connect along a mathematical trajectory

Pedagogical content knowledge

1. Knowledge of content and teaching (KCT), in which teachers need to have knowledge of different representations and need to know the advantages and 
disadvantages of different representations for content understanding and sequencing strategies to take students deeper into the content;

2. Knowledge of content and students (KCS), in which teachers are able to anticipate student difficulties and misconceptions; and

3. Knowledge of content and curriculum.

The work of Ball and colleagues demonstrate the complex level of knowledge needed to teach elementary mathematics. It is important to note that three of the four aspects of PCK in Ball et al.'s conceptualization require teachers to notice the ways in which students are wrestling with mathematical ideas and oblige teachers to operate from a base of centering students' thinking.

Although Ball et al. (2008)—building upon Shulman's (1986) work—provide the foundation for research about PCK, the work of An, et al. (2004) draws out more explicitly the integral role that student thinking plays in teaching and learning. In an international comparative study of teachers from the U.S. and China, the authors examined the PCK of 28 fifth- through eighth-grade teachers in Texas and 33 fifth- and sixth-grade teachers in China. An et al. created a Network Model (see Figure 2.1) which defines the interactions of three types of knowledge that comprise PCK: knowledge about mathematics content, knowledge of curriculum, and knowledge of teaching. At the center of the interaction is the knowledge of teaching. An et al. argue that knowledge of teaching without knowing students' thinking and working with student thinking can only lead the surface level learning rather than a process of learning to understand mathematical concepts. 


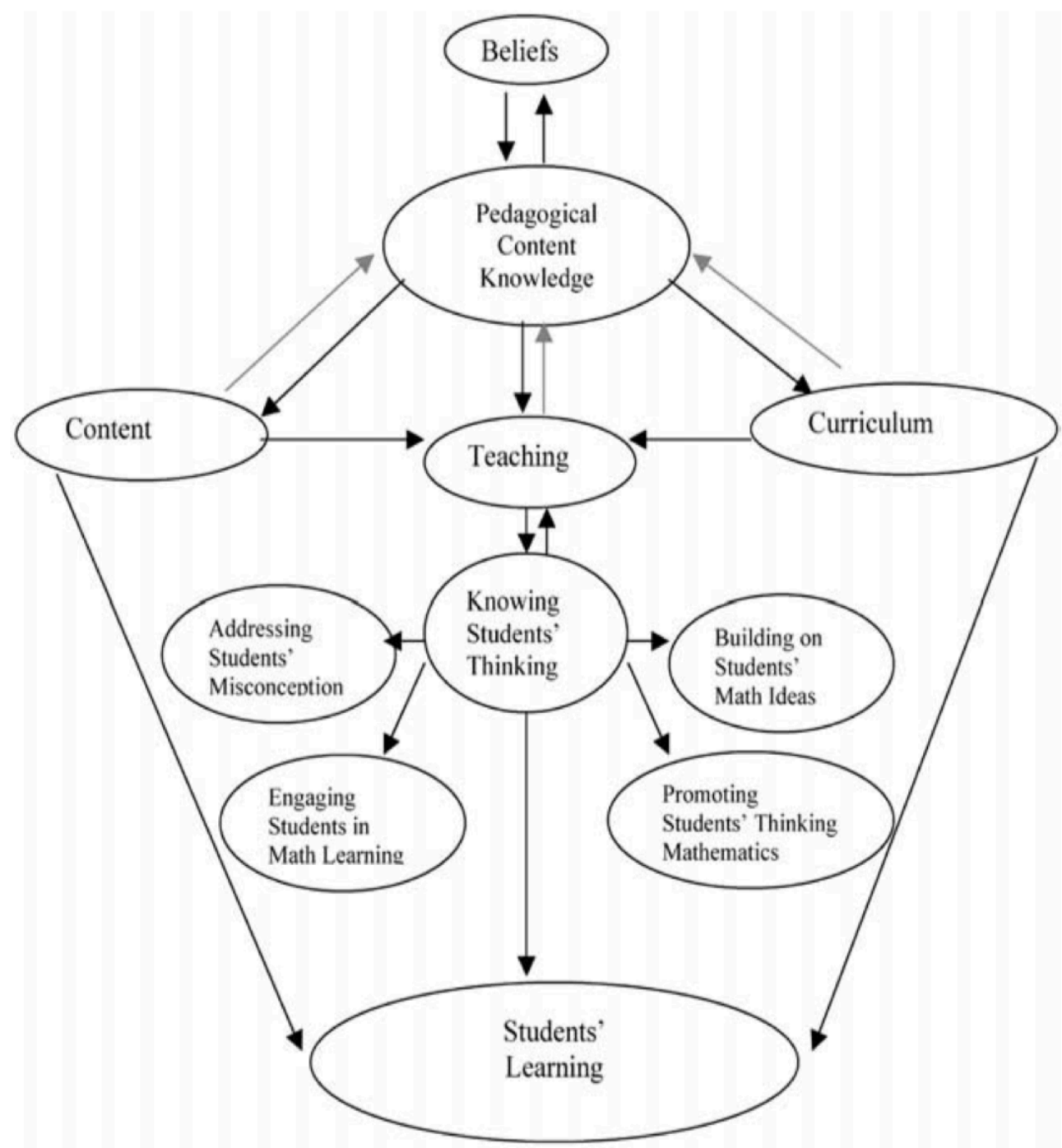

Figure 2.1. Network Model of Pedagogical Content Knowledge. The figure illustrates the interactive relationship of the three key components of PCK: knowledge of teaching, content and curriculum. From "The pedagogical content knowledge of middle school mathematics teachers in China and the US" by An, S., Kulm, G., \& Wu, Z., 2004, Journal of Mathematics Teacher Education, 7, p. 147. Copyright 2004 by the Kluwer Academic Publishers.

The network model justifies the importance of centering instruction on student thinking. An et al. (2004) describe this instructional philosophy as convergent teaching, or teaching with strong knowledge of content, curriculum, and students' mathematical 
thinking. "Under a convergent process, students, not textbooks and curriculum, are the center of teaching" (An et al., 2004, p. 148). Given the entrenched transmission model of mathematics teaching that continues to pervade U.S. classrooms (Banilower, Boyd, Pasley, \& Weiss, 2006; Handal, 2003; NCTM, 2013), convergent teaching represents a marked shift in teachers' instructional practices and beliefs.

It is important to note that the network model of PCK positions each category of knowledge as augmenting and being augments by the other categories of knowledge. For example, strong PCK augments the teaching in the classroom which augments teacher's knowledge of students' thinking. In turn teacher's knowledge of students' thinking augments the classroom teaching which then strengthens the teachers PCK further. At the heart of this cyclical process is the theory that developing a teacher's PCK that leads to deeper, more sustainable learning for teachers.

Teacher noticing. If student thinking is to be placed in the center of instruction, the work of teachers substantially changes. Teachers will need to change the focus of their teaching to students' ideas, misconceptions, conjectures, and mathematical actions. Thus, a crucial feature of this study is the phenomenon of teacher noticing. Teacher noticing refers to that which teachers look for and notice in the classroom, where they look, and how they make sense of what they see and hear. Teacher noticing is relevant to any domain of teaching, but for the purposes of this study, the concept is discussed specific to the teaching of mathematics. In the case of mathematics there are three main features of teacher noticing: (a) attending to student thinking during instruction, (b) interpreting the thinking, and (c) using the thinking in subsequent instruction (Sherin, 
Jacobs, \& Phillip, 2011).

The original conception of noticing is often attributed to Mason (2011). Mason defines noticing practices as a sensitizing activity that allows one to find the opportunities to act "freshly" in classroom situations rather than out of habit. Mason suggests that the act of reflection is essential in noticing. Teachers who reflect on events can prepare and imagine acting differently upon those events in the future (Mason, 2011).

Mason's notion of reflecting in order to act freshly in mathematics classroom situations is fundamental to this study. Allowing teachers time and space to examine their students' thinking and how they are making sense of mathematics opens up the possibility of noticing key ideas that children intuitively use and that can be helpful to build upon. As an example, a young child in a classroom is finding different combinations of 10 with cubes. The teacher may notice that that after this child finds one combination, such as $7+3$, the child quickly moves a cube from one pile (7) to the other (3). Now the child has found a new combination of $6+4$. In this scenario, teacher noticing of an action that a child is displaying provides an opportunity for the teacher to recognize that the child is developing an important idea about decomposing numbers in different ways. Furthermore, the action that is noticed can be used as an opportunity for the whole class to develop the generalization that when joining quantities, you can take a portion from one addend and add it to another addend without changing the sum. If the action is not noticed, the opportunity to highlight the concept in discussion is missed. Mason refers to the child's action as "awareness that enables action," but he notes that the "awareness-in-action" is not necessarily developed. This means that the child is 
using an action, such as moving a cube from one addend to the next addend, that potentially leads to or supports a conceptual advance. However, it might be necessary for the teacher to initiate or cause the child to be "aware of the awareness." Mason refers to the teacher's noticing as the awareness-in-discipline: the ability to call attention to productive actions, comments, or notations that the child is making so the child may choose or continue to adapt this productive strategy in the future.

An important finding related to teacher noticing of students' thinking is that as teachers learn to notice their students' thinking and create more opportunities for new and deeper mathematical learning, there is a positive consequence for the teachers themselves. In fact, a recent line of research suggests that teacher noticing also leads to generative change for teachers (Franke, Carpenter, Fennema, Ansell \& Behrend, 1998; Kazemi \& Franke, 2004). According to Franke et al. (2001) "knowledge becomes generative when the learner sees the need to integrate new knowledge with existing knowledge in light of the new knowledge" (p. 654). The assumption is that inquiring into students' mathematical thinking compels teachers to reconsider their existing beliefs about the capacity of children's thinking and integrate new knowledge about their students. This in turn leads to an interest in learning more about their students' thinking. This inquiry approach into student thinking becomes a source of ongoing knowledge development.

Underlying the present case study is the belief that learning to habitually notice what students are doing, saying, and thinking about mathematics should be at the heart of mathematics PD. This inquiry mindset leads to learning from students' thinking and has 
the potential to accelerate the movement toward better mathematics instruction in service of students' deeper conceptual understanding, student engagement, and more equitable classrooms.

\section{Background Professional Development Literature}

With increased demand for changes in mathematics instructional practices comes increased attention on forms of PD that support teachers in making changes in their practice. Teacher quality is considered the strongest indicator of student growth (DarlingHammond \& McLaughlin, 1995; Darling-Hammond \& Sykes, 1999). However, raising the quality of mathematics teaching is a complex issue for teachers. Researchers suggest that teachers' own mathematical experiences were often markedly different from those suggested in reform efforts (Battista, 1994; Stein, Smith, \& Silver, 1999). For many teachers, the type of rote learning that they experienced in school provided only a shallow understanding of mathematical concepts. If the mathematics learning opportunities in elementary classrooms are to change toward more principled and autonomous learning, so too must the learning opportunities for teachers.

Beyond training and activity PD. Traditional forms of PD tend to focus on training teachers in new initiatives and innovations. Trainings are often large in scale but represent a small investment of time. These traditional PD experiences were designed for a time when the teacher role was to demonstrate procedures and the students' role was to practice those procedures in the ways demonstrated by teachers (Stein, Smith, \& Silver, 1999). These types of PD were often marked by take-away activities and strategies that had little impact on teachers' ability to reflect on and reexamine their practices or to 
develop new beliefs and habits (Borko, 2004; Darling-Hammond \& McLaughlin, 1995; Desimone, Porter, Garet, Yoon, \& Birman, 2002; Little, 1993; Loucks-Horsley \& Matsumoto, 1999). In short, traditional PD designs are poorly suited to supporting teachers in developing their pedagogical content knowledge and changing instructional practice in ways commensurate with reform (Ball \& Cohen, 1999).

The literature around effective PD continues to emerge. However, there is agreement in the research that the definitive features of effective PD include: (a) content knowledge development including PCK; (b) active learning experiences; (c) learning collectively; (d) intensive time duration and (e) coherency (Borko, 2004; Desimone, 2009; Desimone, et al., 2002; Little, 1993; Loucks-Horsley \& Matsumoto, 1999) Desimone (2009) argues that these five common features should be used as a framework for measuring whether the PD is effective or not.

Alternative forms of PD that go beyond the one-shot static PD designs are relatively new and the studies are still predominately small scale, but they are gaining momentum. These alternative opportunities for teacher learning, often referred to as reform $\mathrm{PD}$, focus on opportunities to learn that position teachers as intellectual agents (Franke, et al., 2001; Little, 1993). Several recent studies look specifically at reform PD experiences and focus specifically on PCK or aspects of students' mathematical thinking.

Mathematical content knowledge and PCK. One large quasi-experimental study funded by the National Science Foundation (NSF) involved of a multisite enactment of Developing Mathematical Ideas (DMI). DMI is a national PD program for $\mathrm{K}-8$ teachers that is designed to develop specialized content knowledge (SCK) used in 
teaching (Ball et al. 2008). DMI curriculum is comprised of 7 module each with a different set of core math ideas. Each seminar can be fit into eight 3-hour sessions. DMI is a foundation for the curriculum used in the EaMML content-focused pedagogy courses. I describe the components of a DMI model further in the methods section.

The DMI study was designed to study the impact of the DMI PD model on teachers Mathematical Content Knowledge (MKT). Specifically, investigators were interested in learning about teachers developing SCK as well as the components of PCK - knowledge of content and students (KCS) and knowledge of content and knowledge of content and teaching $(\mathrm{KCT})$. The DMI study compared two groups of teachers $(n=308)$ : a treatment group of DMI participants $(n=179)$ and a control group of non-DMI participants $(\mathrm{n}=129)$. The DMI participant group was made up of special education teachers $(n=10)$, elementary school teachers $(n=62)$, administrators and specialists $(n=13)$ and middle and high school teachers $(n=11)$. The comparison group was comprised of participants in similar quantities by role with the exception of the administrators and specialists $(\mathrm{n}=1)$. The intervention in this study the Building a System of Tens module and the Making Meaning for Operations module. DMI and non-DMI participants were given a pretest and posttest designed to assess their MKT in the area of number and operations. Investigators used a two-level Hierarchical Linear Modeling (HLM) of the data and they found that teachers in the DMI treatment group had a greater increase their MKT in comparison to the control group of teachers.

A critique of this study is that the it focuses solely on how the intervention PD impacted the participants MKT. It does not address other aspects of effective teaching 
such as teacher belief or instructional practice likely to influence the conceptual learning of students. Another critique of this study is that it does not consider participants' perspectives of the impact of the DMI modules related to their instructional practice.

Bobis et al. conducted a similar study $(n=250)$ in New South Wales, called the Victorian Early Numeracy study. In this study, first-grade teachers were involved in 10 days of PD throughout the school year. The teachers in the PD were introduced to learning frameworks that detail the development of student thinking and conducted student mathematical interviews to learn about their students' thinking. Teachers also worked on mathematical content knowledge development and classroom strategies for teaching. These researchers measured growth using both quantitative and qualitative instruments as well as student achievement growth. The findings of the study demonstrated that students from treatment schools were further along in their counting stages (count all, count on, count back/down/up, derived facts,) and were enjoying their math learning.

The Bobis et al. study is similar to the current study in a couple of ways. First, the case study I conducted is part of a larger PD project that measured student achievement, content knowledge and the PCK of the PD participants (RMC, 2017). Second, the Bobis et al. study provides insight into using documents of practice that center teaching practice as a means for teacher learning.

Using student thinking. The last two studies analyzed large-scale PD designs with a content and PCK focus. In this section, I examine studies involving PD that 
embedded research about student thinking as vehicle for participant learning (Carpenter et al., 1989; Swafford, Jones \& Wilson, 2013; Wilson, Mojica \& Confrey, 1997).

Carpenter et al. (1989), continuing the work of Cognitively Guided Instruction (CGI), studied the impact of a 4-week PD workshop centered on learning about students' intuitive strategies in addition and subtraction using non-routine problems. The CGI PD model utilizes research about children's intuitive strategies they call upon as they are solving mathematics problems. In this experimental study, first-grade teachers $(n=40)$, were randomly assigned to two groups. Twenty teachers were assigned to a treatment group in which they participated in the PD Teachers were given time to plan instruction on the basis of their learning. Investigators in this study used multiple instruments to measure the impact of the PD intervention. Investigators (a) tested the teachers knowledge of their students, (b) observed the teachers in their classroom, (c) gave teachers a beliefs questionnaire, (d) tested students using a pre and multiple post standardized achievement test, (e) interviewed and observed students as they solved problems and (f) measured students attitudes and beliefs about mathematics.

Although treatment teachers did not show a statistically significant difference in the amount of time that they spent on problem solving compared to control teachers, these teachers did demonstrate a change in their beliefs about children's ability to construct mathematical understanding. Moreover, treatment teachers showed greater interaction with students around problem solving and allowed students to use multiple strategies. Differences in the achievement of students were modest but favored the CGI- 
trained teachers. In cases of students who struggled on the pretest, the improvement in results for the CGI group were more significant.

One critique of this study is that it did not address the pedagogical aspects of teaching mathematics beyond process and answer focus codes: questions process, explains process, gives feedback to process, listens to process, etc. The study may not serve to help teachers see the link between pedagogy and students reasoning.

In another study, Wilson, Mojica, and Confrey (2013) explored the use of learning trajectories that track students' development of mathematical ideas as a form of PD. Wilson et al. examined the effect of using the Equipartitioning Learning Trajectory, to determine the impact on $\mathrm{K}-2$ teachers' $(\mathrm{n}=33)$ abilities to describe, compare, and interpret student thinking. The researchers used a qualitative design for their study. They collected observation data and coded transcripts of PD sessions and three clinical interviews each teacher implemented with their own students.

Although this study showed an increase in teachers' abilities to notice and interpret students' mathematical thinking, the extent to which teachers utilized this skill in their classroom instruction was not documented. This study, however, provides insight into using observation for measuring teachers' growth in noticing and using students' mathematical thinking.

A critique of this study is that the design was narrowly focused on the learning trajectory as one document of practice. The subsequent measure was also narrowly focused on the outgrowth of that trajectory. The study, however, uses a student mathematical interview assignment as a type of scenario from which to collect data about 
how teachers are attending to, interpreting, and building on student thinking. The interview is similar to the ways in which teachers can interview students one-on-one to determine their knowledge levels.

Swafford et al. (1997) used the van Hiele levels of geometric development as a basis for a PD design. This study $(n=49)$ looked at the results of a 4-week PD course for fourth- through eighth-grade teachers about geometric learning using the van Hiele levels as a framework. Using a content knowledge assessment, the authors found modest gains in teacher content knowledge, reportedly limited by the fact that the test was too easy, and participants did not have much room to demonstrate growth in their content knowledge. Eight of the teachers, four demonstrating strong performance on the final assessment and four demonstrating weaker performance on the final assessment, were then chosen for classroom observations of three to five geometry lessons and subsequent interviews using a stimulated recall interview (SR). The investigators used the SR interview approach to learn what goals and expectations they had for particular students as well as their rationale for making particular decisions during the lesson.

The investigators used a grounded theory inductive approach to learn the instructional patterns that were exhibited by the teachers as well as teachers' perceptions of changes in their math instruction. Results showed that participants grew in their understanding, interpretation, and use of the van Hiele levels of geometric thinking as evidenced by a lesson planning task and classroom observations. Observational and SR interview data demonstrated that they spent more quality time teaching geometry, were more willing to try new things and take risks if the risks would enhance student learning 
and they felt more confident responding to students based on the van Hiele levels.

The findings of this study lend promise for the PD design focused on teacher learning about mathematics content and the use of a student-thinking framework. The focus on students' mathematical thinking represents one connection to my own study. In addition, the research design connects to the research design of the current case study. In particular, Swafford et. al. used the SR interview technique to give teachers a venue for watching their own practice discussing the goals and expectations they have for students in the videos as well as the rationale for decisions they made during the lesson.

In this section, I reported on studies that incorporated opportunities for teachers to learn from student thinking. One critique of the last two studies is that their work was domain specific which calls into question the transfer of the skills to other domains. Additionally, the evidence of sustained changes in classroom instruction that centers student thinking was either not measured or was only measured following the PD learning. One would not be able to determine substantive changes in mathematics instruction overall or evidence of the type of generative change that makes PD most effective given the short timeframe between the intervention and the data gathering.

Impact of PD on teacher noticing. Teacher noticing is one line of research considered ripe with possibility for supporting change in teachers' PCK and subsequent instructional practices. Jacobs, Lamb, Philipp, and Schappelle (2011) conducted a study to learn how teachers who have experienced different levels of mathematics PD interpret students' comments, notations, questions, and actions in intentional ways and decide how to act based on these interpretations. In this study, participants $(n=131)$ were involved in 
professional development using the CGI principles in order to help teachers learn about how children think, how children's mathematical understandings evolve, and how teachers can use this knowledge to guide their instruction. The teachers were each asked to respond to a video-recorded interview of a student solving a problem. The responses were coded to reflect the ways in which the participants attended to student strategies and responded on the basis of student understanding.

The authors found that teachers who (a) had four or more years of sustained PD focused on children's thinking and (b) were emerging teacher leaders (i.e., beginning to engage in some PD to support other teachers) had the most robust attention to student thinking and student strategies. The strength of this study is that it offers insight into how teachers question students and respond to students when they engage in practical inquiry into children's mathematical thinking. The study positions mathematical interviews as an important document of practice that supports teachers in learning about their students' thinking. In the present case study, teachers engaged in multiple iterations of student thinking assignments much like Jacobs et al.'s mathematical interviews. The documents of practice resulting from the student thinking assignments provided important data as to how the case study participants articulated or enacted their noticing, interpretation and response to student thinking in their mathematics instruction.

Although the Jacobs et al. study was not a study to measure the effectiveness of a particular PD treatment, the authors explored factors that relate to greater noticing of students' mathematical thinking. The findings support the positive impact of multiple mathematics PD experiences, but the nature of those PD experiences is undefined. 
Using classroom artifacts. Another category of PD learning gives insight to the use of classroom artifacts as documents of practice and sites for powerful learning about students' thinking (Franke \& Kazemi, 2004; Borko, Jacobs, Eiteljorg, \& Pittman, 2008; van Es \& Sherin, 2008).

Borko et al. (2007) examined the use of video from teachers' own classrooms as a form of PD. This study was conducted in a middle school context in six different schools. The study was relatively small, with eight teachers ranging from one to 27 years of experience. In this study, teachers developed a common lesson during each professional development session and video recorded the enactment of the lesson in their classrooms. Project facilitators then chose particular video clips to use at subsequent PD sessions. The teachers discussed what they noticed first about both the teacher's role in lesson enactment and then about student thinking during the lesson. Transcripts of workgroup sessions were coded to measure characteristics of discourse and participants' reactions to students' mathematical thinking.

The findings in this two-year study showed that conversations around the classroom videos changed over time to become more analytical about issues of teaching and learning. Teachers in this study demonstrated more willingness to engage student reasoning and unique solution strategies as well as engage in the meaning behind different students' solution strategies.

van Es and Sherin (2008) also looked at the use of videos as a PD vehicle to support the development of teacher noticing of students' mathematical thinking. This small study $(n=7)$ represents a quantitative study measuring the impact of video clubs on 
changes in teachers' abilities to notice their students' thinking. Video clubs in this study occurred 10 times throughout the year. A facilitator was instrumental in this study, intentionally directing participants to look for specific examples of student thinking and provide evidence to support the noticing. The authors in this study used the Learning to Notice Framework (van Es, 2011) that detailed levels of teacher noticing of student thinking in classrooms. The framework looks at two aspects of teacher noticing: what teachers notice and how teachers notice.

The authors of this study used pre- and post-interviews with the video club treatment group and a control group of teachers. Teachers were asked to comment on what they noticed about video clips showing aspects of student thinking in the context of a classroom mathematics lesson. van Es and Sherin also observed, transcribed, and coded video club sessions. Both data points were coded using the Learning to Notice Framework and quantified to look for statistical relationships. Statistical findings suggest that this PD approach contributed to greater incidences of noticing student thinking, helped teachers move from a descriptive stance to a more interpretive stance as they commented on student thinking, and demonstrated that participants became more grounded in the specifics of video lessons and student thinking.

One useful aspect of this examination of video-based PD is the different ways in which teachers changed. Some teacher changes were more direct and sustained, others were cyclical, and a third group of teachers demonstrated a more incremental change in that they noticed a few aspects of student thinking at a time. Further, the authors used an analysis in which they looked for change points and chunked their transcripts by those 
change points, providing access for connecting those points to the factors that may be correlated to the changes. This manner of segmenting data may be a productive technique for the present study.

In another study, Franke and Kazemi (2004) investigated a teaching workgroup using artifacts of children's work. The authors used grounded theory to trace the trajectory of teacher change over a year as the teachers discussed student work samples that they brought to each workgroup session. The workgroups, comprised of K-5 teachers $(\mathrm{n}=10)$, met once a month for seven months after school for one academic year.

The first change the authors noted was the teachers' shift of attention to students' thinking and the second was the teachers' attention to possible trajectories of students' mathematical thinking. During early meetings, teachers demonstrated discomfort eliciting students' thinking and shared mostly evaluative comments about the correctness of their students' work. By the third workgroup, participants had transitioned to attending to student thinking and demonstrating surprise and respect for the thinking they saw. The second shift involved a greater focus on the trajectories of student strategies and the principled knowledge of children's mathematical understanding. Similar to Borko and her colleagues' use of video, Franke and Kazemi's use of observation and grounded theory analysis allowed access to the characteristics of teacher changes with respect to noticing student thinking across the PD workgroups.

These studies lend credibility to the notion that when teachers are engaged in the intellectual endeavor of making sense of students' mathematical thinking and the students' development of understanding in mathematics, there is a shift of stance from 
one of evaluation of student work to one of understanding and interpreting student thinking.

Taken together these classroom artifact studies represent professional learning that is situated in the context of practice (Ball, et al., 2009). The limitation of these studies is that they represent a smaller n-size and they do not provide evidence of whether these changes translate into changed instructional practices in the mathematics classroom. Another limitation is that the aforementioned studies do not measure the impact on classroom practice and student achievement.

\section{Case Studies Measuring the Impact of PD}

In the previous section I described studies that measured teacher noticing of students' thinking as well as broader studies that measured changes in the PCK of teachers. In this section, I will shift my attention to studies that employ a case study research design.

The first group of studies is particularly useful to my research design because the studies were implemented to provide robust description to corroborate findings within a larger study (Franke, et al., 1998; Roseberry \& Puttick, 2008).

Case study as a support to a larger study. Franke, et al. (2009) used a case study approach to measure the process of change of three teachers over a four-year period. These three teachers were a part of a group of 21 teachers involved a larger study of the impact of CGI professional development. The authors in this case study used observation of teacher interactions in PD workshops, 10 observations of mathematics classroom instruction, and two different interviews: a belief interview and a semi- 
structured interview using a discussion of a classroom scenario taken from each teacher's classroom observation.

The findings in this study described three different trajectories of teachers' change process as a result to PD focused on student thinking. The authors conjectured that teachers who learn to listen students' mathematical thinking would demonstrate a sustained generative change in their instructional practice. Time-sequenced narratives were used to describe the trajectories of change each teacher experienced and the factors that contributed to that change.

Another example of a case study that contributed to a larger study, is a study conducted by Roseberry and Puttick (2008). This study documented the changes in PCK which one teacher experienced as a result of a science PD workshop. The purpose of this case study was to illustrate changes to a teacher's PCK as a complement to the statistical findings of the larger study.

Each of these studies can be useful to inform the use of a case study research design because they provide explanations of ways to conduct qualitative observation and interview analysis to answer research questions that call for more illustrative description. The Franke et al. (2001) case study is particularly important because it demonstrates a method for chunking the data into segments in a way that makes the findings more credible and useful to an audience. The Roseberry and Puttick study is useful in that it highlights the importance of drawing interpretations from the participants of a study.

Case Studies to illustrate propositions. The Roseberry and Puttick case study is an example of a purely inductive analysis of observation and interview data. In contrast, 
Franke et al. (2009) used both a deductive and inductive analysis in order to validate existing research propositions while also allowing for the themes to emerge iteratively. Hufferd-Ackles, Fuson, and Sherin (2004) also use a case study analysis of one teacher in the process of creating a mathematics discourse community in the classroom. The data in this study expanded and illustrated levels of "math talk" as well as validated themes in the math reform literature.

The case study literature I reviewed contributed three insights for the present study. First, I used a stimulated response (SR) interview which provided an opportunity for participants to examine specific episodes of their own classroom instruction. This technique was similar to the interview in Franke et al. (1998) because both techniques provide specific moments of classroom practice that they can respond to and reflect upon in order to access teacher thinking that is representative of their daily thinking, habits and beliefs as they conduct math lessons.

Finally, I use the learning to notice students' mathematical thinking framework (van Es, 2011). This framework was used to code student thinking assignments participants engaged in throughout the pedagogy-focused mathematical content courses of the EaMML project. The purpose was to determine the character of teacher noticing of participants over time.

The literature review makes a clear path for professional development that supports teachers to develop their PCK and teacher noticing skills. The application of teacher noticing, while gaining traction, is still distant from many classrooms. The case study description adds to the literature about this critical teacher skill. In the next chapter, 
I describe the recruitment, methods and analysis for the case study. 


\section{Chapter 3: Methods}

If the field of mathematics education is to provide access to high-quality and equitable instruction that prepares all children for access to college and contemporary careers and life, teacher learning opportunities need to be developed that attend to the complex learning environments in which teachers work. Many suggest the key to this learning is to support teachers in developing a better understanding of mathematical content and how students authentically interact with content (Ball \& Cohen, 1999; Bell, et al. 2010; Shulman, 1986). If teachers need to better understand how students interact with content in authentic ways, a shift is necessary in professional development toward developing a deep understanding of student thinking. Learning to implement mathematics instruction that centers students' thinking, promotes student engagement, and employs student reasoning is complex. A current focus in mathematics education research is to describe effective practices of professional development (PD) that support teachers to enact ambitious math instruction (Ball \& Cohen, 1999; Lampert, 2009; Lampert, et al., 2010; Smith, 2001).

The research I conducted was embedded in a larger PD model that provides opportunities for teachers to deepen their understanding of mathematics content through the lens of students' authentic mathematical thinking, their conceptions and misconceptions of mathematical content and their ways of representing their mathematical ideas. Teachers in this study implemented teaching practices that are "likely to lead to comparatively large advances in student learning" (Ball, et al., 2009, p. 460) in three ways. These were as they designed student thinking tasks and enacted them 
in their own classrooms; engaged in lesson studies that are enacted in real-time in other classrooms; and analyzed students' thinking about mathematical content in written and video episodes of student thinking.

For many teachers, centering student thinking and ideas represents a significant shift in instructional habits as well it requires release of responsibility to students to reason and make meaning of mathematical ideas. The purpose of my study was to explore and describe how participants articulated or enacted these shifts in their beliefs and instruction and the ways in which they notice students' mathematical thinking. I address three questions in my research:

1. In what ways does being involved in a reform-oriented PD project that is focused on integrated mathematics content and pedagogy development and students' mathematical thinking impacting teachers' a) instruction and b) beliefs about mathematics teaching or c) themselves as a math teacher?

2. Which activities, tools or frameworks from the PD elements do teachers point to as the most impactful in terms of their work in the classroom?

3. How do teacher's notice their students' thinking and in which tasks of teaching is teacher noticing — whether strong or weak — most apparent?

\section{Research Methods}

In order to answer these questions, I used a qualitative case study design of three teachers. The case study design is rooted in a social constructivist research paradigm. I drew upon observational methods, analyzed documents of practice and conducted interviews utilizing the stimulated recall (SR) approach. The data was coded both deductively and inductively using thematic networks analysis. I will describe these procedures in more detail later in this chapter. 


\section{Research paradigm.}

In this study, I employed a social constructivist research paradigm. According to the view of social constructivism, knowledge is gained through social interactions. Knowledge represents multiple realities, and as such participants' views and perspectives are necessary in order to understand how a particular phenomenon is impacting the participants. As participants continue to experience the phenomena their constructions of knowledge become more sophisticated (Lincoln \& Guba, 1994).

Justification of the research paradigm. The social constructivist research paradigm subscribes to interpretive techniques to analyze data. In this research paradigm interviews, observations, and document analysis are common data sources. The social constructivist paradigm is warranted in this study because it allows the researcher to better understand the participants' experiences which are inextricably linked to the contexts in which they work and to the reality of their own personal experiences (Cresswell, 2013). Moreover, social constructivism recognizes the subjective perspective of the researcher (Lincoln \& Guba, 1994). In this case study research design, I recognize that my own perspectives and beliefs about the teaching and learning of mathematics cannot be separated from what I observe. For this reason, I allowed themes to arise inductively from the participants' experiences as well as deductively from the teacher noticing research.

\section{Justification of case study within the social constructivist paradigm. A case} study design is justified within a social constructivist paradigm as it connects to the experience of readers. A case study is steeped in context and developed by reader 
interpretation (Merriam, 1998). Case studies are useful for studying bounded systems, events, processes, or organizations (Creswell, 2012; Merriam, 1998; Thomas, 2011; Yin, 2009); providing additional evidence in a larger research study (Yin, 2009); and studying complex contextual interactions holistically (George \& Bennett, 2005; Merriam, 1998).

\section{Case Study Embedded in Larger EaMML Project}

The case study research I conducted, operated in concert with the larger mixedmethods East Metro Mathematics Leadership (EaMML) Math Science Partnership project. The EaMML project and case study shared a common purpose of finding a solution to the problem of how to support teachers to understand and enact teaching practices that translate to principled mathematics learning for students. Teachers' efforts to notice, interpret, and use student thinking lie at the heart of these teaching practices. More specifically, in my view, the principal investigators of the EaMML project and I seek to support teachers in shifting toward a view of children as untapped vessels of knowledge from which we can draw to construct more formal mathematical principles.

Justification of a case study design. Clark and Creswell (2010) suggest that qualitative approaches are warranted in a study when the purpose of the study is exploration and the goal is to seek understanding about a given research problem. I wanted to understand more about how teachers come to change their stance towards mathematics teaching as they learn to place student ideas and thinking at the center of classroom instruction. More specifically, I theorized that learning to notice students' authentic mathematical reasoning can have a powerful impact on participants' beliefs and 
instruction. I hoped that the depth of the case study approach would provide a way to capture this impact. The PD approach from the EaMML project utilized students' mathematical thinking as a frame to develop teacher's pedagogical content knowledge. Therefore, I anticipated that I could learn from the participants, how that particular frame impacted their beliefs and instruction. A key purpose of this research was to provide illustration of the practice of teacher noticing of students' mathematical thinking. I hoped to learn the ways in which participants attended to, interpreted, and responded to students' reasoning. For all the aforementioned reasons, employing a qualitative case study design made the most sense.

Limitation of a case study design. I acknowledge that one of the weaknesses of this study is the small number of participants $(\mathrm{n}=3)$. The objection is that small $\mathrm{n}$ studies lack generalizability to a larger population. However, I agree with Yin (2009) that case studies can be generalizable to a proposition or theory, which makes the findings transferable to the research field. Thus, in my study, I endeavored to add to the research about teacher noticing of children's mathematical thinking and corroborate some of the earlier work of van Es (2011). In addition, the case study description will contribute explanation to the findings of the larger EaMML study similar to the Franke et al. (2001) study. Further, I hoped to provide description needed for teacher practitioners to envision the practice of teacher noticing, interpreting and taking up student thinking in classroom mathematics lessons. 


\section{Participants}

As the case study research was situated in the larger EaMML PD project, the three case study participants were drawn from one of the partner school districts in the project. I will briefly describe the context of the EaMML study and the participants, then I will describe the sampling and recruiting methods I used.

Context and participants of the EaMML project. The 3-year EaMML project was a collaboration between Portland State University (PSU), the Multnomah Education Service District (MESD) and two large suburban school districts in Portland, Oregon. The PD activities for the EaMML project commenced December 1, 2014 and continued for a 3-year period, culminating in November 2017. My case study drew participants from only one of the partner districts involved in the EaMML project.

Context of case study. The case study school district is situated in east Portland, Oregon and covers a 12- mile residential area. At the time of the data collection period, the district served 10,720 students in their K-12 school system. Of these students, $75.6 \%$ received free and reduced lunch, 59.1\% come from minority populations, and 9.8\% received special education services.

The EaMML project included 68 voluntary participants from the two K-12 partner school districts who made up the Mathematics Leadership Team (MLT).

Context of the EaMML PD project. The 68 teachers from the MLT were invited to engage in an array of PD activities offered. From those 68 MLT's, 30 teachers volunteered to be a part of the Mathematics Leadership Cadre (MLC). These participants 
were also asked to design and lead PD activities in their buildings starting in the second year of the project.

The PD activities included book studies, lesson studies, mathematics instructional leader content and leadership courses offered by PSU, district summer work and yearly Kick-Off Activities (Appendix A).

The three case study participants were drawn from MLC and they engaged in 5 Mathematics Instructional Leader (MIL) content courses and two leadership courses. The courses were part of a pre- $\mathrm{K}$ to grade 8 specialization certification. The classes were available to all of the members of the MLT. The course titles are included in figure 3.1.

CI 511 Examining Base Ten Numeration and Operations (BST)

CI 512 Examining Operations with Whole Numbers and Fractions (EO)

CI 513 Enhancing Algebraic Thinking: Generalizations about Operations (GAO)

CI 514 Enhancing Algebraic Thinking: Patterns and Functions (PFC)

CI 515 Developing Geometric Thinking and Concepts (GC)

CI 516 Exploring Measurement Concepts (M123)

CI 517 Developing Concepts of Data Analysis: Representing and Modeling with Data (Data)

CI 518 Implementing Mathematics Reform (Reform)

CI 519 Mathematics Leadership: Influencing \& Facilitating Improvement (Leadership)

CI 521 Mathematics Leadership Practicum (Practicum)

Figure 3.1. Course titles for the EaMML pedagogical-focused content courses.

MIL content-focused pedagogy course structure. The MIL content courses were offered each term. They were structured in ten 3-hour weekly sessions. In each session participants engaged in doing math using mathematical tasks that dovetailed with video and written episodes of students' mathematical thinking. They watched and discussed 
video and written episodes of teachers and students grappling with the mathematical ideas they had explored; they also read related research and studied the Common Core State Standards for Mathematics K-8 as well at the Progressions for the Common Core State Standards for Mathematics.

Case Study Participants. A sample of three teachers was drawn from the Math Leadership Cadre (MLC) as the case study research participants. I drew from this pool primarily because these participants had the greatest exposure to mathematics content and PCK learning in the context of students' mathematical thinking. I argue that in order to realize classrooms that center students' mathematical thinking, teacher learning in practice must include learning about how to listen to and learn from students' authentic ways of thinking that is often very different from the thinking of adults. If my purpose is to describe how teachers attend to, interpret and respond to students' thinking, as well as describe the articulated and enacted shifts in instructional practice, and the impacts of the $\mathrm{PD}$, then it follows that the teachers engaged in the bulk of the PD activities will provide the richest source of data. An equally important rationale was that the MLC teachers were asked to reflect regularly on their mathematical and pedagogical learning and engage the students with student thinking assignments within their classrooms where they would analyze the student thinking that emerged. These documents represented the most consistent and robust data source available from the study.

The three participants were all elementary school teachers and pseudonyms were used in this study in order to protect their anonymity. Christine Jones is the most veteran teacher of the three. She taught 12 years all in the same school district, At the time of the 
EaMML project, Ms. Jones taught $3^{\text {rd }}$ grade. Brian Wells taught 6 years when he joined the project at the beginning of year 2 . He looped from kindergarten to $1^{\text {st }}$ grade during the project duration. The last participant was Henry Nelson. Mr. Nelson had been teaching 11 years and taught $5^{\text {th }}$ grade all three years of the project. I describe each participant more fully in the next chapter.

\section{Procedures}

In this section, I describe the phases of the case study. Next, I describe the instruments and measures in the data collection phase. Finally, I describe how I coded and analyzed the data.

Phases of the case study research design. The case study process began in the winter of 2017 toward the end of the EaMML project. My rationale for starting toward the end of the project was one of a practical nature. The participants themselves were quite busy and although I started recruiting in the fall of 2016, participants did not sign up until the winter of 2017. Figure 3.2 outlines the timeline and case study procedures. 


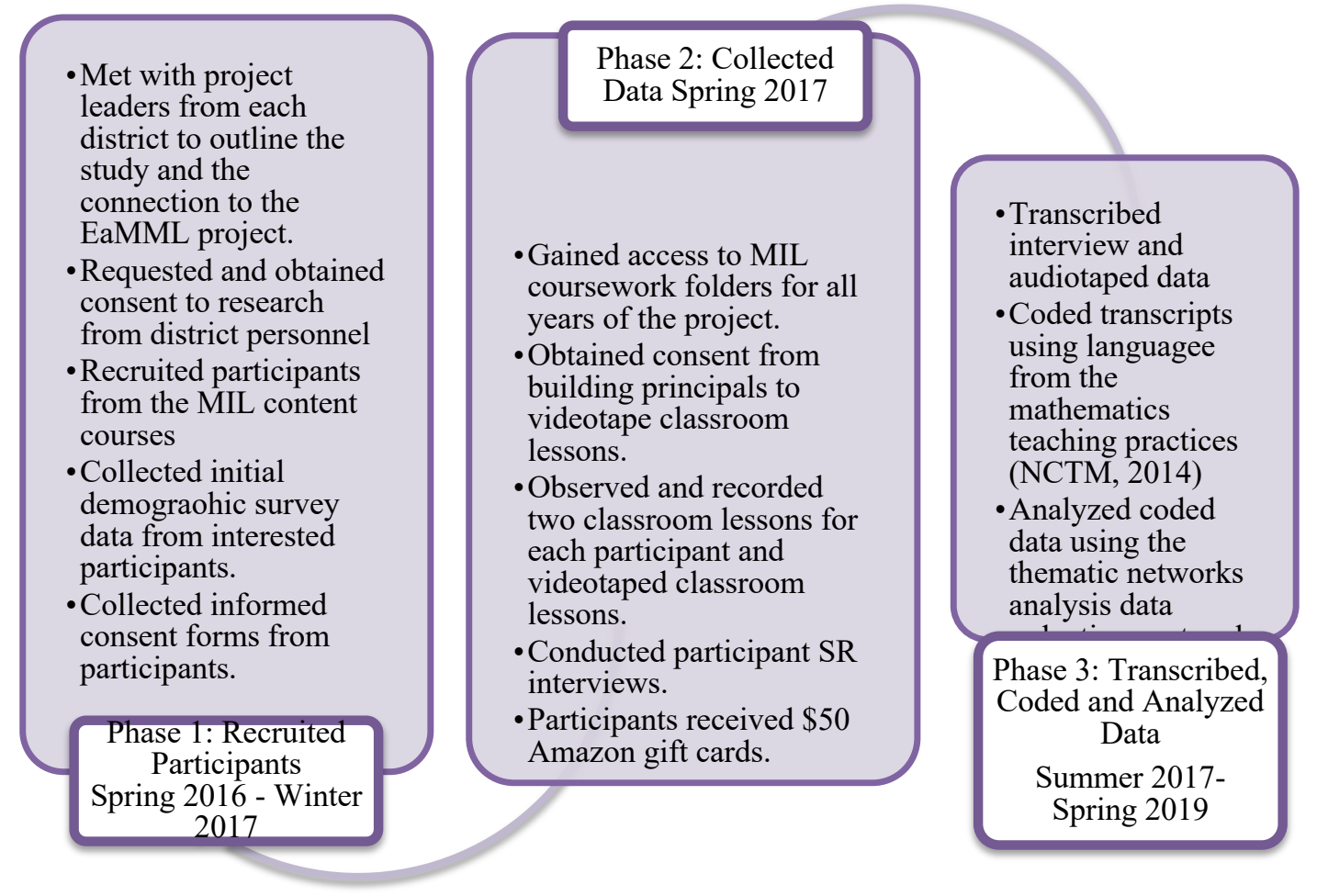

Figure 3.2. Phases of the case study research design spanning spring 2016 to spring 2019.

Phase 1: Recruitment of participants. During the first phase of the study, I met with EaMML project leaders to share my research goals and garner support to situate the case study within the EaMML project. Once I received their support, I shared my research goals with district personnel and was granted permission to conduct research in both districts. I initiated an in-person power point recruitment presentation (Appendix B) in the fall of 2016 during the PSU MIL content course. I followed up by sending emails to a selected pool of participants suggested by project leaders. This first attempt yielded no participant volunteers, so I followed up with another presentation and email appeal in 
the winter MIL content course. Four participants volunteered, but one participant had to drop out later in the spring.

Participants expressed interested by completing a 10-minute recruitment survey to provide details about themselves. The initial survey is included in Appendix C. When the survey had been submitted, I provided each of the participants an informed consent document outlining the phases of the project and their responsibilities if they should choose to join the study (see Informed Consent in Appendix D).

Phase 2: Collection of data. During the second phase, the participants granted me access to their Google folders. We then scheduled dates for the SR interview and classroom lesson videotaping. When interview dates had been established, I obtained the appropriate permissions for the data collection from participants' classrooms.

Coursework documents. The largest data source for this study was the documents that were collected from the MIL content courses. Coursework documents were stored in individual Google folders for each participant in the study and included assignments from each of the MIL content courses as well as the leadership courses. The case study participants electronically shared their folders with me granting me access to all of their coursework documents. After examining each category of course assignment, I decided four categories of documents were most likely to provide data to answer the research questions: the student thinking assignments, portfolio reflections, research and impactful cases assignments, and practicum and leadership reflections.

SR Interviews. In order to put the least amount of stress on case study participants the SR interviews were enacted very close to the end of the school year when 
state standardized testing and MIL coursework had been completed. I scheduled two visits in each classroom in which I videotaped mathematics lessons for the stimulated recall (SR) interview. The rationale for the timing of these interviews was to minimize the time commitment from the participants.

One week after the classroom lessons, I met with each participant to conduct the SR interview. Interview questions can be found in Appendix $\mathrm{J}$.

Obtaining consent to videotape classroom lessons. Before visiting the classrooms, I emailed each participant's building principal to inform each of my study and my intent to videotape classroom lessons. It was important to assure each principal that the students were not the subject of the research study and the videotaping would only be used to support the participant's reflection. In addition, each teacher was given a Parent Consent Form (Appendix E) to notify parents of their students about the project, and to assure them that their children were not the subject of the study.

Videotaping classroom lessons. Once permission from the building principal was obtained, I began the two classroom visits. My rationale for videotaping two classroom lessons was to increase the likelihood of instances of student thinking that the participants could reflect upon. In addition, if the videotaping malfunctioned or participant had to cancel the visit, we would be assured of at least one classroom lesson to discuss. In fact, Mr. Nelson did have to cancel one classroom lesson, but we still had a videotaped lesson to draw upon. In each classroom, I introduced myself to the students and shared with them the purpose of my visit. I also explained that I would be videotaping, but I would not be focusing on their faces and instead I was interested in the lesson and their teacher. 
Phase 3: Transcribing, coding and analyzing the data. Once the data was collected, I transcribed the selected segments of the audiotaped interviews. In addition, I prepared 96 artifacts of practice to be coded. I coded the documents using the mathematics teaching practices (NCTM, 2014) then I used the thematic networks analysis data reduction system to draw out themes inductively. Of the 96 documents, I then recoded 43 student thinking assignments using an adapted Learning to Notice framework (van Es, 2011).

\section{Instruments and Measures}

In the previous section, I explained the procedures of the case study data collection. In this section, I describe the instruments and measures I used to collect the data. First, I will describe the instruments and measures from the larger EaMML project that I will draw upon to support my own findings. Next, I will turn to the instruments and measures specific to my case study research.

EaMML instruments and measures. The EaMML project leadership team conducted a mixed methods study of the project in conjunction with RMC Research Corporation. Between the two groups data was collected in a variety of ways from several sources. Table 3.1 summarizes the research instruments and measures.

EaMML instruments and measures utilized in the case study. Findings from the EaMML research data were used triangulate the data from the case study. For the purposes of the case study research, I supplemented my data by accessing (a) the observation of classroom practice, (b) the pretest posttest teacher survey. 
Table 3.1

EaMML Data Collection Measures and Instruments

\begin{tabular}{|c|c|c|}
\hline Data Source & Measurement Purpose & Instrument or Measure \\
\hline Pre-Post Surveys & $\begin{array}{l}\text { - Enhanced teachers' professional } \\
\text { knowledge and skills } \\
\text { - Increase district/school capacity to } \\
\text { provide math PD }\end{array}$ & $\begin{array}{l}\text { Leadership and Pedagogical } \\
\text { Content Knowledge Likert } \\
\text { scales }-7 \text { scales }\end{array}$ \\
\hline $\begin{array}{l}\text { Pre-Post Classroom } \\
\text { Observations }\end{array}$ & $\begin{array}{l}\text { Increased teachers' use of research- } \\
\text { based math instructional practices }\end{array}$ & $\begin{array}{l}\text { Instructional Quality Assessment } \\
\text { (IQA) Observation }\end{array}$ \\
\hline $\begin{array}{l}\text { Pre-Post Artifact } \\
\text { Analysis }\end{array}$ & $\begin{array}{l}\text { Effective mathematics learning } \\
\text { experiences }\end{array}$ & $\begin{array}{l}\text { Instructional Quality Assessment } \\
\text { (IQA) Math Assignment Rubric }\end{array}$ \\
\hline Vignette Analysis & $\begin{array}{l}\text { Increased participants' mathematical } \\
\text { knowledge and pedagogical content } \\
\text { knowledge }\end{array}$ & Vignette reflection form \\
\hline $\begin{array}{l}\text { Mathematical } \\
\text { Knowledge for Teaching } \\
\text { (MKT) }\end{array}$ & $\begin{array}{l}\text { Increased participants' mathematical } \\
\text { knowledge and pedagogical content } \\
\text { knowledge }\end{array}$ & $\begin{array}{l}\text { Number Concepts and } \\
\text { Operations (NCOP) for } \\
\text { elementary teachers }\end{array}$ \\
\hline RMC Focus Group & $\begin{array}{l}\text { - Increased teachers' use of research- } \\
\text { based math instructional practices } \\
\text { - Increase district/school capacity to } \\
\text { provide math PD } \\
\text { - Increased student achievement on state } \\
\text { assessments } \\
\text { - Increased participants' mathematical } \\
\text { knowledge and pedagogical content } \\
\text { knowledge }\end{array}$ & $\begin{array}{l}\text { Focus Group protocol designed } \\
\text { by EaMML and RMC project } \\
\text { leaders. }\end{array}$ \\
\hline $\begin{array}{l}\text { Quasi-Experimental } \\
\text { Comparison of Student } \\
\text { Achievement Data } \\
\end{array}$ & $\begin{array}{l}\text { Increased student achievement on state } \\
\text { assessments }\end{array}$ & $\begin{array}{l}\text { Smarter Balanced Assessment } \\
\text { Consortium (SBAC) }\end{array}$ \\
\hline
\end{tabular}

Classroom observation data. Observations of classroom practice were conducted in the fall of 2015 and the spring of 2017. The EaMML drew from a proportionate random-stratified sampling of the 69 MLT participants. Only one of the case study participants was originally included in the observation sample and was observed in the fall. The other two participants were added into the sample to more closely examine the difference the coursework made in what was being observed in teachers' respective classrooms. Principal investigators for the EaMML project used the Instructional Quality 
Assessment Classroom Observation Tool (IQA). The rubric uses 10 categories which raters score from N/A to 4 . The organization of the rubric is displayed below.

\begin{tabular}{l|l}
\hline \multicolumn{2}{c}{ Instructional Quality Assessment Observation Tool (IQA) } \\
\hline \multicolumn{1}{c}{ Academic Rigor } & Accountable Talk \\
\hline Rubric 1: Potential of the Task & Rubric AT-1: Participation \\
Rubric 2: Implementation of the Task & Rubric AT-2: Teachers' Linking \\
Rubric 3: Discussion Following the Task & Rubric AT-3: Students' Linking \\
Rubric AR-Q: Questioning & Rubric AT-4: Asking (Teacher Press) \\
Rubric AR-X: Mathematical Residue & Rubric AT-5: Providing (Student Response) \\
\hline
\end{tabular}

Figure 3.3. List of rubrics used to measure classroom instruction in the EaMML project. Adapted from the "Instructional Quality Assessment Observation Tool" by Boston \& Wolf, 2005. (For further examination of the IQA rubric see Appendix K.)

Teacher survey data. The EaMML project leaders developed a teacher survey to measure changes in teachers PCK and instructional leadership skills. The survey included quantitative items scored with a Likert scale from 1 or not at all comfortable/prepared to 4 very comfortable/prepared. The survey included 7 scales, one measuring instructional leadership and 6 measuring PCK. The teacher survey was administered in the spring of Year 1(pre) and in the spring of Year 3(post).

EaMML data and the case study. Portions of each of these two data sources were used to triangulate the data in the case study. I describe the content of the IQA rubrics and teacher survey and how the data triangulates with the case study data in the next chapter. 
Case study instruments and measures. Table 3.2 summarizes the study

questions and the data sources I used to answer the research questions I posed. In this

section, I describe the data sources, instruments and measures that are specific to the case

study. Later in this chapter, I detail the analysis of the data collected.

Table 3.2

Research Questions Connected to Data Sources

\begin{tabular}{|c|c|c|c|c|c|c|}
\hline \multirow[b]{2}{*}{ Research Question } & \multicolumn{6}{|c|}{ Sources of Data } \\
\hline & $\begin{array}{c}\text { Student } \\
\text { Thinking } \\
\text { Assignments }\end{array}$ & $\begin{array}{l}\text { Portfolio } \\
\text { Reviews }\end{array}$ & $\begin{array}{l}\text { Cases with } \\
\text { Impact: } \\
\text { Research } \\
\text { Review }\end{array}$ & $\begin{array}{l}\text { Stimulated } \\
\text { Response } \\
\text { Interview }\end{array}$ & $\begin{array}{c}\text { EaMML } \\
\text { Classroom } \\
\text { Observation } \\
\text { (IQA) }\end{array}$ & $\begin{array}{l}\text { EaMML } \\
\text { Teacher } \\
\text { Survey }\end{array}$ \\
\hline $\begin{array}{l}\text { In what ways does being } \\
\text { involved in a reform- } \\
\text { oriented PD project that is } \\
\text { focused on integrated } \\
\text { mathematics content and } \\
\text { pedagogy development and } \\
\text { students' mathematical } \\
\text { thinking impacting } \\
\text { teachers' a) instruction and } \\
\text { b) beliefs about } \\
\text { mathematics teaching or c) } \\
\text { themselves as a math } \\
\text { teacher? }\end{array}$ & $\checkmark$ & $\checkmark$ & & $\checkmark$ & $\checkmark$ & $\checkmark$ \\
\hline $\begin{array}{l}\text { Which activities, tools or } \\
\text { frameworks from the PD } \\
\text { elements do teachers point } \\
\text { to as the most impactful in } \\
\text { terms of their work in the } \\
\text { classroom? }\end{array}$ & $\checkmark$ & $\checkmark$ & & $\checkmark$ & $\checkmark$ & $\checkmark$ \\
\hline $\begin{array}{l}\text { How do teachers notice } \\
\text { students' mathematical } \\
\text { thinking and in which tasks } \\
\text { of teaching is teacher } \\
\text { noticing - whether strong } \\
\text { or weak - most apparent? }\end{array}$ & $\checkmark$ & $\checkmark$ & $\checkmark$ & $\checkmark$ & & \\
\hline
\end{tabular}

MIL coursework documents. The richest source of data in this study were the documents of practice produced as a part of the MIL content courses. Included in these coursework documents were (a) portfolio reflections (b) mathematics assignments (c) 
research and impactful cases assignments (d) student thinking assignments and (e) lesson analysis assignments and (f) leadership and practicum reflections. The coursework documents used in the case study included portfolio reflections, student thinking assignments, research and cases with impact, and leadership and practicum reflections.

Ball and Cohen (1999) suggest that professional learning in and from practice does not imply that the work of teacher learning must always occur in the classroom context. The authors propose instead that using documents of practice such as student work, curriculum materials, lesson planning, etc. offers opportunities to rehearse instructional practice in a more thoughtful way. For my purposes, the coursework documents provided insight into participants' reflections about their learning, beliefs, and instructional practices.

The specific documents of practice that supported teacher learning in the MIL courses included analyzing curriculum materials, analysis of teacher moves that support mathematics learning in principled ways, analyzing productive tasks and, most relevantly to the case study, analysis of the written and video episodes of student thinking and the student thinking assignments. In fact, I refer to these last two activities as rehearsals of teacher noticing because of their potential to prepare teachers to sustain their focus on specific student thinking and the relationship of the thinking to students' mathematics understanding.

My purpose for choosing to use assignments in this way is to illuminate the data source most closely connected to the theoretical framework of this study. To further 
explore the course assignments, some examples have been included in Appendices F, G, H, I.

Participant interview. Another source of data was culled from two video-taped classroom lessons and a Stimulated Recall interview (SR). This data source included both researcher observation and teacher self-report data. The two classroom lessons were opportunities to observe each participants' classroom practice so these data could be triangulated with the self-report data sources. I used the observation data for the purpose of confirming articulated practice that participants discussed in their interviews, reflections, student thinking exercises, and teaching surveys

During the first portion of the interview, I prompted each participant to watch the clips I had chosen and reflect using some prompts or just talking about the clip. In order to allow for emergent ideas, I developed open ended prompts and then followed up with questions to draw out more of the participants' thinking regardless of their path. The other half of the interview was more structured, prompting the teacher to reflect on changes in their practice and the activities that impacted them the most. I describe the interview instrument in more detail in the next section. The SR Interview questions can be found in Appendix J.

Classroom lessons and SR participant interview. The rationale for the videotaped classroom lesson was to provide a platform for the participants to reflect about specific instances of their mathematics instruction using the SR technique. Dempsey (2010) argues that SR is particularly useful because "motivations and rationales that informants 
describe retrospectively may not conform to those that they actually held in the moment of the experience."

SR is a process designed to access participants' cognitive processes (Lyle, 2003).

Classroom lessons were videotaped in order to engage participants in viewing episodes of their own teaching and recalling the thinking, and decision-making. This process was chosen for the current case study because I wanted to learn about what and how participants notice their students' mathematical thinking and how their decision-making was connected to their students' mathematical thinking.

Limitations of the SR approach. One of the limitations of SR approach is that it necessitates participant awareness of the rationale and purpose of videotaping classroom practice ahead of time (Calderhead, 1981). In order to mediate this concern, I included a description and rationale for this methodology in the initial recruitment presentation (Appendix B) as well as in the Informed Consent document (Appendix D). In addition, researchers suggest that a rapport should be developed with the participants. The researcher should have deep understanding of the context and practice of the participants work (Dempsey, 2010). As a teacher-researcher with special interest in the field of mathematics and a co-facilitator of two of the early MIL content courses, I had built a rapport with the participants before the study started. They knew that I was also a classroom teacher and my interest in the field of mathematics gave me deep insight into their work. 
A third validity concern was time sensitivity. If the time between the classroom lesson and the interview is too long, the participants responses do not constitute recall (Lyle, 2003) I scheduled the interview less than week after the classroom lessons.

An additional validity concern with the SR method is the possibility that the questions themselves may "alter the cognitive process being employed at the time of the event” (Nguyen, McFadden, Tangent \& Beutal, 2013). I used targeted clips, and asked participants to respond to some possible questions from an open-ended set of prompts:

1. What decision were you facing in the clip?

2. What did you notice?

3. What did you learn about this students' thinking?

4. What decision did you make and what made you make this decision?

The design of the questions was to provide prompts, but to allow participants to respond to the prompts that made sense for them as they watched the clip.

The interviews were conducted in a setting of the participant's choice and were planned to be no more than one hour.

Targeted interview questions. In addition to the SR portion of the interview, I included some targeted questions to allow participants to talk about the impacts of the EaMML project, the changes in their instruction and what they felt was still needed for them as well as other teachers they might support. My intent was to keep the questions open enough to allow them to talk about what they wanted to discuss and then ask follow-up questions to learn more. 
Rationale for one interview. A teacher's time is very valuable, and I was

aware that videotaping two classroom lessons followed by an hour interview could be a considerable a burden added to an already heavy schedule of EaMML project activities, MIL coursework, and full-time teaching. Given these realities, I felt strongly that only one interview should be conducted it should be kept to less than an hour.

Limitation of the interview. Although I tried to follow the path of the participants and listen rather than inserting my own thoughts inadvertently, I noticed at times that I slipped into this pattern of sharing. As I examined text segments, I tried to look for responses that were indicative of a response that was suggested by my questioning. If I found any such responses, I did not use them.

\section{Limitation of the Data Sources}

A limitation of the study is that the data sources are largely self-report data. The self-reflection data sources included the participant interviews, the EaMML teaching survey, and the artifacts from the MIL content courses. The MIL coursework artifacts represented a different type of self-report data in that it provides a picture of ongoing articulated practice with supporting evidence of student thinking or work, as opposed to reflection at a single point in time. In the SR interview, a single point reflection source, the participants would often discuss a shift in their practice. This shift could then be corroborated through the MIL coursework artifacts and in the EaMML pre-post survey data. Finally, I would look to the observation data from the classroom visits or the EaMML classroom observation data for evidence of these shifts or evidence of participants' articulated practice. 
The balance of self-report data and observation data was skewed. The study would have been stronger if I had included observation data of the MIL courses, lesson studies, and ongoing observations of classroom practice. There are two reasons for limited observation data sources: a case study context change and an effort to treat participant time respectfully to keep participants in the study.

Case study context shift. The current case study was originally designed to be embedded in a large-scale PD efficacy study slated for the 2013-2016 school years. Circumstances related to the larger research project made it difficult for the case study to take root. The investigators in the first efficacy study were working with new administrative teams from the partner school district that needed reassurance about the large-scale study. It seemed that they were not comfortable with any additional investigative elements outside of the original research design. For this reason, I separated the current case study from its original context. This case study was redesigned to fit the EaMML context also nearing its end. The recruitment of participants took place in the winter of 2017 with only two terms left to collect data.

Participant and researcher time limitations. When I began the recruitment process for the new case study context, I was aware that the teachers in the EaMML project were already stretched timewise. Each participant was involved in an evening MIL course once a week for three hours. They were assigned a few homework items to complete each week and they were teaching full time. They were also participating in lesson studies and book studies across the school year. Finally, the EaMML participants—given the leadership focus of the grant—were also planning and leading 
mathematics professional learning in their building. In addition, I was working full time for a math PD organization and traveling several times a month around the state. Time was a limitation for completing this study, so I made a deliberate choice to limit the observation events in order to respect participant time and work within my own time constraints. I instead chose to draw upon EaMML project evaluation data sources to round out this case study and corroborate my analysis of learning through the MIL courses and the relative impact on participants' beliefs and classroom practice.

\section{Maintaining Data}

The raw and transcribed data was maintained online on my home computer as well as in an online folder on a Google Drive account that is only accessible by me. Transcribed observations of the interviews were recorded on an Olympus DM 720 audio recorder. The recorder was stored in the fire-proof vault until the data was downloaded and transcribed. Transcribed data was stored in the same Google Drive account as well as on the researcher's home computer. The data will be kept until the completion of the dissertation project.

Participant information is identified only by a pseudonym to maintain anonymity. All of this information about storage and anonymity was provided to the participants during the informed consent stage.

\section{Positionality of the Researcher}

Examining issues equity alongside of conceptual understanding in mathematics education research is the responsibility of any researcher (Aguirre et al., 2017; Gutierrez, 2009; Moschkovich, 2013) As a white woman who has experienced and continues to 
experience privilege, this responsibility is great given the diversity of the population of the students with the three case study teachers work. Aguirre and her colleagues argue that mathematics education research is inherently a political act and as such one responsibility we have is to own our positionality in the research space and interrogate the impact positionality has on the community being researched.

The first layer of my positionality is my identity as a mathematics learner. I studied mathematics in a white upper-class high school in Portland, Oregon. Procedurally, I was adept at mathematics and always performed in the top of my class. I recognize now that as a white upper-class student, I was positioned to do well. My mother enjoyed success in the same mathematics system, so I had the support to learn ideas presented in class from more than just my teachers in school. My success in mathematics is the success enjoyed by the dominant culture to which other racial and cultural groups are compared.

What I chose to investigate and what I valued was driven by my identity and positionality. What was valued in my study was the deepening conceptual understanding of students in mathematics and how students make sense of the mathematics. I know that often what counts as important mathematics and how a student is deemed successful is defined by the white middle class norm. What counts as valuable mathematics does not always take into account what mathematical expertise students bring from their homes.

On the other hand, I recently worked with teachers in populations designated "focus" and "priority" by the Department of Education. These schools received these labels because they needed extra support to improve student achievement. The focus of 
my work was to help teachers resist the labels of students or test outcomes as a definition of their students' identities in mathematics, and instead focus on ways in which students were making sense of mathematical ideas. The professional development I facilitated included attending to the thinking that authentically comes from students as they use their own language (home or informal), use multiple representations, use multiple modes and different kinds of talk and focus on mathematical reasoning over accuracy (Moschkovich, 2013). From this experience, and my own teaching experiences with diverse populations, using informal language, gestures and representation is a value I am inclined to look for in my research. As well, I focus on the value the formation of students' mathematical identities. According to Aguirre, Mayfield-Ingram and Martin, "Teaching involves not only developing important skills and conceptual understanding in mathematics but also supporting students coming to see themselves as legitimate and powerful doers of mathematics." (2017, p. 14)

The participants in my case study examined different frameworks for teaching and reflecting on teaching practice. These frameworks are shown in Table 3.5. The first framework, mathematics teaching practices (NCTM, 2014), I previously noted as the framework I used to develop language to code my data. Alongside this framework, EaMML teachers examined the practices of ambitious teaching (Lampert, et al., 2013) and equity-based instructional practices (Aguirre, Mayfield-Ingram \& Martin, 2013). Although the latter two frameworks are not explicitly tied to my research questions, they provide a lens to connect the teacher noticing of students' mathematical thinking and equity practices. 
Table 3.3

Frameworks for Reflecting on Teaching Practices and Equity-Based Practices

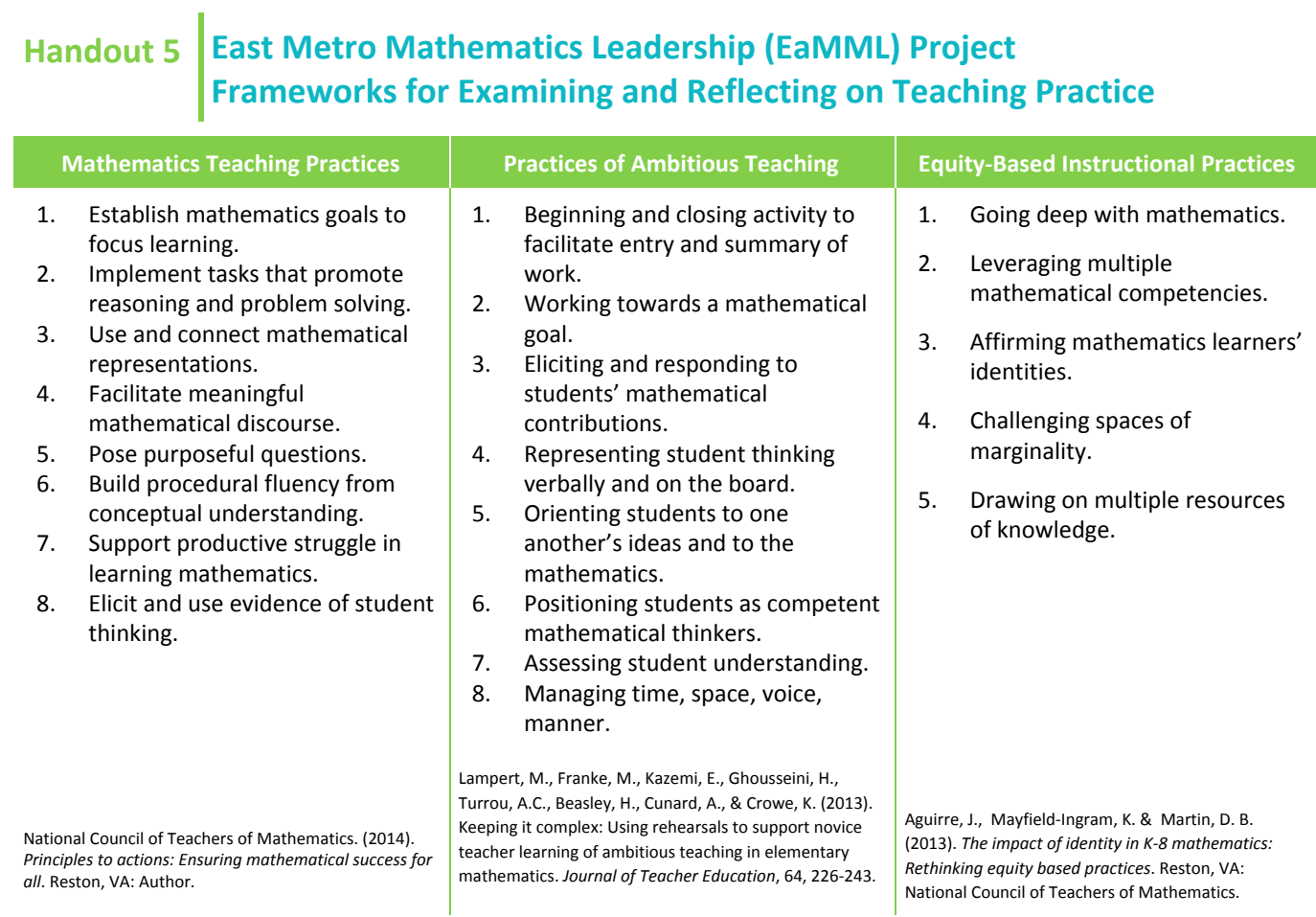

Reprinted from Rigelman, N., Lewis, C., Gray, M., McQueen, A., \& Prigodich, K. (2018). Let's talk about professional development models that work. Paper presented at the National Council of Teachers of Mathematics Annual Research Conference, Washington, DC.

One of philosophical tents of the EaMML project is the importance of going deep into mathematics. Aguirre, Mayfield-Ingram and Martin (2013), argue that going deep with mathematics which includes elements such as supporting students to analyze, justify and prove their solutions. Going deep with mathematics also includes opportunities for students to debate mathematical ideas. Further, providing high cognitive tasks with multiple solution strategies and supports multiple representations are instrumental in the notion of going deep with mathematics. 
As I examined the research findings for each of the three case study participants, I acknowledged the teaching practices they articulated or enacted that demonstrated attention to equity-based teaching.

Finally, in this study, I acted primarily as an observer and researcher. When I decided I would conduct my research within the EaMML project, I withdrew myself from teaching any of the content courses in year 3. However, my role as a co-facilitator of two of the EaMML content-focused pedagogy courses in spring of year 1 and fall of year 2 of the project could be considered both a strength of the research study and a limitation.

The benefit of my connection with the EaMML project, was that I had developed a relationship with many of the participants. The participants and I had all developed a level of mutual trust which likely helped in recruiting participants for my study, and also encouraged them to share the impact of the PD project.

On the other hand, the position I held as a facilitator and the subsequent relationship I developed might also be considered a limitation of my research. The participants may have felt that they needed to report only positively about the EaMML projects and its impacts.

Furthermore, it is important to position myself as a subjective actor in this study. My background as a teacher practitioner for 21 years means that I have my own values and beliefs about the nature of math instruction. I have participated in the majority of the MIL program's mathematics content and leadership courses. I am very passionate about the importance of centering instruction on student thinking. As a researcher, I placed high value on this aspect of elementary mathematics teaching practice. A social constructivist 
paradigm maintains that the values a researcher brings into an inquiry process are unavoidable and shape the meaning making process (Guba and Lincoln, 1994). The social constructivist stance holds that by including participant voice in the data, there is a co-construction of meaning in response to the research questions. I acknowledge my subjectivity in several places in this paper. In order to mitigate my bias, I maintained a researcher reflection journal. In this journal, I wrote metacognitively about instances where bias may be seeping in to my coding or writing.

\section{Analysis of the Data}

Earlier in this chapter, I described the different instruments and measures that I utilized to collect data to answer my research questions. In this section, I describe how I coded and analyzed the data.

Coding data. Once the data was collected, I transcribed sections of the data that were particularly useful for the research questions. Then I read through the MIL assignments and interview data and tagged sections that answered the questions. Once I had noted a connection to the research questions, I coded the data sample using words or phrases that came out of the text. I found this to be challenging and I was having a hard time creating categories of codes. I turned then to NCTM's Principles to Actions (2014), mathematics teaching practices and productive and unproductive beliefs about teaching and learning to look for language that could help me create more a more consistent coding scheme. My rationale for choosing this text was that it was a resource that EaMML participants had read and worked with in a few of the PD activities. The language seemed like it fit well with what participants were sharing. 
Using thematic networks analysis to develop themes. Thematic networks analysis is a data reduction system that allows themes to emerge through analysis of overt text structures and underlying patterns. The strength of this system of coding is that it provides a systematic approach to coding data. As a novice researcher, this system forced me to go back and forth from the data to the themes. I continually asked myself if I truly see the sample text segment as connected to the themes, or if I was connecting the themes to my own experiences. Below is a figure detailing the thematic networks analysis protocol.

When all the data was coded, I looked at a category of coded text segments to determine themes derived from the codes. I repeated this same process with each code category. At times themes from two coded categories would blend together. These initial themes make up the set of basic codes. When I completed a code set, I reread the text segments in each theme to see if the theme truly represented the codes. When the theme language lacked alignment to the text segments, I reworded the theme to better match the text segments. The basic codes were then linked up to form organizing themes, and the organizing themes were connected to make global themes. For each iteration of theme building, I returned to the text segments to align the themes or shift text segments to more appropriate themes. When this process was complete, three themes emerged. The completed thematic networks themes are included in figure 3.4. 


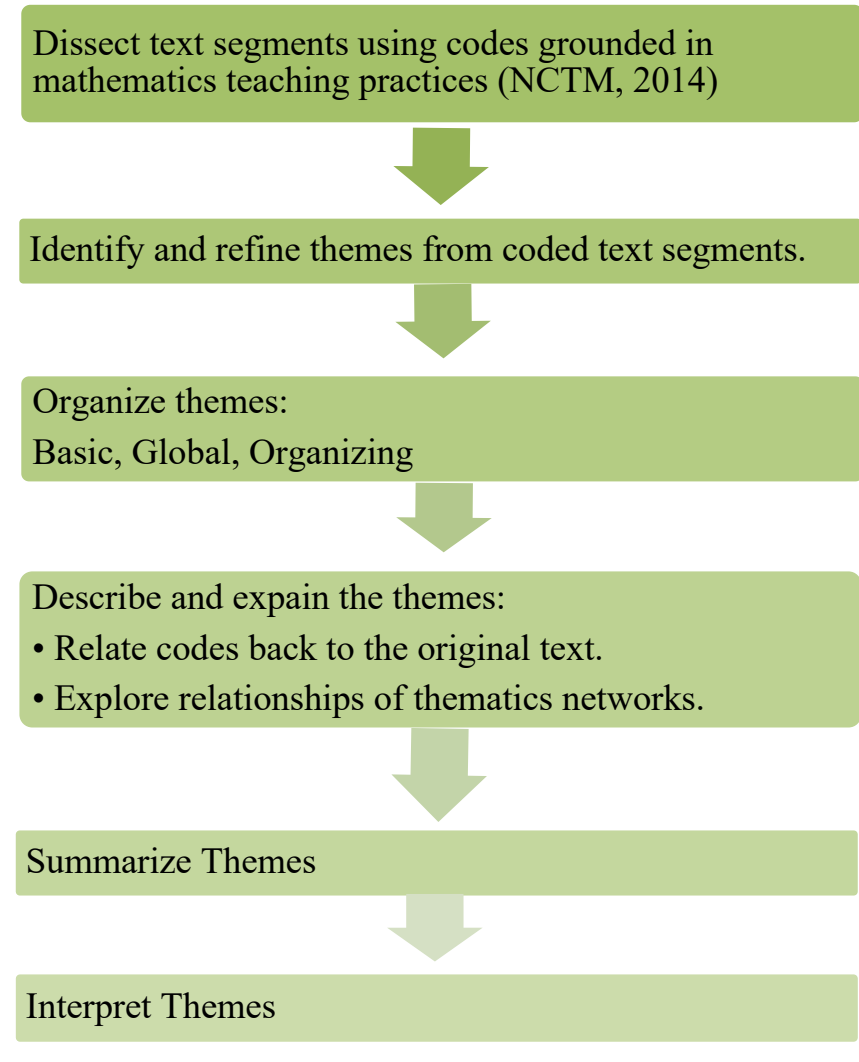

Figure 3.4. Process of the thematic network analysis data reduction protocol.

Learning to notice framework. After creating the themes using all of the text segments, I returned to complete versions of the student thinking assignments. I used a few sample assignments to make sense of the learning to notice students' mathematical thinking framework (van Es, 2014). The original teacher noticing framework was designed to capture teacher noticing in the context of video club discussions. The participants in this study used video clips as an object for noticing aspects of others' teaching mathematics lessons. The context of teacher noticing in this case study were student thinking assignments in which participants described their own students' thinking and their own pedagogical actions. As a result, the language and descriptors of the 
original learning to notice framework were adapted to fit the context and object of the teacher noticing in this present study. The original learning to notice framework (van Es, 2014) is included in Appendix L.

Once the descriptors were adjusted, I coded four student thinking assignments using the framework. In Table 3.4, I include the adapted version of the learning to notice framework and a sample response to illustrate the descriptors. These descriptors were then shared with the co-principal investigator to calibrate the coding and test my interpretations. We worked out some specific language, I revised the adapted framework, created de-identified sample papers, and asked two other mathematics PD facilitators to code the sample papers and give me feedback on the adaptation of the framework. Once the adapted framework had been revised sufficiently, I coded all 43 papers.

\section{Validity}

Triangulation using multiple sources of data, corroborating data from the broader EaMML study, and rich description are all ways in which this qualitative study derives its validity. Earlier in this chapter, I demonstrated a few sources of data for each question and reported the ways in which these data sources will layer onto each other to distill the strongest themes and connections. I also chose data sources (i.e., SR interviews and teacher reflection) in which I accessed teacher interpretations of what changes occurred in their instructional practice. 


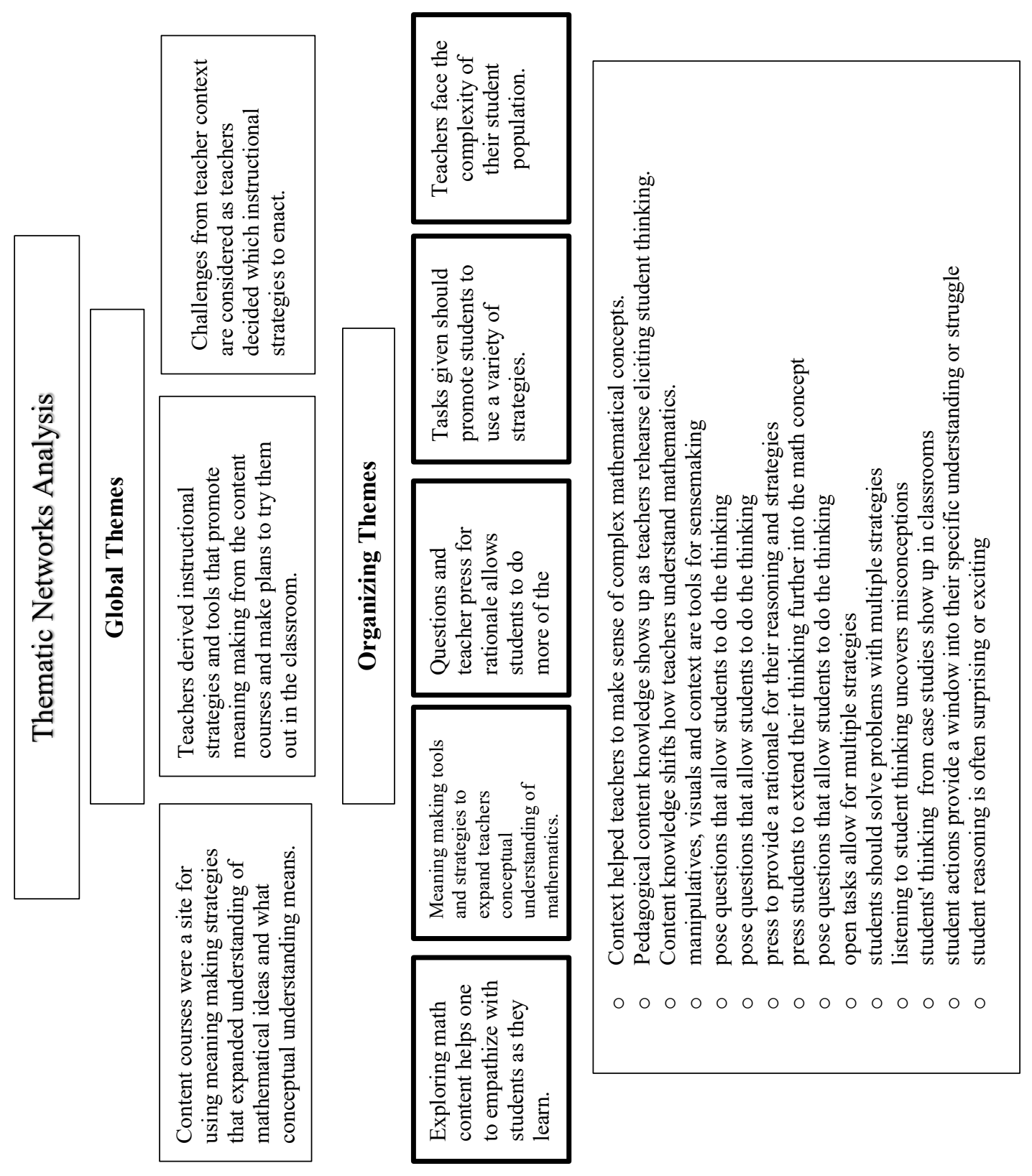

Figure 3.5. Thematic networks analysis of case study data. The bottom text box shows all of the basic themes that emerged inductively from the coded data. These basic themes were combined to create the organizing themes in the middle. The final layer at the top represent the final 
Table 3.4

Adaptation of the Learning to Notice Framework

From van Es, E. (2011). A framework for learning to notice student thinking. In M.G. Sherin, V.R. Jacobs \& R.A. Phillip (Eds.) Mathematics teacher noticing: Seeing through teachers' eyes, (pp.134-151). New York: Routledge. Adapted and reprinted with permission.

\begin{tabular}{|c|c|c|c|c|c|c|}
\hline 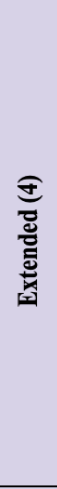 & 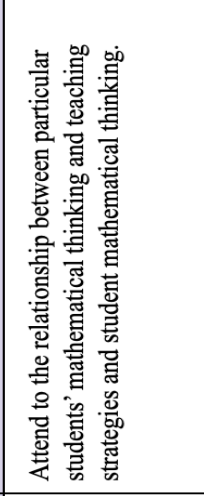 & 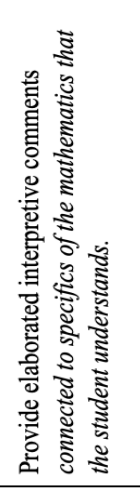 & 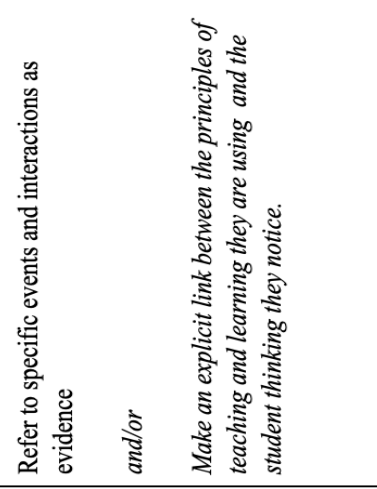 & \multicolumn{3}{|c|}{ 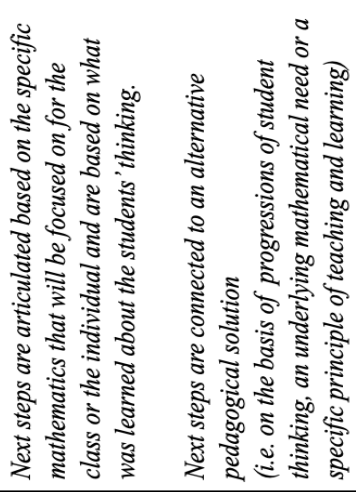 } \\
\hline 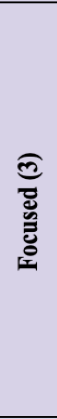 & 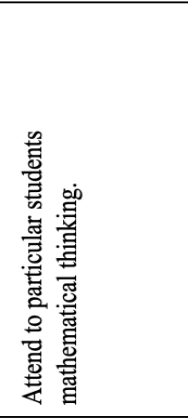 & 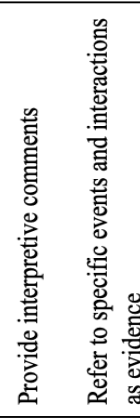 & 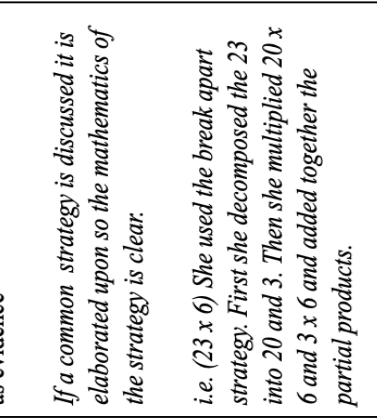 & 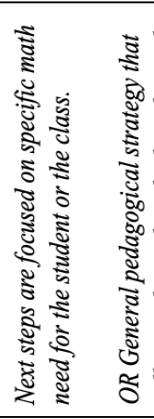 & 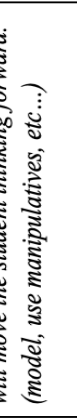 & \\
\hline 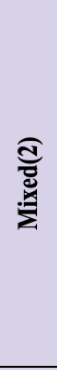 & 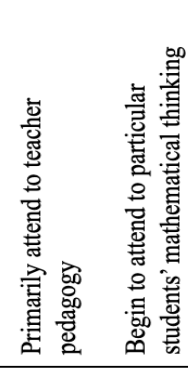 & 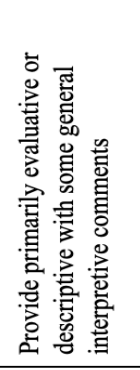 & 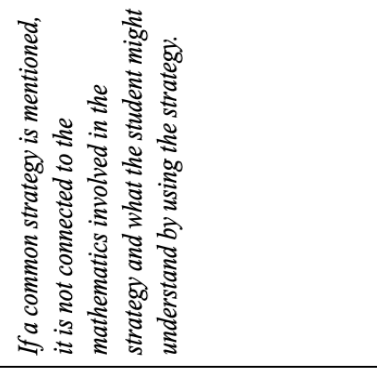 & 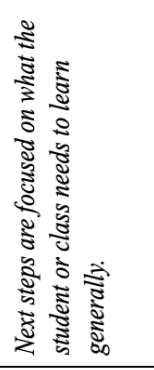 & & \\
\hline 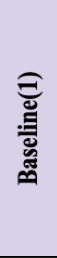 & 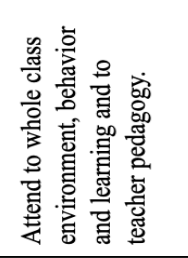 & 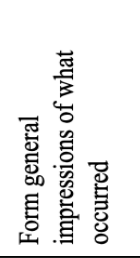 & 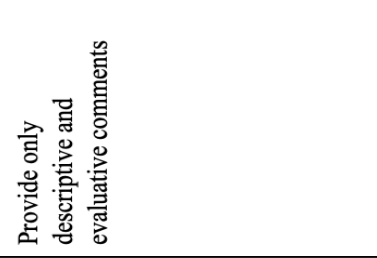 & 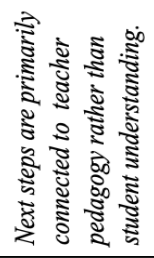 & & 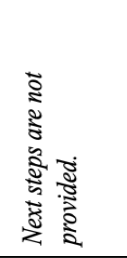 \\
\hline & 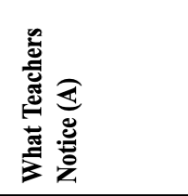 & 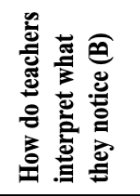 & & 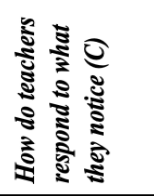 & & \\
\hline
\end{tabular}




\section{Chapter 4: Analysis and Findings}

\section{Introduction}

Children come to school with ideas about mathematical concepts which are not always aligned with the way adults think. Teachers often struggle to elicit these ideas from students and allow them autonomy necessary for students to use their own sensemaking capacity while engaging in mathematics. Moreover, teaching mathematics for conceptual understanding can be an elusive task for teachers who do not themselves understand math in conceptual ways or lack the tools to determine what their students are understanding.

The EaMML project represents a PD model designed to address this problem of practice. Through my analysis of data from three participants involved in the EaMML project, I seek to answer these three questions:

1. In what ways does being involved in a reform-oriented PD project that is focused on integrated mathematics content and pedagogy development and students' mathematical thinking influence teachers' a) instruction and b) beliefs about mathematics teaching and/or c) their view of themselves as a mathematics teacher?

2. Second, which activities, tools, and frameworks from the PD elements do teachers point to as the most impactful in terms of their work in the classroom?

3. Third, how do teachers notice student's mathematical thinking and in which tasks of teaching is teacher noticing - whether strong or weak - most apparent?

\section{Presentation of the Data}

In order to answer the first two research questions, I analyzed documents of practice such as portfolio reflections and student thinking assignments from the content focused pedagogy courses as well as engaged participants in interviews. 
Analyzing these data sources inductively using thematic networks analysis allowed global themes to emerge, which were used to tell the story of each participant and how the program impacted their beliefs and instructional practices.

To answer the third question, I analyzed the student thinking assignments holistically using an adapted Learning to Notice Framework (van Es, 2014) to tease out more fine-grained details about participants as they learned to notice their students' mathematical thinking.

I would be remiss if I suggested that the global themes answer the research questions in the same way for each participant. The complexity of each participant's situated contextual practice warrants a descriptive discussion of each participant's experience in relation to the global themes. My research questions and connected Global Themes are listed in Table 4.1.

Table 4.1

Research Questions and Global Themes

\begin{tabular}{|c|c|}
\hline \multicolumn{2}{|c|}{ Research Questions \& Global Themes } \\
\hline Research Questions & Themes \\
\hline $\begin{array}{l}\text { 1. In what ways does being involved in a reform- } \\
\text { oriented PD project that is focused on } \\
\text { integrated mathematics content and pedagogy } \\
\text { development and students' mathematical } \\
\text { thinking impacting teachers' a) instruction and } \\
\text { b) beliefs about mathematics teaching or c) } \\
\text { their view of themselves as a math teacher? } \\
\text { 2. Second, which activities, tools or frameworks } \\
\text { from the PD elements do teachers point to as } \\
\text { the most impactful in terms of their work in } \\
\text { the classroom? }\end{array}$ & $\begin{array}{l}\text { - Content courses were a site for using meaning } \\
\text { making strategies that expanded understanding of } \\
\text { mathematical ideas and what conceptual } \\
\text { understanding means. } \\
\text { - Teachers derived instructional strategies and } \\
\text { tools that promote meaning making from the } \\
\text { content courses and make plans to try them out in } \\
\text { the classroom. } \\
\text { - Challenges from teacher context are considered } \\
\text { as teachers decided which instructional strategies } \\
\text { to enact. }\end{array}$ \\
\hline $\begin{array}{l}\text { 3. Third, how do teachers notice students' } \\
\text { mathematical thinking and in which tasks of } \\
\text { teaching is teacher noticing —whether strong } \\
\text { or weak-most apparent? }\end{array}$ & $\begin{array}{l}\text { Adapted Learning to Notice Framework (van Es, } \\
\text { 2014) }\end{array}$ \\
\hline
\end{tabular}




\section{EaMML Data and Context Case Study Participants}

Before I delve into the analysis of each participants experience in the project, I will introduce each participant and their situated contexts. For each participant, I display the results of the EaMML IQA observation and PCK survey data in order to triangulate my interpretations from the case study data with the EaMML project data. Considering the observational data, I chose to limit my interpretations to the accountability to knowledge and rigorous thinking and academic rigor. I chose these two sections of the IQA because they are closely aligned to the aims mathematics instructional practice that is principled in nature. The only category, I do not discuss for the three case study participants is the mathematical residue category as it is under development. It is important to note that this observation represents only one instructional lesson. For a more detailed look at the IQA rubrics from which these scores were given see Appendix K.

Figure 4.1 displays observation findings from a random stratified sample of the MLT participants. This observation data was collected in the spring of 2017 for all three case study participants. The domains reported included teaching practices organized under accountable talk, accountability to knowledge and rigorous thinking and academic rigor. The EaMML data included pre-observations for the majority of the random stratified sample participants, but of the three case study participants only Ms. Jones had both pre and post observations. I explained why this happened in chapter 3 . The gray dot indicates aggregate pre observation scores of all the EaMML participants included in the sample for each teaching practice domain and the green dot indicates aggregate post 
observation scores. The scores were calculated on a 1-4-point scale with scores in the 3 to 4-point range indicating strong mathematical practices. Strong mathematical practices refer to teaching moves that were likely to result in student conceptual understanding of mathematics. The green bar indicates strong mathematical practices. The three case study participants' scores are represented largely at the end of each data line or beyond the line as you can see in tables 4.2-4.7. For example, Ms. Jones' IQA scores are 3's or 4's for all domains of the classroom observation. Her scores would place her mathematics instruction squarely in strong mathematical practices and outside the aggregate data line.

The EaMML observation data showed clear growth of participants' observation scores across all of the research-based practices. The greatest increase shows up in the area of questioning. The two categories that fell into the strong mathematical practices zone are participation and potential of the task. These scores gave an overview of the growth of the participants in their use of research-based practices likely to support principled mathematics teaching. 


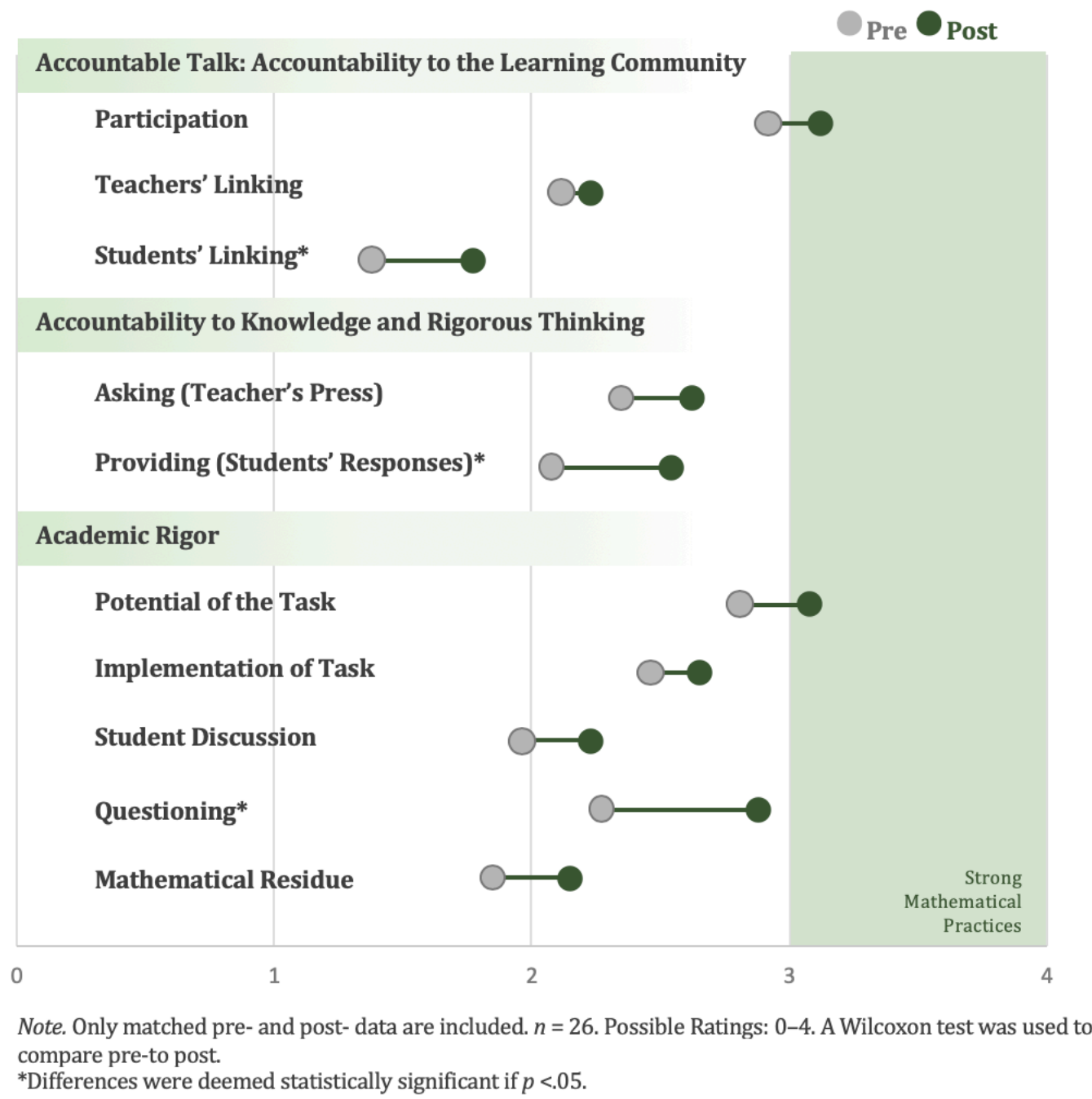

Figure 4.1. EaMML classroom observation data using the IQA observation tool. From RMC (2017). East Metro Mathematics Leadership Project. Portland, OR: RMC Research Corporation.

Context and EaMML findings for Ms. Jones. Ms. Jones, the most veteran teacher of the three participants, had been teaching for 12 years in the school district, and at the time of this study taught $3^{\text {rd }}$ grade. Ms. Jones' school context enrolled 601 students from Kindergarten to $5^{\text {th }}$ grade. Of those students $70.4 \%$ of the students qualified for free and reduced lunch and 1/3 of the enrolled students were designated second language 
learners. Ms. Jones is a white Caucasian female who speaks English. $49 \%$ of the students at her school represent a different ethnic group than Ms. Jones.

The EaMML findings specific to Ms. Jones found in Table 4.2 and 4.3, suggested that Ms. Jones classroom instruction by the end of the project was often focused on conceptual understanding. Overall the task during the classroom observation was implemented at a consistent level of conceptual focus. Students were engaged in reasoning and thinking that had great potential to connect to underlying mathematical underpinnings. Ms. Jones teacher survey corroborates these findings. In almost every category she reports feeling very prepared to support her students to learn math conceptually using their reasoning capacities. It is important to note that from the outset of the project Ms. Jones felt very prepared to support her students to develop and connect representations, implement high cognitive tasks, and facilitate discussions. By the end of the project, Ms. Jones reported feeling more prepared to use probing questions with her students and support them to justify why strategies and solutions work mathematically.

The findings demonstrate that overall Ms. Jones already utilized many researchbased instructional practices when she began her work in the project. In fact, her scores are stronger in all categories observed except for the potential of the task in which she is in line with the average score. In order to really analyze the shifts in Ms. Jones instruction the descriptions from this case study provide useful evidence for the differences in her mathematics beliefs and instructional practice. 
Table 4.2

EaMML Findings for Ms. Jones' Classroom Observation

IQA Observation of Classroom Instruction

\section{Accountability to the Mathematics/ \\ Academic Rigor \\ Constructs}

4
Consistent attention to
conceptual understanding
and connections that reveal
the mathematical meanings.

Variable attentior conceptual understanding and connections that reveal the mathematical meanings.

3

$x$ pre $x$ post

Attention is to procedures explicitly or implicitly suggested with no attention to why they work.

Potential of the

Task

Implementation of

$\mathbf{x}$

$\mathbf{X}$ $\mathbf{x}$

$\mathbf{X}$

$\mathbf{X}$

$\mathbf{X X}$

$\mathbf{X X}$

Teachers

Questions

Table 4.3

EaMML Findings for Ms. Jones' Teacher Survey Pedagogical Content Knowledge Construct Teacher Survey

How prepared do you feel to...

Pre Post

Implement high cognitive demand tasks Somewhat Somewhat

Support students to connect representations

Very

Very

Support students to develop representations

Very

Very

Facilitate discussions with students that focus on a high

Very

Very 


\begin{tabular}{|c|c|c|}
\hline Develop probing questions & Somewhat & Very \\
\hline Support students to justify reasoning. & Somewhat & Very \\
\hline $\begin{array}{l}\text { Develop students' capacity for sensemaking, reflection, } \\
\text { justification. }\end{array}$ & Somewhat & Somewhat \\
\hline
\end{tabular}

Context and EaMML findings for Mr. Wells. Mr. Wells entered the EaMML project at the beginning of year 2. During this year, he taught Kindergarten and then he moved up to $1^{\text {st }}$ Grade during year 3. Mr. Wells was in his $6^{\text {th }}$ year of teaching at the time of the study. He had recently returned after a time away from teaching and an exploration of a different career field. Mr. Wells' school context enrolled 553 students from Pre-K to $5^{\text {th }}$ grade. Of those students $84.3 \%$ qualified for free and reduced lunch and nearly half of the students are designated English Language Learners. Mr. Wells particular class makeup was diverse. Mr. Wells states that $75 \%$ of his students speak a different language at home than at school and many of his students are newcomers. Mr. Wells himself is a Caucasian male that speaks English.

Mr. Wells was not part of the original stratified sample of EaMML project participants, so the only observation data available is post data. Table 4.4 and Table 4.5 display Mr. Wells data results for the EaMML sources. Mr. Wells scores suggest that he is often attending to conceptual understanding as a part of his instruction, but his discussion score shows that his lesson discussion tended toward more procedural explanation of the mathematics involved. According to the post teacher survey data, $\mathrm{Mr}$. Wells reported increases in all pedagogical content knowledge categories. This demonstrated increases in his feeling of preparedness to support his students in learning 
important conceptual mathematics. Implementing high cognitive demand tasks, developing probing questions and supporting students to justify their reasoning represent the most significant shifts in his feelings about his preparedness.

Like, Ms. Jones, Mr. Wells also sits in the strongest end of the whole data set for classroom observations, with the exception of classroom discussion, which despite increases in scores, still is one of space in which the EaMML participants' instructional practices remained more procedural.

Table 4.4

EaMML Classroom Observation Scores for Mr. Wells

\begin{tabular}{|c|c|c|c|}
\hline \multirow{3}{*}{$\begin{array}{l}\text { Accountability to } \\
\text { the Mathematics/ } \\
\text { Academic Rigor } \\
\text { Constructs }\end{array}$} & \multicolumn{3}{|c|}{ IQA Observation of Classroom Instruction } \\
\hline & $\begin{array}{l}\text { Consistent attention to } \\
\text { conceptual understanding } \\
\text { and connections that } \\
\text { reveal the mathematical } \\
\text { meanings. }\end{array}$ & \begin{tabular}{l}
\multicolumn{1}{c}{$\mathbf{3}$} \\
Some attention to \\
conceptual \\
understanding and \\
connections that reveal \\
the mathematical \\
meanings.
\end{tabular} & \begin{tabular}{l}
\multicolumn{1}{c}{$\mathbf{2}$} \\
Attention is to \\
procedures explicitly \\
or implicitly suggested \\
with no attention to \\
why they work.
\end{tabular} \\
\hline & & $\mathbf{x}$ & \\
\hline \multicolumn{4}{|l|}{$\begin{array}{l}\text { Potential of the } \\
\text { Task }\end{array}$} \\
\hline \multicolumn{4}{|l|}{$\begin{array}{l}\text { Implementation of } \\
\text { the Task }\end{array}$} \\
\hline \multicolumn{4}{|l|}{$\begin{array}{l}\text { Asking (teacher's } \\
\text { press) }\end{array}$} \\
\hline $\begin{array}{l}\text { Providing } \\
\text { (students' } \\
\text { responses) }\end{array}$ & & & $\mathbf{x}$ \\
\hline Discussion & & $\mathbf{x}$ & \\
\hline $\begin{array}{l}\text { Teachers } \\
\text { Questions }\end{array}$ & & & \\
\hline
\end{tabular}


Table 4.5

EaMML Mr. Wells' Findings for Teacher Survey

Pedagogical Content Knowledge Construct

Teacher Survey

How prepared do you feel to...

\begin{tabular}{cc}
\hline Pre & Post \\
A little & Very \\
Somewhat & Very \\
Somewhat & Very \\
Somewhat & Very \\
A little & Very \\
A little & Very \\
Somewhat & Very
\end{tabular}

Implement high cognitive demand tasks

Support students to connect representations

Support students to develop representations

Facilitate Discussions

Develop probing questions

Support students to justify reasoning

Develop students' capacity for sensemaking, reflection, justification.

Context and EaMML findings for Mr. Nelson. At the time of this research study, Mr. Nelson had been teaching for 12 years. He explained that 6 of those years were in an experiential education setting, and the recent 6 years had been in a traditional education setting. Mr. Nelson's school enrolled 610 students from kindergarten through $5^{\text {th }}$ grade. Of these students $76.8 \%$ qualified for free and reduced lunch and about $1 / 3$ received ESL services. Mr. Nelson is a Caucasian male who speaks English. 65\% of the students at the school represent a different ethnic group from Mr. Nelson.

As was the case with Mr. Wells, Mr. Nelson was also added into the observation sample during the post observations only, so there is no pre observation data. As reflected in Tables 4.6, Mr. Nelson's observation scores pointed to a few areas where his instruction attends to some conceptual instruction. In the area of discussion and questions, his scores suggested that he held a more procedural discussion with little 
attention to underlying mathematical meanings. It is possible that the procedural nature of the questioning he used limited the discussion.

In terms of preparedness to use research based instructional practices, Mr. Nelson seems a little bit more tentative. The data in Table 4.7 suggest that Mr. Nelson felt far more comfortable at the end of the project with developing questions and supporting his students to connect representations. In other PCK sensemaking areas, however, he only reported a slight change in his preparedness to support his students to justify their reasoning or use reasoning and sensemaking capacities. The explanation for this tentativeness is expressed by Mr. Nelson in clear ways in the case study data.

Table 4.6.

EaMML Mr. Nelson's Findings for Classroom Observation

\section{IQA Observation of Classroom Instruction}

\begin{tabular}{|c|c|c|c|}
\hline $\begin{array}{l}\text { Accountability } \\
\text { to the } \\
\text { Mathematics/ } \\
\text { Academic } \\
\text { Rigor } \\
\text { Constructs }\end{array}$ & \begin{tabular}{l}
\multicolumn{1}{c}{$\mathbf{4}$} \\
Consistent attention to \\
conceptual understanding \\
and connections that \\
reveal the mathematical \\
meanings.
\end{tabular} & \begin{tabular}{l}
\multicolumn{1}{c}{$\mathbf{3}$} \\
Variable attention to \\
conceptual understanding \\
and connections that reveal \\
the mathematical \\
meanings.
\end{tabular} & $\begin{array}{l}\quad \mathbf{2} \\
\text { Attention is to procedures } \\
\text { explicitly or implicitly } \\
\text { suggested with no } \\
\text { attention to why they } \\
\text { work. }\end{array}$ \\
\hline $\begin{array}{l}\text { Potential of the } \\
\text { Task }\end{array}$ & & $\mathbf{x}$ & \\
\hline $\begin{array}{l}\text { Implementation } \\
\text { of the Task }\end{array}$ & & $\mathbf{x}$ & \\
\hline $\begin{array}{l}\text { Asking } \\
\text { (teacher's } \\
\text { press) }\end{array}$ & & $\mathbf{x}$ & \\
\hline $\begin{array}{l}\text { Providing } \\
\text { (students' } \\
\text { responses) }\end{array}$ & & & $\mathbf{x}$ \\
\hline Discussion & & & $\mathbf{x}$ \\
\hline
\end{tabular}


Teachers

Questions

Table 4.7

EaMML Mr. Nelson's Findings for Teacher Survey Pedagogical Content Knowledge Construct Teacher Survey

How prepared do you feel to...

Pre Post

Implement high cognitive demand tasks

Somewhat Somewhat

Support students to connect representations

A little Very

Support students to develop representations

Somewhat Somewhat

Facilitate Discussions

Somewhat Somewhat

Develop probing questions

A little Very

Support students to justify reasoning

A little Somewhat

Develop students' capacity for sensemaking, reflection, justification.

A little Somewhat

\section{Impact of the PD on Ms. Jones' Beliefs and Instruction}

Consistent with her overall data, Ms. Jones reflected that when she joined the EaMML project she was "on board" with allowing students to explore mathematical ideas and use their own reasoning capabilities. In an early IQA self-reflection of her one of her mathematics lessons, Ms. Jones reported "I would like to work on holding back and letting students engage in more productive struggle, especially when it comes to making connections between strategies." (IQA, Self-Reflection, Winter 2015) I think this reflection coupled with the EaMML data already shared, further exemplifies that Ms. 
Jones was knowledgeable and used research-based practices to engage her students in conceptual learning of mathematics at the onset of the project.

Sensemaking as an adult learner. Ms. Jones points to the content courses as the most impactful portion of the EaMML project. Through each course she reflected that she was learning more about the complexity of how students develop concepts such as place value, the progression of student understanding from counting to operations, the broadening of the meaning of algebra beyond x's and y's and generalizing about mathematical ideas and relationships. In an assignment for the second content course, Ms. Jones notes:

I liked the idea from line 457- 459 that "multidigit addition and subtraction can be a vehicle for learning about the meanings that underlie our place value system". This part resonated with me because I've always thought of place value as something that we teach before jumping into calculations, but based on everything we've learned, this statement is so true. If given the time to explore a variety of methods and manipulatives, a child learns more about place value within the context of adding and subtracting, than in an isolated unit (EO, Portfolio Reflection, Fall, 2015)

In this reflection, Ms. Jones described a new connection she is making about place value learning. This quote demonstrated a greater understanding that students develop conceptual ideas of place value through exploration of problems rather than through teaching of the value of each place. This is one of many examples of her own developing PCK through the MIL courses.

Ms. Jones also expressed that her own mathematics learning in these courses opened her eyes to the complexity of conceptual understanding. She described herself as feeling pretty competent with mathematics prior to the work in the courses, but the 
content learning made her realize that her feeling of competence was more related to her algorithmic understanding than understanding of concepts. During the content courses, she explained that her own mathematical understanding was being challenged when she was asked to make sense of the meaning of operations; how graphs and functions connect to context and meaning and the complexity of the relationship of decimal values to one another.

Ms. Jones exploration into mathematics concepts as a learner pressed her to identify what was helping her to make more sense of these mathematical concepts.

I notice my thinking about learning how to reason and express generalizations has changed so much this term. I was pushed to question rules that I had been taught and accepted as truth, and never been asked to prove. This was exciting and challenging. Looking back in my notes from class, and reflections on my learning, the hardest part was creating models that work for all numbers. This came up again and again in my notes, yet I feel by the end, I was more comfortable with creating visuals. I think seeing so many other representations was such a good way for me to expand my view and to see things more flexibly (GAO, Portfolio Reflection, Winter 2016).

As a learner, Ms. Jones experienced the depth of understanding involved in creating generalizations. This class stretched and changed previous understandings about mathematical rules. Ms. Jones was experiencing the disequilibrium that often comes when creating models that show why a mathematical idea works conceptually. Her understanding of the value of visuals and models expanded during this course.

Ms. Jones portfolio reflections provided many references to the expansion of her content knowledge. What stood out clearly as unique to Ms. Jones in this study was the value she placed on sensemaking tools and strategies she experienced as a mathematics learner. 
Tools for sensemaking as an adult learner. Using models to prove

mathematical ideas and developing more of a sense of mathematical representation was a powerful idea for Ms. Jones. In particular she reflected that three sensemaking tools were useful for her as a learner: manipulatives, visual models, and contexts. The use of manipulatives seemed to take on a profound meaning in Ms. Jones role as a learner and as a practitioner.

Many of my notes about learning math are consistent with my observations from previous classes. Several of these things relate to experiencing the math in multiple ways (graphs, models, contexts, algebraic expressions) and relating the math to context. "Seeing data in graph format can help patterns become clear" I mentioned in one of my important moment sheets. I also noted that, "pictures and models help clarify the meaning of the equations and make them more than numbers." This connects to the idea that MANIPULATIVES HELP ME UNDERSTAND THE BIG IDEAS and is yet another reminder that manipulatives are essential in the mathematics classroom. (PFC, Portfolio Reflection, Fall 2016)

Manipulative use came up again for Ms. Jones as she examined written cases of student thinking. The following quote suggests that her thinking around manipulative use represents a shift in her instructional practice.

I also was interested in the conversation between Mrs. G \& Ellen. This was a perfect example of how that concrete, manipulative-based understanding evolves into a more independent understanding that a student can verbalize, thus increasing their understanding further. I was interested in this part, because sometimes I rush through the exploration with manipulatives, and this is something I've been thinking about since our lesson study. It makes me realize how important that time is, and how many kids will decide when they are ready to move away from that concrete representation to do the math mentally and articulate what they are thinking, instead of what they are doing. (EO, Portfolio Reflection, Fall 2015)

Use of manipulatives as a tool thinking had a profound impact for Ms. Jones. These two quotes demonstrated that Ms. Jones did not previously understand the purpose of 
manipulatives as a tool for thinking. Her experience with manipulatives as a learner allowed her insight into this thinking involved when modeling mathematical ideas. These quotes also illuminated that she may have previously also held the belief that manipulative use was only for beginning conceptual understanding.

\section{Using tools for sensemaking in the classroom during rehearsals teacher}

noticing. Indeed, looking into her student thinking assignments, Ms. Jones demonstrated evidence that she consistently offered the use of manipulatives to her students. She pressed students to use the manipulatives to solve problems and demonstrate their thinking. As she asked students questions about their strategies, Ms. Jones focused on how the student's thinking was represented in the manipulative models they created.

$\mathrm{M}$ built an interesting model with purple blocks showing numbers below zero and a white block representing zero. Positive numbers were represented with orange and green blocks. She pointed to 14 above zero, then counted backwards by ones twenty-five times to prove her answer of negative 11. Before $\mathrm{F}$ showed her thinking with blocks, she drew a picture with a vertical number line, 14 labeled lines above zero and eleven below. She had crossed off each number between +14 and -11 . When she moved on to the blocks, she built a tower of 25 . Then she broke the tower into two smaller towers. I asked her to explain what she'd done, and she pointed to the taller-14 block tower. "This is how cold it was." Then she pointed to the shorter 11 block tower. "This is what was left over from 25." (GAO, Student Thinking Assignment, Winter, 2016).

This quote provides us insight into how closely Ms. Jones is paying attention to her student's thinking through her model. The specificity in her description about her students' thinking about positive and negative numbers using a manipulative model showed that she recognizes this tool offers a window into what her student was thinking. In this particular example, it is not clear whether Ms. Jones connected the student's 
thinking to what she understands, but it is clear that her focus is on authentic thinking versus looking for a predetermined way of solving the mathematics problem.

Offering manipulatives to her students to use as sensemaking and thinking tools represented one powerful way Ms. Jones accessed her students' thinking as she rehearsed attending to, interpreting and responding to her students thinking for the student thinking assignments. Ms. Jones also reported that students created visual models such as number lines and arrays as tools for sensemaking.

An additional valued sensemaking tool that emerged from Ms. Jones reflections was the role of story context.

Well I think it's really important when you're doing problem solving to kind of keep taking it back to your story, so you remember 'what are we talking about here?'. I mean otherwise it can get really confusing. So, I really wanted them to be thinking about where these numbers come from in our story. Do they make sense? Is it reasonable? And when I talk about adding labels, it helps me understand what I'm talking about. So, when I'm talking about 150, where do I see that in my story? Does it make sense that I have it in my equation? (Interview, Spring 2017)

In the quote above, Ms. Jones described the mathematical teaching practice of using and connecting mathematical representations (NCTM, 2014). In this case, she referred to the connection of the story context to the visual or symbolic representations students use. My interpretation is that Ms. Jones is recognized that the story context helps students to ground their thinking and apply mathematical meaning to the numbers.

Using and connecting mathematical representations is one teaching practices Ms. Jones noted comfort using even before she joined the project. Further, this teaching practice shows up as she reflects on her rehearsals of teacher noticing.

\section{Ms. Jones' Teacher Noticing}


Teaching mathematics in principled ways is a cognitive activity. Noticing thinking is a critical aspect of teaching mathematics because teachers need to determine what counts as evidence of student learning. The graph in figure 4.2 illustrates a picture of Ms. Jones' teacher noticing practice across the EaMML project. This teacher noticing graph includes the three categories of teacher noticing practice I described in chapter 3. These categories are what and how the teacher noticed their students' mathematical thinking and the teachers' response to their students' mathematical thinking. Teachers were scored on a 1 to 4-point scale corresponding to the adapted learning to notice framework in table 3.6. This is indicated on the y-axis of the graph. Scores in the 3 to 4point range indicate that the teacher was mostly attending to specific students' thinking and interpreting the students' thinking. Each data point referred to a specific student thinking assignment for the MIL content courses and most courses included 3 student thinking assignments. Each individual MIL course is indicated on the graph by a letter, for example A1, A2, A3 correspond to the Building a System of Tens course. The numbers indicate the student thinking assignment number. I refer to these student thinking assignments as rehearsal numbers because they represented opportunities for participants to rehearse their teacher noticing of students' mathematical thinking.

Each participants' teacher noticing levels are reported on their individual graphs (see figure 4.5 and 4.8, for Mr. Wells' and Mr. Nelson's respective teacher noticing graphs) and include 14 instances of rehearsing teacher noticing in their student thinking assignments. 


\section{Ms. Jones' Noticing Scores by Rehearsal}

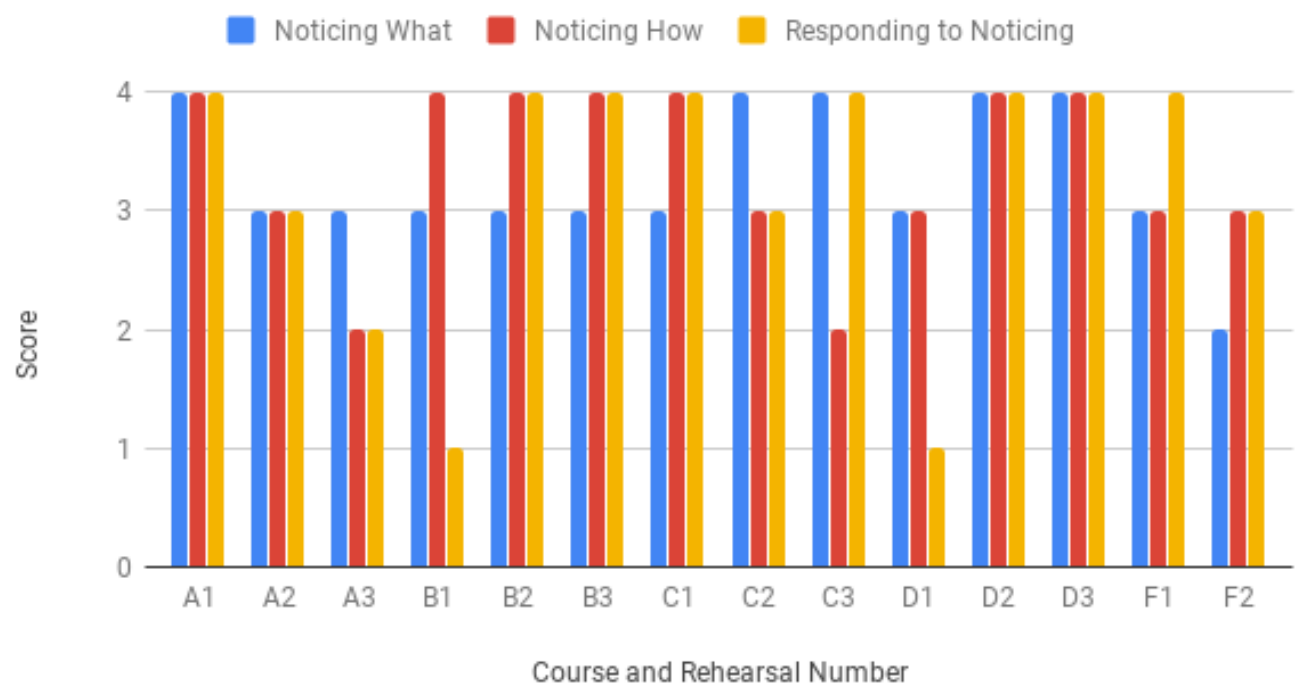

Figure 4.2. Ms. Jones' graph of teacher noticing from the student thinking assignments as the part of the MIL courses.

The EaMML project provided a multitude of layered opportunities for teachers to learn how to notice thinking. In our interview, Ms. Jones reflected that the focus on learning about student thinking was critical.

I mean how do you anticipate what a student is going to be thinking or misconceptions that they might have, until you actually look at student thinking. Because you know how to do the problem, but I think there's a lot of times when students see things differently than we might, or we might never anticipate seeing things and you have to kind of be ready for that. And. If you've only thought about the content in one way then you're not as flexible in your thinking, does that make sense? So, I think the student thinking portion is really important. (Interview, Spring 2017)

Ms. Jones believed that noticing student thinking is important. She takes the stance that student thinking is authentic to them and not always represented in the same ways that adults view mathematics. Thus, it is imperative that teachers notice their students 
thinking and make sense of what is revealed. Franke and Kazemi (2004) refer to this view as a practical inquiry stance into students thinking.

Throughout the EaMML project, Ms. Jones rehearsals of teacher noticing resonated this practical inquiry stance. The figure above displays the teacher noticing scores for each rehearsal of teacher noticing. When Ms. Jones reflected on her rehearsals of teacher noticing, she consistently scored at a focused or extended level for what she noticed. This meant that what she noticed was specific students' thinking rather than a general sense of the what the class understood, how students behaved or her own teacher pedagogy. Ms. Jones descriptions of a student's thinking during these rehearsals was often specific and detailed. Her attention to this reasoning had potential to reveal what the student understands. How she noticed student thinking also fell into the focused or extended level. Her focused interpretations included some type of interpretation that grew out of a specific student's thinking. In almost half of Ms. Jones rehearsals teacher noticing, her interpretations of the students' thinking were specific the mathematical content of the problem the student was solving. The category that seemed most variable over time was a response to the student thinking she noticed and interpreted. Specifically, what next steps would be appropriate based on what was learned about the student or students' thinking. This particular category was a bit harder to interpret. The student thinking assignments did not prompt specifically for next steps. The prompt directed participants to write an analysis about student thinking. However, Ms. Jones often reflected on what she learned about student thinking, then made a teaching move to connect the student with another student to extend that students thinking. I tagged this a 
focused or extended response if the teacher interpretation and teacher response were tied together and the teacher commented about why the move would support one or both of the students.

Activities of teaching as sources for teacher noticing. Ms. Jones consistently noticed her student's mathematical thinking in focused and extended ways. To answer the research question, I posed I also had to examine the teaching activities in which teachers noticed their students' mathematical thinking. The graph in figure 4.3 illustrates the four major activities of teaching the teachers reported in their rehearsals of teacher noticing. After reading each of the 14 student thinking assignments for the three participants, I determined that the four most common teaching activities in which teachers noticed students' mathematical thinking were a) monitoring b) facilitating discussions c) analyzing student work and d) conferring. These are noted on the x-axis of the graph. The graph shows the frequency of each teacher activity when teachers reported noticing their students' mathematical thinking on the y-axis. It is important to note that the teaching activities reported do not represent a one-to-one correspondence with the student thinking assignments. In other words, a teacher may have reported that they noticed something about their students' mathematical thinking while they were monitoring as well as when they analyzed the students' student work. (see Graphs of Teaching Activity when Teacher Noticing occurred for Mr. Wells in figure 4.6 and Mr. Nelson in figure 4.9). In analyzing the sources of student thinking for her rehearsals of teacher noticing shown in figure 4.3, Ms. Jones most often rehearsed teacher noticing while she was monitoring her students. This may point to her ability to home in on specific student's 
thinking and interpret it. She often posed purposeful questions (NCTM, 2014) to her students while she was monitoring. I refer to this conferring with students. I interpret this to mean that while monitoring, Ms. Jones had the space to watch the students then pose purposeful questions of them to learn more about their reasoning.

\section{Ms. Jones' Activity of Teaching when Noticing Occurred}

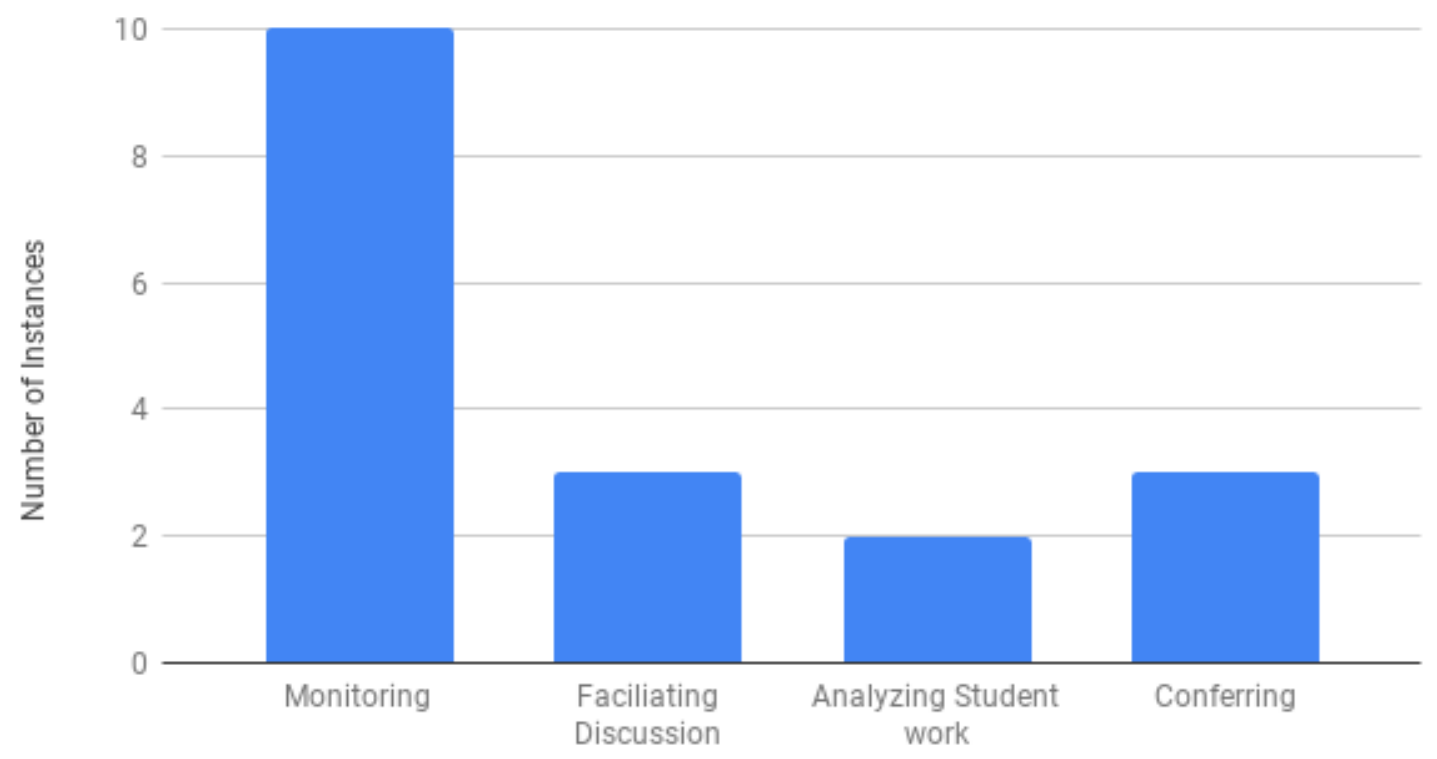

Figure 4.3: Sources of Ms. Jones' teacher noticing. The y-axis indicates the number of instances each teaching activity occurred. The $\mathrm{x}$-axis names the teaching activities.

The practice of teacher noticing had a great impact on Ms. Jones

instructional practice. She noted this impact during the first MIL course.

The real learning in this course for me focused more on what students say, what they do, and how this can help me know what a student does and doesn't understand and how to inform instruction. I found one of the most challenging things for me was answering the question in our weekly responses about what I would do next. It really moved me from a bystander observing learning to an active participant in the students' experiences. (BST, Portfolio Reflection, 2015) 
This quote demonstrated that Ms. Jones practical inquiry stance dovetailed with the aims of the course. Data from Ms. Jones reflections and the IQA pre-observation scores suggest that she was comfortable allowing students the autonomy to reason from their own schema. Thus, the practice of teacher noticing was new for her, but fit into a model of teaching with which she already felt comfortable. To illustrate this claim, I turn to an example from Ms. Jones rehearsals of teacher noticing to draw further interpretation about Ms. Jones' teacher noticing practice.

Example of Ms. Jones' teacher noticing. During the Examining Operations course Ms. Jones asked her students to count the number of squares in a $4 \times 4$ array with one square missing. The challenge was to determine the number of squares without counting them one by one. An example of student work and Ms. Jones interpretation of the work is included in figure 4.4. The task was inspired by a task in the written case studies. Ms. Jones stated that her class had been working with complete arrays and her goal was to see if students would find a way to determine the beyond counting by ones and whether some would find ways to break apart the figure into smaller arrays to determine the area. 


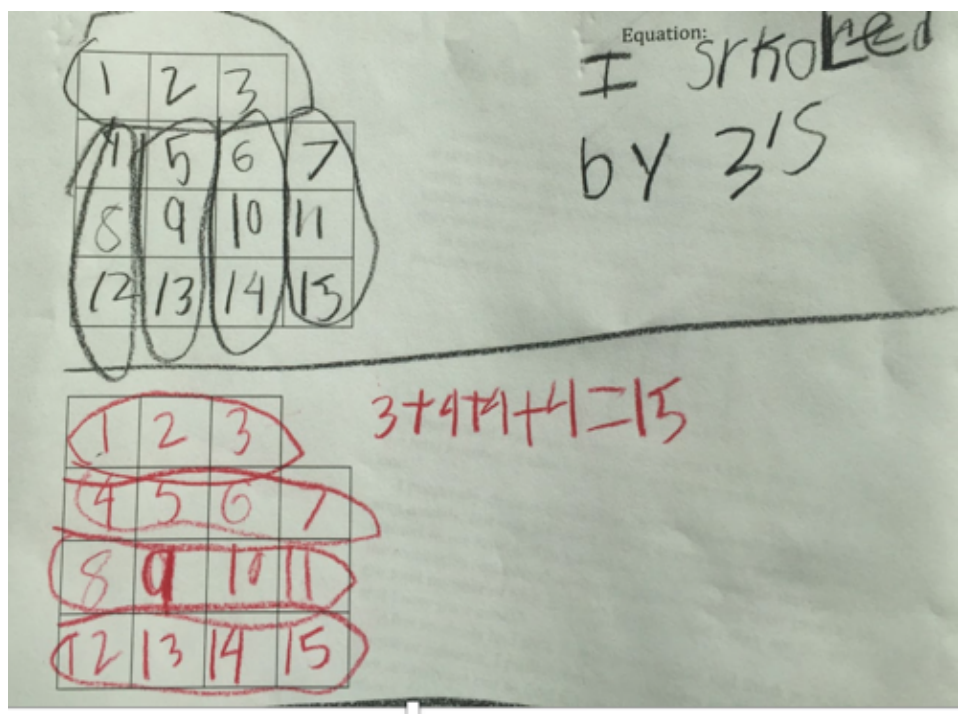

Figure 4.4. Student work sample from Ms. Jones' student thinking assignment.

E did not record an equation, instead counting by ones and then explaining that she circled by threes. I get the sense that $\mathrm{E}$ is still depending on counting square, but after she does that, she looks for patterns. After E shared her strategy, I asked another student who also found threes to make a connection and share her equation. She said she had 4 groups of 3 plus 3 (recorded $4 \times 3+3=15$ ). I notice that in E's next pictures, she still labels each square, but also includes an equation. When I ask E where she sees the four from her equation (in her second example), she explains that she has four circled in each of the groups. I see that she is making connections between her model and her equation. (EO, Student Thinking Assignment \#3, Fall 2015)

Ms. Jones analyzed the student work and then interpreted her student's thinking based on the specific mathematics of the counting progressions. In this example, the ways in which Ms. Jones noticed her student's thinking was characteristic of the extended level because the interpretation was tied to the mathematics at hand and her goals for the lesson. What is significant about this example is that the response to what she noticed about her student's thinking is embedded in the interpretation when she links the student to another student to compare their thinking. I interpret this to mean that she believes this 
comparison will support $\mathrm{E}$ to see that her counting can be represented by an equation. In fact, Ms. Jones notes that an equation shows up on E's work that is connected to the way she grouped the squares.

What is also significant about this vignette is how Ms. Jones orients $\mathrm{E}$ to another student. Ms. Jones could have chosen to ask the child the directly to include an equation or shown the child how to do this, but instead she uses the orienting strategy to support her student to move forward in her thinking by working with a peer who Ms. Jones' notices was source of knowledge for this concept. When a teacher makes a move to orient students to other students' thinking, the teacher is positioning the students as mathematical authorities. Aguirre, Mayfield-Ingram and Martin (2013), argue that this is one of the elements of the practice of "challenging spaces of marginality" because the mathematical authority is distributed and interconnected within the class of learners.

\section{Summary of Impact for Ms. Jones}

Ms. Jones came into the EaMML project comfortable with student autonomy and curious about student thinking. The impacts she noted through the project activities seemed to expand her understanding of teaching in principled ways rather than transform her instructional practice and beliefs. Nonetheless, Ms. Jones feels strongly that her instructional practice has shifted in significant ways as a result of this PD model. The MIL content courses provided her more sensemaking tools to support her students. The practice of teacher noticing provided her a lens to discern her students' understanding of the mathematics they were making sense of from their own authentic reasoning.

\section{The Impact of the PD on Mr. Wells Beliefs and Instruction}


Mr. Wells held a strong identity as a mathematician when he joined the EaMML project. As evidence he cited that he always did well in his math classes as a student, he participated on the high school math team and he scored high on the National Math Exam. As a mathematician, Mr. Wells noted that he was "best at memorizing formulas... and okay as a conceptual thinker.” (EO, Portfolio Reflection, Fall 2015)

Sensemaking as an adult learner. The content courses provided Mr. Wells the opportunity to develop his conceptual understanding of mathematics. In Examining Operations, Mr. Wells shared that he had entered the course feeling skeptical. As the sessions continued, he became acutely aware that the mathematical strategies he used were limited to solving problems by solving for $\mathrm{x}$.

Looking back, I realized I was one who really just memorized the operations so well that it became a language to me. Yet, I don't think I ever knew exactly what division or fractions really meant. I understood what the operations were supposed to look like and how to maneuver through them, but I think I lacked the conceptual framework of what they meant in the world. (EO, Portfolio Reflection, Fall 2015)

This reflection seemed to represent a shift in Mr. Wells' thinking about what conceptual understanding really meant. He realized his own math instruction lacked mathematical meanings and connections. Mr. Wells reflections from this point forward echoes this new metacognition of the limitation of his strategies as a learner of math. However, he remained skeptical about the connection of the mathematics ideas he was encountering in relation to his kindergarten students.

As his learning in the content courses continued, Mr. Wells primarily focused on his own unique way of processing mathematics. He used metaphors such as a language, a 
familiar neighborhood and a home to return to as illustrations of his comfort with mathematics computations and finding the x-variable. With each course he gained insight into new ideas about what conceptual understanding really looks like in mathematics and how it fits into his narrative of math learning. Mr. Wells' skepticism at the outset gave way to a connection to his classroom practice and the need for more of a focus around conceptual understanding.

I worried when signing up for this class that focusing on algebraic equations might be difficult for finding lessons to apply to my kindergarten class. I almost wanted to say something up front but realized that this class was more about adjusting and altering how I approach math instruction and my own metacognition around thinking about math than it is about what I'm actually teaching. (GAO, Portfolio Reflection, Winter 2016)

At this point in the project, Mr. Wells recognized that the MIL courses offered him a new perspective about how to approach math. This new approach was not dependent on the specifics of the problems being explored, but mathematics problems in general. Yet he still held on to some of the beliefs about his own students and what they could or could not handle.

Case studies provide a picture of student sensemaking to emulate. As Mr.

Wells learned new ways of thinking about the mathematics he loves, he also learned new ways of thinking about how conceptual understanding could be enhanced in his classroom. Mr. Wells articulated his thinking about how to bring sensemaking into his kindergarten classrooms in the following reflection.

I've learned in this class that the best way to unpack meaning, and to allow a process of understanding to begin in your students, is to encourage as much talking about math as possible, to provide open ended questions with scaffolding 
so everyone in the class can approach the subject, and to stop focusing on drill and kill memorization. (EO, Portfolio Reflection, Fall 2015)

Here Mr. Wells scratched the surface in this reflection of what became a new narrative in his classroom practice. Student discourse became to object of his attention to bring meaning into his mathematics instruction. It was also a source of disequilibrium. His initial rehearsals of teacher noticing of student thinking stood in contrast to what he was seeing in the case studies of student thinking in class.

Limited expectations of students. The written case studies of student thinking provided a site for Mr. Wells to mine for sensemaking tools and an opportunity to examine his own instructional practices. As he read different cases, he often noted surprise at what young students were doing in the case and what was possible.

Furthermore, he questioned whether the expectations he held for his young kindergarten students were inconsistent with what the students might actually be able to do and think about mathematically. In the following sample Mr. Wells reflected about a written case of student thinking from the MIL content course.

The main impact of this case is that I realized I had limited expectations about my own students. I didn't think I could ever give ways of allowing kindergarten students to do multiplication yet seeing how students were counting the different bunny legs made me realize there are ways I can carefully craft specific contextual questions that enable my K students to do multiplication operations. In reading this story, it was very insightful to see students having a choice over which manipulative they want to use. It inspired me to restructure my room so that I had a manipulative center where students could check out their own manipulatives. (EO, Cases with Impact, Fall 2015)

The case of kindergarteners exploring a problem that represents multiplication challenged his beliefs about the work of young students and what problems they might be able to 
think about. It also brings to the forefront students exercising their autonomy by choosing which manipulatives they use to make sense of mathematics. However, in this quote it is not clear whether he believes the locus of control of the thinking comes from his young students. He seems to regard his questioning as the means for student sensemaking. In other words, they can think about multiplication if he designs questions to help them navigate the problem.

As he moved into other courses the written case studies of students' thinking provided a context to consider the role his expectations played in his students' mathematics learning. The rehearsals of teacher noticing reinforced this idea for Mr. Wells. He began to give them problems that he originally believed his students were not ready to explore largely because he had not taught the concepts yet.

I think I had very low expectations to pose a question where I ask students to essentially use subtraction. I was surprised the vast number of students who were able to perform both questions I asked. and I felt slightly ashamed for not having higher expectations. (EO, Student Thinking Assignment \#1, Fall 2015)

The students in this example were showing Mr. Wells that they could think about more complex ideas than he originally believed. It is clear the very early on Mr. Wells is wrestling with his beliefs and the disequilibrium he is feeling. Mr. Wells expressed that his students handled subtraction well. However, his general interpretation of his students understanding was based on questioning designed to get at the correctness of their thinking. At this early stage, Mr. Wells did not yet tap into students' authentic thinking. Mr. Wells reflected that the EaMML project impacted his beliefs. Yet the context of his situated practice presented a challenge. One hundred percent of his students were 
on free and reduced lunch and $75 \%$ of students were English Language Learners.

These demographics caused him to wonder how to increase the talk and sensemaking in the math classroom.

Learning situated in practice. From my research standpoint, I believe that there is an important juxtaposition of teachers learning in and from their situated practice by implementing new ideas in their own classrooms while at the same time reading and watching other teachers' practices. Examining cases of student thinking that offer new ways of viewing how students can think about math has the potential to create tension in teachers formerly held beliefs that has to be resolved. Battista(1994) suggests that this is either resolved by teachers rejecting new ideas outright, folding new beliefs into their existing belief structure, or throwing out old beliefs. This last scenario is what is referred to as transformative. Mr. Wells seems to be in this juxtaposition at this point in the project.

Mr. Wells expressed a shift in his beliefs about what young students have the capacity to make sense of and how mathematics can be taught in a less heteronomous way, but his new beliefs were tentative due to the everyday reality of his context.

Yet I continue to ask myself, how do I approach the teaching of these basic skills through a process that allows for narrative, conceptual understanding, and perhaps approach generalization. I want to allow for generalization to happen in my classroom, but I still feel like I'm struggling to get my ELL students to just talk and participate and it seems unfathomable to get them to start making generalizations about math. I wonder if on the kindergarten level there are other ways of getting students to express generalizations without having to do so with verbal language. (GAO, Portfolio Reflection, Winter 2016)

My interpretation of this piece of data is that Mr. Wells needed to know more about the mathematics teaching practices and sensemaking tools that would help him to hold high 103 
expectations and actualize these beliefs in the classroom. Moreover, he needed to be able to make sense of those teaching practices and tools within the context of his situated practice.

Posing purposeful questions and increasing student talk. In year 3 of the EaMML project, an opportunity to explore the mathematics teaching practices in a deeper way opened up. Mr. Wells volunteered to be the lesson study lead for the K-1 group. During the lesson study, he had access to support from the district math coach and colleagues from the Math Leadership Cadre (MLC) who taught the same grade level as him. Working with these new supports, parallels a shift in the way Mr. Wells writes about his students' thinking, his expectations of his students and the tools he is using to allow for sensemaking. One particular mathematics teaching practice, posing purposeful questions, represented a turning point in his practice. This is evidenced by his reflections in the Enhancing Algebraic Thinking: Generalizing about Operations course.

In Developing Elementary Teachers' "Algebra Eyes and Ears" they talk about algebraic thinking as asking these types of questions:

- Tell me what you were thinking?

- Did you solve this a different way?

- How do you know this is true?

- Does this always work?

Had I looked at these questions a year ago, I thought they would have been esoteric questions that I wouldn't have seen as important to my class. Now, I see them as essential to my math instruction. (GAO, Portfolio Reflection, Winter 2016)

This quote suggests a more definitive shift in his instructional practice. Early in the project, Mr. Wells situated practice in a kindergarten classroom of mostly language learners was described as a barrier to imagining students generalizing about mathematics. He expressed at times that generalizing was too abstract for his students. At this later 
point, Mr. Wells had embraced generalizing as a regular process of doing mathematics and the questions are a vehicle for supporting this thinking.

A year later, Mr. Well's noted in our interview that posing purposeful questions along with other teaching moves, became more than just a new practice.

I was reflecting in one of the papers recently of like automaticity with the grant where last year was my first year with it and everything felt really new and the teacher moves I had to be really, like, plan out and have it written down and be very intentional about beforehand plan. Where now it's feeling a bit more flexible or I've done enough and I think I've read enough ... that I can kind of be like oh let me use this line of questioning with a student so that they can be mainly student led and student conversation with me sort of aiming students to where they need to go. (Interview, Spring 2017)

Mr. Wells not only embraced the questions, but recognized they became part of the fabric of his instructional practice. This quote also demonstrated a shift in his belief about student autonomy. Classroom discussions are student led in his view, and he takes on a facilitation role. This change is also corroborated by the data from the EaMML teaching survey. His responses on the teaching survey shift greatly from the pre to post survey, particularly in the areas of developing questions and supporting students to justify their reasoning. By the end of the project, Mr. Wells felt very prepared to use these practices. It is important to note that the literature around PD suggests that teacher reflections of their practice are not sufficient to determine the extent to which a teacher's articulation of practice is enacted in the classroom (Parise \& Spillane, 2010). In the case of Mr. Wells, the lesson study process and the IQA observation data provided evidence that posing purposeful questions was a mathematics teaching practice enacted in the classroom. As evidenced by the EaMML observation data, Mr. Wells' scores of 3 on both 
questioning and teachers press suggest that he asked questions in his observed lesson that were focused on drawing out mathematical meaning and connections.

In Table 4.8, I compare two different samples of Mr. Wells questioning patterns in order to describe the shifts Mr. Wells alluded to in his reflections and teaching survey. The first sample is from a discussion in 2015 that Mr. Wells reflected upon in a student thinking assignment. The second sample is from a discussion in 2017 that I observed for the SR interview.

Table 4.8

Comparative Samples of Mr. Wells Questioning Patterns

\begin{tabular}{|c|c|}
\hline Sample of Mr. Wells Questions, Fall 2015 & $\begin{array}{l}\text { Sample of Mr. Wells Questions, Spring } \\
2017\end{array}$ \\
\hline $\begin{array}{l}\text { Mr. Wells: I have five cookies, let's count } \\
\text { together. Then I give one away. How many do I } \\
\text { have left? Let's count together. } \\
\text { Students: } 1,2,3,4 \text {. }\end{array}$ & $\begin{array}{l}\text { Students are in a circle around a model of } \\
\text { unifix cubes that were used to measure three } \\
\text { people. The unifix cubes are connected in } \\
\text { groups of ten and placed in a line of } 20 \text { groups } \\
\text { of ten with } 4 \text { loose ones at the bottom. }\end{array}$ \\
\hline Mr. Wells: How many cookies are left? & $\begin{array}{l}\text { Mr. Wells: Friends, what can we say about } \\
\text { counting by tens? }\end{array}$ \\
\hline $\mathrm{V}: 4$ & T. There's alot of 10 's \\
\hline $\begin{array}{l}\text { I modeled the activity again and had everyone } \\
\text { repeat it. Then I posed the question } 1 \text {. }\end{array}$ & Mr. Wells: There's a lot of what? \\
\hline $\begin{array}{l}\text { Mr. Wells: I have five cookies. I give two } \\
\text { cookies away. How many cookies do I have left? }\end{array}$ & $\begin{array}{l}\text { T: It goes by tens and then it switches to } \\
\text { ones. }\end{array}$ \\
\hline $\begin{array}{l}\text { I counted each unifix cube and then took two } \\
\text { cubes away. When I asked the class for an answer, I } \\
\text { got many different answers. }\end{array}$ & $\begin{array}{l}\text { Mr. W: It goes by tens and then it switches } \\
\text { to ones. }\end{array}$ \\
\hline T: You have three cookies left & $\begin{array}{l}\text { T: And then there's the same colors, but } \\
\text { there all moved around. }\end{array}$ \\
\hline Mr. Wells: How did you figure it out? & $\begin{array}{l}\text { Mr. Wells: Uh huh, some same colors all } \\
\text { moved around. What else can we say about }\end{array}$ \\
\hline $\begin{array}{l}\text { T: I took two away from five, and now I'll } \\
\text { count, I have three left. }\end{array}$ & $\begin{array}{l}\text { counting by tens? } \\
\text { J: It goes from } 200 \text { tens and } 4 \text { ones. You } \\
\text { have } 200 \text { and then you put } 4 \text { on it. It's } 204\end{array}$ \\
\hline
\end{tabular}


I: One.

I tried to work with $\mathrm{V}$, and count the objects, but he either was stuck on the first model example or couldn't understand he needed to count the objects in front of him. because it's 200 tens and then it would just be 200, but if you add 4 ones it would be 204 .

Mr. Wells: I am hearing two different ideas from J. I heard her say $200+4$, but then I just heard her say 200 tens and 4 ones. Friends, how many tens do we have? Everyone take a moment and turn and talk. Ask someone next to you. (Students talk together)

Mr. Wells: Friends, J said 204, but then she said 200 tens and 4 ones. Do you agree with what she is thinking?

T: I think it's 20 tens and 4 ones.

Mr. Wells: Oh, you think it's 20 tens. St. 2 what do you think about that?

J: I think it's 200 tens in all. If you take away the 4, there's 200 tens. But St. 1 is saying that he counted in ones in each 10 .

Mr. Wells: $\mathrm{T}$ is that what you counted by?

$\mathrm{T}$ : [inaudible]

Mr. Wells: S, I am hearing some different ideas, can you help us?

The sample on the left side of Table 4.9 is an example of a traditional Initiate-ResponseEvaluate (I-R-E) style of questioning typically designed to draw in responses that the teacher specifically has in mind and then evaluate them for correctness (NCTM, 2014).

"This patterning generally provides a very limited opportunities for students to think and provides no access to whether or how the students are making sense of mathematics" (NCTM, 2014, pg. 37). Mr. Wells' talk and questioning in this sample is designed to show kids what to do to solve the problem and, I would argue, how to think about the mathematics. The student talk as a result was often one-word answers with limited 
explanation. Although there is one instance of student explanation, the explanation mimicked the teacher demonstration, so it may or may not be evidence that the student understands the meaning of subtraction.

In contrast the transcription of a class discussion on the right side of Table 4.9, demonstrated a marked shift Mr. Wells questioning practice. The questioning style Mr. Wells adopts can be characterized as open-ended. Responses generated from the questions are returned back to the students to agree, disagree or elaborate upon. The response from the students are lengthy and explanatory, and there is more student talk than teacher talk. It must be noted that the student talk is limited to a few students in this sample. Whether or not this questioning style is characteristic of all of his lessons is not clear from this data, but the shift in questioning seems consistent with how Mr. Wells described the change in his instruction during our interview.

I think earlier I was just responding to students' actions and somebody pointed out, 'But what do you think those action represent in their thinking?' and also, someone early on said that especially from an ELL context we think of student thinking usually is just words that people are saying but thinking can be the thoughts that they have, or the writing they put down on paper, or for non-verbal kid like the way that they communicate ... So, I would say my understanding of what student thinking can be, has grown to encompass a lot more. And by doing that I think the way that I structure lessons and structure the way that students can have ways to show their thinking...Y Yeah and then also the other thing I want to add to that is about using student thinking, and to a further extent student talk or at least whatever artifact they are showing, to guide lessons and to allow for like peer discussion and peer discovery the whole getting students to say 'I agree with this person's thoughts', but I want to add so students are being really aware instead of just being like I have this idea. They're somehow building off of other students' ideas and that their ideas are as valid as other people's ideas. (Interview, Spring 2017) 
In this reflection, Mr. Wells described the change in questioning in his classroom and points to specific feedback that seemed to catalyze this instructional shift. Further, this quote illustrated a shift in Mr. Wells comfort with student autonomy. He seems to see his role as the teacher moving out of the center of the instruction and the student thinking moving into the center. His questioning is described as facilitating student conversations rather than questioning for correct answers.

Mr. Wells reflected that he had adopted a new mathematics teaching practice which increased the amount of student talk and provided more open-ended tasks to open up opportunities for students to show their thinking.

The ways in which Mr. Wells leverages his students' contributions in this lesson vignette suggests that his expectations of his students had changed. As opposed to narrowing his questions to focus only on answers, Mr. Wells' questions have shifted. The example shown in table 4.8, shows that Mr. Wells affirmed mathematics learners' identities by assuming that mistakes are places for new learning (Aguirre, MayfieldIngram \& Martin, 2013). The students were debating whether the cube representation of the quantity 204 was made up of 20 tens and 4 ones or 200 tens and 4 ones. The debate demonstrated a critical learning edge for these young students as they learn to unitize. Unitizing includes the ability to see a group of ten objects as both ten ones and one ten, or one hundred objects as ten groups of ten or one hundred ones or one group of one hundred. It is a common for students who are in the process of learning to unitize to mix up the unit names with the unit quantities. Mr. Wells used this misconception as an opportunity to learn by positioning students' ideas as worthy of examination. This is an 
example of challenging spaces of marginality by distributing mathematics authority among class members. In addition, Mr. Wells was beginning to see discussion as integral to his mathematics classroom. This discussion encouraged student-to-student discussion as a means to increasing participation. Broadening participation is another element of the practice of challenging spaces of marginality.

The ways in which Mr. Wells' practice shifted toward discourse as a means to increase participation and encourage authentic opportunities to practice language provided a lens to examine the shifts in Mr. Wells teacher noticing of his students' thinking.

\section{Mr. Wells' Teacher Noticing}

As I described in the findings and analysis for Ms. Jones, the graph of teacher noticing shows each teachers level of teacher noticing by student thinking assignment. I The dialogue samples in Table 4.9 paint a picture of a shift in Mr. Wells mathematics beliefs and instruction. My analysis of Mr. Wells' student thinking assignments from the first Examining Operations course show the dominance of the I-R-E pattern of questioning resulting in sparse student talk. Thus, the beginning assignments may have had little to notice in terms of student thinking. In the graph below, it is apparent that what Mr. Wells noticed was in the mixed band. His discussion of the lessons he taught focused on what he did as a teacher. Moreover, how he noticed student thinking was also in the mixed band, suggesting that his teacher noticing was mostly evaluative or descriptive. At this early stage in the project, Mr. Wells was noticing the correctness of 
student actions and answers and receiving back evidence that students were doing what he had modeled.

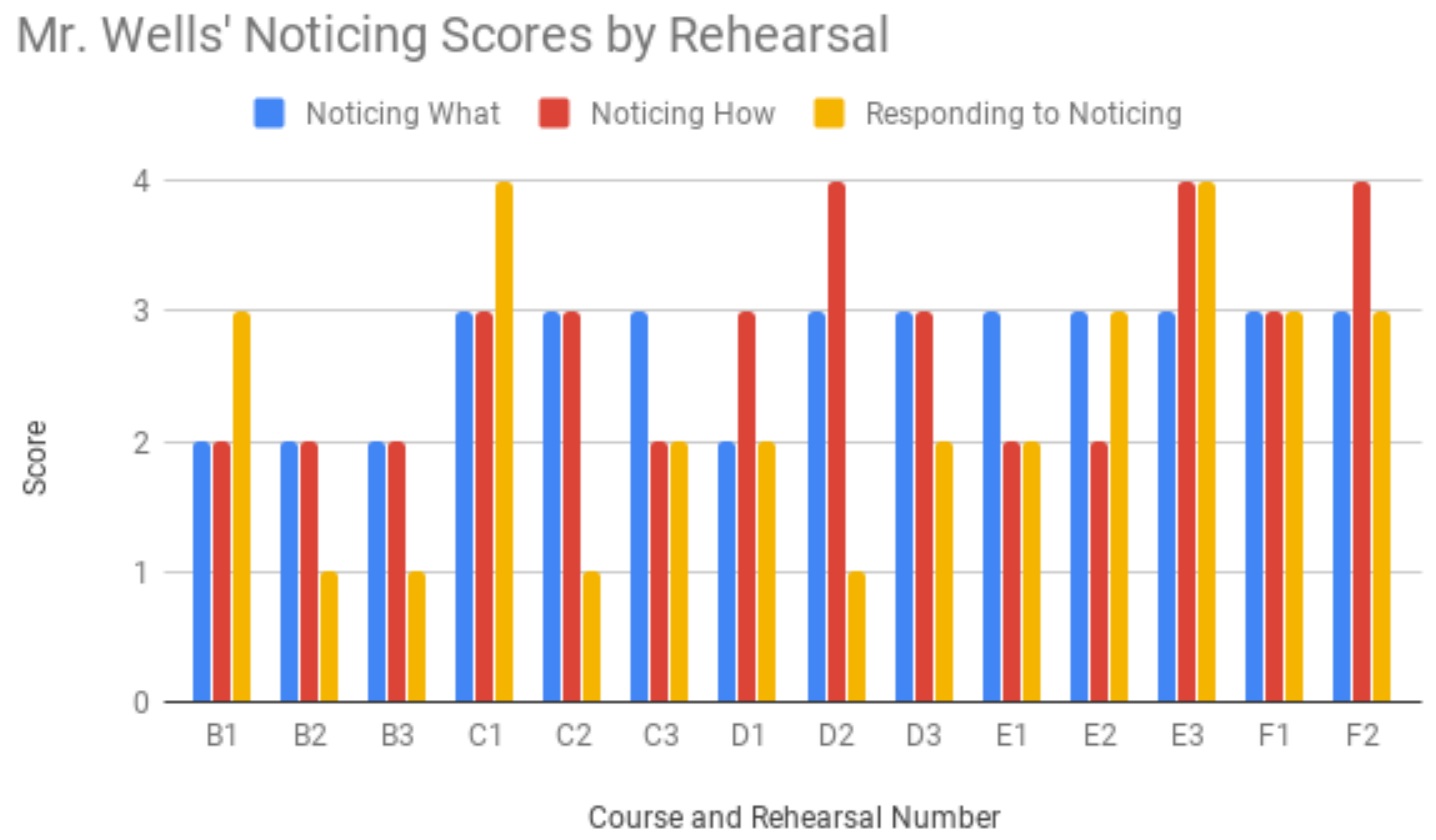

Figure 4.5. Mr. Wells' graph of teacher noticing from the student thinking assignments as the part of the MIL courses.

Smith (1996) refers to this phenomenon as teaching as telling. The teacher demonstrates or tells, students practice the procedures and if they are uncertain the teacher is able to demonstrate again. The picture of practice of teaching by telling is more simplistic: the math content is reduced to the simple steps, the steps and suggestion for carrying out that teaching is prescriptive and when students struggle teachers can go back to the steps. Smith suggests that teaching as telling can be tied to teacher's sense of self-efficacy. When teachers lean in to a more autonomous teaching approach it can be difficult to define the success of the lesson (Smith, 1996). 
Later in the courses, Mr. Wells described a shift toward centering his students' thinking in his lessons, and thus teaching toward more student autonomy. The shift seemed to follow his deepening knowledge about conceptual understanding which may have precipitated the change in mathematics teaching practices to increase student discussion. Furthermore, Mr. Wells' student thinking assignments demonstrated that his rehearsal of teacher noticing became more specific and student-centered generally more indicative of the focused band. You can see this happening sporadically starting at assignment D1 and in each assignment at E3.F1 and F2. Mr. Wells was consistently noticing individual students' thinking during most of his student thinking assignments. But now the teacher noticing was not trained on whether his students were doing what he had modeled for them. He was noticing their authentic ideas and interpreting those ideas. As an example, consider the following clip from rehearsal of eliciting student thinking during the Concepts of Measurement course.

Example of Mr. Wells teacher noticing. The context of this teacher noticing example is a $1^{\text {st }}$ grade measurement lesson using. At this point in the lesson, students were creating their own strategies for comparing the heights of the students in their group. The stated mathematical goals of this lesson were to help students develop vocabulary and understanding around the attributes longer, shorter, and taller; to collect and analyze data; and to make a graph from tallest to shortest. In addition, Mr. Wells listed a pedagogical goal to enact more open-ended tasks. In this clip, Mr. Wells is monitoring students as they work.

Mr. Wells: What did you figure out 


$\begin{array}{ll}\text { G: } & \text { I am second } \\ \text { Mr. Wells: } & \text { Second what? } \\ \text { G: } & \text { Second tallest! } \\ \text { Mr. Wells } & \text { How can you figure out who is tallest and who is shortest? } \\ \text { G: } & \text { With numbers }\end{array}$

I think this is interesting as we haven't involved numbers at all in the lesson yet, but that $\mathrm{G}$ is equating the numerical value representing someone's height with string.

Mr. Wells: What do the numbers have to do?

G: When we know who is tallest and who is shortest we can use numbers.

Mr. Wells: Are we using numbers today?

J: I don't know.

Mr. Wells: I don't know either. Let's find out.

(M123, Student Thinking Assignment \#2, Winter 2017)

This was an example of focused teacher noticing. Mr. Wells attended to a specific student's thinking and interpreted this student's thinking in relation to a mathematics principle that numbers can represent the height of objects being measured and can help you compare more than one object. It also illustrated again how Mr. Wells questioning pattern shifted to allow for student reasoning. His questions pressed students for more specificity and drew out their ideas about measuring. The questions also allowed for autonomous thinking. Certainly, there were missed opportunities to press for more understanding in this rehearsal. It is not clear from his questioning how they knew G was second tallest, but the example demonstrates a marked shift from the I-R-E pattern of questioning he used earlier. Later in this rehearsal of teacher noticing paper, Mr. Wells reflects on general class thinking as well as specific student thinking and creates next steps

I want to return to S and A's height to talk about exactness or actual. I want to create a discussion where students realize that changing (stretching) the string can change 
what we measure, and to offer ribbons and other non-changeable measuring tools. (M123, Student Thinking Assignment \#2, Winter 2017)

Mr. Wells' response to specific student thinking is characteristic of the extended band. His plan was tied to ideas with which students were wrestling and related to important mathematics. Standard measures are used because they are consistent and communicate the same length, height, distance, weight, etc., no matter who is measuring.

Mr. Wells teacher noticing practice showed general trend toward more focused and extended teacher noticing. The more he attended to specific students' thinking with a practical inquiry stance the reasoning available to interpret increased. However, his scores fluctuated throughout the teacher rehearsals, I believe this fluctuation represents different lessons and how they played out in the classroom. Some lessons did not turn out as expected and Mr. Wells seemed to summarize general student understanding. Some lessons such as rehearsal E1 were marked by specific descriptions of students' actions and thinking. The descriptions did not include much interpretation of what the thinking represented or what should happen next. It could be the case that at times the write-up of the assignment was rushed, and the interpretation was not reported.

Activities of teaching as sources of rehearsals of teacher noticing. Mr. Wells teacher noticing seemed to be primarily drawn from two teacher activities as seen in figure 4.6:monitoring and facilitating discussion. His first few rehearsals were mainly couched inside the discussion he facilitated, while later he more often noticed student thinking during the monitoring portion of his lessons along with the facilitated discussion. 


\section{Mr. Wells' Activity of Teaching When Noticing Occurred}

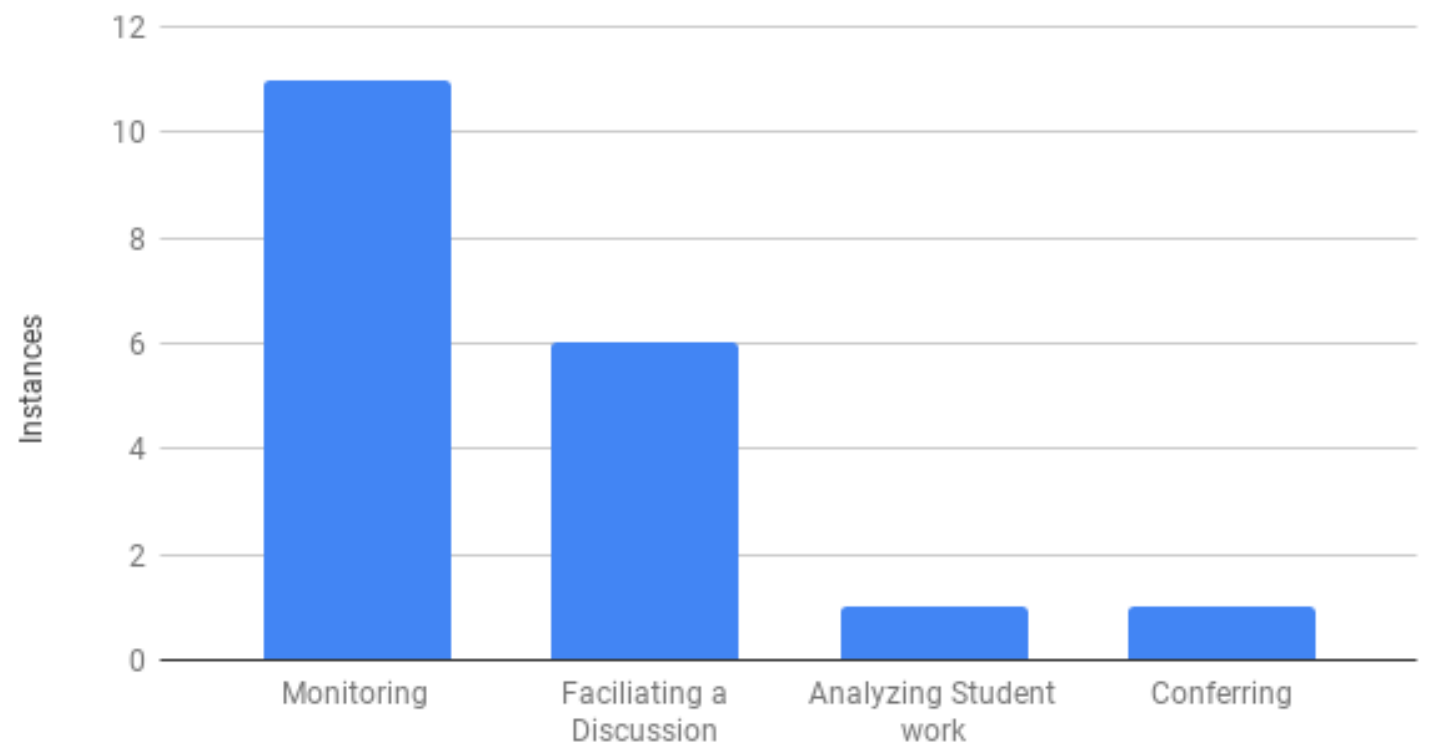

Figure 4.6: Sources of Mr. Wells' teacher noticing. The y-axis indicates the number of instances each teaching activity occurred. The $\mathrm{x}$-axis names the teaching activities.

This may provide further explanation to the mixed level of teacher noticing in his first few rehearsals of teacher noticing. Mr. Wells reflections were often heavily focused on his pedagogical practice and less on student thinking. When his instructional practice shifted, the discussions in his room were qualitatively different and the student thinking he sourced during these rehearsals was more authentic as evidenced in the example of teacher noticing and the comparison of questioning in Table 4.9. It is also likely that while monitoring his students he was asking more probing questions and thus had more access to his students' thinking.

\section{Summary of Impact for Mr. Wells}


Mr. Wells' story is one of shifting beliefs about what young students can make sense of in mathematics. It seemed clear in our interview that this was an important shift for Mr. Wells toward student autonomy.

I think sometimes I like to prioritize the students to go-, so students are having very vivid memories and moments of discovering themselves and that they're hearing from each other what they are supposed to go through and learn. So, I would say my comfort- I definitely often aim for those areas. I think I as a teacher- I'm more willing, especially after this grant and everything I've learned about open tasks and good [questions] for differentiation and equity for students to allow places where the students can be self-directed to move into these areas of, in your words, nebulousness or unknown-ness. (Interview, spring 2017)

Mr. Wells was impacted first by his discovery that his story of mathematics learning, while positive, lacked conceptual understanding of the mathematics. Then the written and video episodes of student thinking served as examples of young students making sense of ideas beyond what his students were experiencing. The disequilibrium this caused made him aware of his low expectations. New questioning tools helped him learn about what student actions and drawings represent in students thinking. The new instructional practice of eliciting and using student thinking through probing questions carved a path for a different instructional paradigm, and discourse routines opened up the door for students to take more of a lead in their mathematics learning.

\section{The Impact of the PD on Mr. Nelson's Beliefs and Instruction}

Mr. Nelson's experience with the PD was, like Mr. Wells, largely shaped by the situated context in which he taught. When he joined the EaMML project as an MLC member, Mr. Nelson expressed that he had already experienced what he described as a transformational experience in mathematics education working with a coach at a previous school. Mr. Nelson reflected that he struggled as a learner of mathematics. In school he 
only experienced learning in heteronomous environments. The following reflection from Mr. Nelson's recruitment survey represented a theme that ran through his experience.

My K-12 experience consisted of a traditional math education based on memorization and speed. I remember questioning and asking for an explanation of why math consisted of the procedures that I was memorizing but these questions were quickly shut down. Entering college, I tested as low in math and had to enroll in remedial math classes. My first attempt at these classes, consisted of sitting in a room with 40-60 other students completing random naked number problems independently and submitting my solutions to a TA. I quickly withdrew and re-enrolled for an in person course the next semester. While still a struggle, my professor was the first to engage in a math discussion. Through my elementary education core classes, I started to learn about problem-based instruction and manipulation of number base systems. (Dissertation Recruitment Survey, Spring 2017)

Mr. Nelson's formative experiences with mathematics did not support conceptual understanding. He struggled to find experiences that support him to make sense of mathematics. This reflection also illustrates the negative impact these experiences had on his identity as a mathematics learner. He used words such as "shut down", "low" and "remedial" to describe his experiences. It was clear from the recurrence of this narrative throughout his reflections and assignments that this was not an experience he wanted for his students. It was also clear that he had had a taste of math discussion as a mathematics learner which provided a contrast to his previous math experiences and a glimpse into what he valued in his own mathematics instruction.

Sensemaking as an adult learner. Mr. Nelson's early experiences with mathematics provide a backdrop and an explanation for the shifts in instructional practice that emerge in his story. The work in the content courses deeply impacted Mr. Nelson. 
The one word that best describes my learning in this course is recovery. More than any of the courses that I have completed as a part of this program, this course has proven itself linked most to my personal mathematics...In this course, I have rediscovered the context for functions and graphing. Reading the text, working through the math tasks and observing my students work allowed me to make meaning for this mathematics. Some of the concepts that I don't think I fully understood are beginning to make sense. For example, the importance of the quadratic formula made no logical sense to me. It was not until we built, represented in a table and graphed that I saw a real function for this string of numbers.

The lasting impact of this course in my classroom is a greater confidence and rationale. I feel like I will be more likely to represent a context with a table, graph or function than I would have before. I really want to further examine the bubble web of representation with my students. I want to be able to draw value from every area rather than simple equations. (PFC, Portfolio Reflection, Fall 2016)

Mr. Nelson described his experience in this course using the term "recovery". The courses affirmed his belief that the opportunity to learn math experientially and conceptually - an opportunity denied to him in school - was imperative for math understanding. This experience did not impact his beliefs about teaching math conceptually, he already believed that teaching conceptually was important. Looking closely at this reflection Mr. Nelson was impacted by the idea of representation of mathematical ideas and the connection of those representations.

As the courses went on, the understanding Mr. Nelson craved, grew his confidence in himself as a math teacher. Mr. Nelson described having a deeper understanding of the array model of multiplication and how multiplicative thinking grows for a child. He described how composing and decomposing shapes helped him determine the area of trapezoids. He also discussed the challenge students experience thinking twodimensionally. 


\section{Inspiration from cases of students' mathematical thinking. Mr. Nelson}

often found the student thinking in the written case studies to be inspiring. He looked to these cases as places to find inroads into tasks to would support his own students to think more critically about mathematics.

In reflecting back on my work for this class, I see the brilliant work of many students. Each of these students in the text that we have been reflecting on, have been exploring difficult topics in unique manners and with the creation of meaning. For example, I would love to have one of my students create the negative number strategy that I reflected on in Chapter 3. Hallie's thinking shows a flexibility and creativity that my students often lack. (BST, Cases of Impact, Spring 2015)

Mr. Nelson noted in this quote a value for flexibility and creativity in his student's mathematics instruction. He also noted that this was lacking in his own students. In fact, a recurring theme that emerged from Mr. Nelson's narrative was the limitation of his students' ability to think about mathematics.

Similar to Ms. Jones, Mr. Nelson saw these case studies as models of what he could try in his classroom.

I think that the greatest potential for classroom impact is found in the "DataBased Functions" section. I was really impressed and hope to emulate the teachers who regularly integrate data collection of natural phenomena into their classrooms. I see the potential for great benefits for students as the see models for data tracking and graphing. The added benefit of interpreting the data provides the justification or reasoning component that my students tend to struggle with. (PFC, Portfolio Reflection, Fall 2016)

Mr. Nelson expressed the desire to try creating data-based functions in his own classroom because he recognized in the written case the reasoning that grew out of this activity. $\mathrm{He}$ was in search of activities that would engage his students in the same type of reasoning 
and justification. Lack of reasoning, he recognized was a constant struggle in his classroom,

Mr. Nelson's end of course reflections consistently included strategies and plans for his classroom. His goal was to create authentic mathematical tasks that allowed his students to make meaning of math ideas, engage students in more meaningful conversations and bring creativity into teaching. He endeavored to encourage his students to model with manipulatives and create contexts around math. In fact, his student thinking assignments consistently painted a picture of rehearsal of these articulated ideas. Mr. Nelson's beliefs about the mathematics teaching practices aligned with his beliefs about sensemaking for students.

However, like Mr. Wells, Mr. Nelson's situated context was a major barrier to experiencing "success" as he enacted the mathematics teaching practices that he believed would support his students to develop conceptual understanding of mathematics.

"Overall, I see so much value in the creation of authentic experiences for students with mathematics. I struggle to design and engage my students in experiences for which they derive meaning.” (EO, Portfolio Reflection, Fall 2105)

In short, Mr. Nelson reflected that he had worked hard to develop pedagogical structures that allowed students to make meaning from mathematical experiences, but his students did not seem to be impacted by these experiences. Mr. Nelson saw the standard algorithm and rote procedures taught too early as the culprit.

The context of Mr. Nelson's student thinking rehearsals. The fifth-grade classes in Mr. Nelson's situated hovered above 30 students and the students presented 
serious behavioral challenges. The narrative of lack mathematics understanding at his school was exacerbated by state math assessment scores. Only $17 \%$ of fifth grade students passed the assessment in 2017, compared to $28 \%$ in the district and $39 \%$ in the state of Oregon. Mr. Nelson reflected that his own students in prior years had experienced little instruction beyond traditional algorithms and procedures. He believed that this instruction seriously hampered his students' ability to think critically. When given mathematical tasks, his students would often just employ procedures mindlessly.

In this class and through the case studies, we have begun to change this approach of instruction. In going through the student thinking assignment tasks, my students have begun the process of using experience to create meaning. My one regret is the low level of understanding that my students brought to the table. They too have been procedure followers. They struggle to break the mold of past experience. (PFC, Portfolio Reflection, Fall 2016)

Mr. Nelson reflected attempts to change his instructional approach. He even suggested that his students have gained some traction toward meaning making. However, it seems that he does not see any strength in the thinking of his students.

Mr. Nelson described new content ideas from the coursework, that he used to try to address these challenges. During the measurement course, Mr. Nelson explored the research decomposing and recomposing space and children's developing notions around the 2-dimensional array. He saw this spatial structuring as a potential solution to his students' misconceptions around the meaning of multiplication. Mr. Nelson described planning with his grade level colleagues to develop supports for his students throughout lessons around volume. Yet, when he enacted these plans, he again lamented the struggle to get his students to think. 
For much of the course, I struggled with my students' lack of understanding around arrays and area models. I often depend on the predictability of 2dimensional area and the calculation of length times width. Many of my students occupy the mindset of Kalil. They can solve through a procedure but fail to think through arrays in a non-counting or one-by-one manner. These same students tend to struggle when we move to a third dimension and the calculation of volume. They love to create and count invented volume statues. When we start to groups layers and decompose through arrays, these students fail to make the leap in understanding. (M123, Portfolio Reflection, Winter 2017)

Mr. Nelson explored a possible solution to help students make sense of multiplication and volume. His interpretation was that his students continued to struggle with the array model and when they moved to a 3-dimensional model for determining volume, the struggle remained. Mr. Nelson often takes an evaluative stance toward his students' thinking. What is not clear through this stance were the moves he did or did not make to support students to develop along the trajectory of multiplicative thinking. He described some of his students as struggling with this conceptual idea, but it is not clear how widespread that struggle was in the class. What was clearly evident was that these reflections discouraged Mr. Nelson and marked roadblocks in his own path of supporting his students to make sense of mathematics.

This narrative is expressed repeatedly in Mr. Nelson's student thinking assignments and reflections. Yet in all of the data he never suggested a lack of conviction that sensemaking was the way to help his students to improve in mathematics.

Search for Structures and Routines. In several of his reflections and assignments, Mr. Nelson sought out more structures and routines to support his students. During our interview, Mr. Nelson reiterated the story of challenge he experienced, but 
suggested that a little traction toward thinking and sensemaking had been gained

through a few new structures he was trying out in the classroom.

I think a lot of my time is spent more on managing behaviors and wandering around keeping kids on task rather than pushing for better mathematics, which is just frustrating. But [I am] working a bunch on what structure I can put into place to make that a little more successful. Part of that is the crew. This crew of students. Part of it is still setting up some of those routines... One of the things that I was pretty excited about that I was working on developing a bunch of the CASTL stuff, the classroom assessment for student learning, and so having an example of student strong and weak work, having a really focused learning target and I think that that was one of the things [I put] in this lesson. (Interview, Spring 2017)

Mr. Nelson again felt frustrated about the challenges in his context, but he does not dismiss the importance of mathematical sensemaking. Instead he pursued structures to counteract the roadblocks he experienced with his students. These new ideas gave him opportunities to move forward in his own thinking about more effective mathematics instruction. They gave him small pictures of success and possibility in his classroom.

Further, Mr. Nelson was excited about a PD workshop about open tasks given by Robert Kaplinsky. Mr. Nelson argued that this was one of the most impactful experiences as a part of the EaMML project. At this workshop, he learned about how to create open tasks that allow students to enter from many different points of understanding.

Tasks with Potential. Despite his frustration working with such a challenging population, one practice that seemed to provide a shift in Mr. Nelson's instructional practice is the development of tasks that promote student reasoning. An example of one of his tasks is included below. 
The Odds and Evens task, shown in figure 4.7, was one that Mr. Nelson enacted in his classroom during the Generalizing about Operations course. This task was derived from one of the written cases of student thinking he examined during the course. Although there were no stated mathematical goals, my interpretation is that mathematical goal for students was to create generalizations about adding even and odd numbers. What is significant about this task is the structured opportunities embedded in the task for students to process their ideas with partners and listen to the ideas of peers. It is sequenced from smaller quantities to larger quantities to provide students a way to make sense of odds and evens before considering the addition of odd and even numbers.

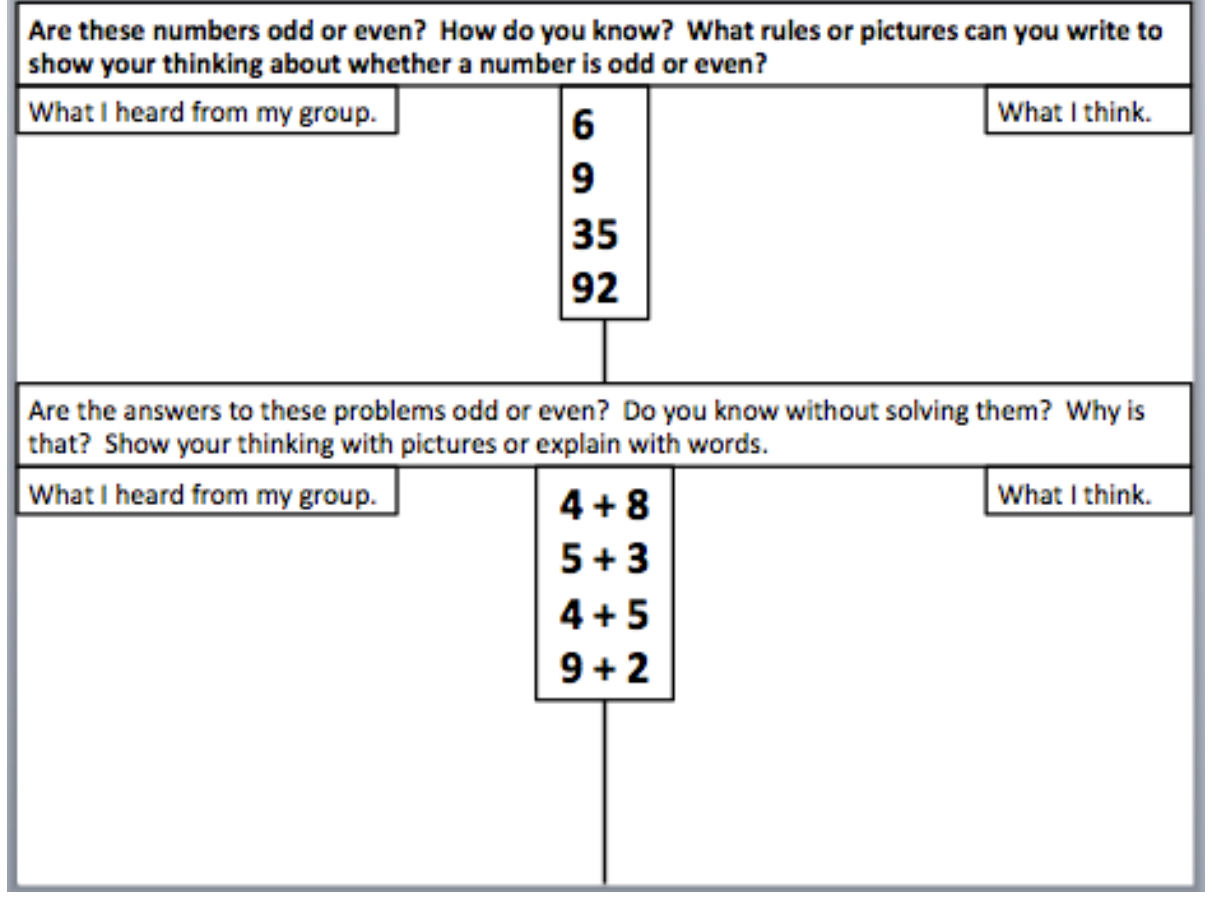




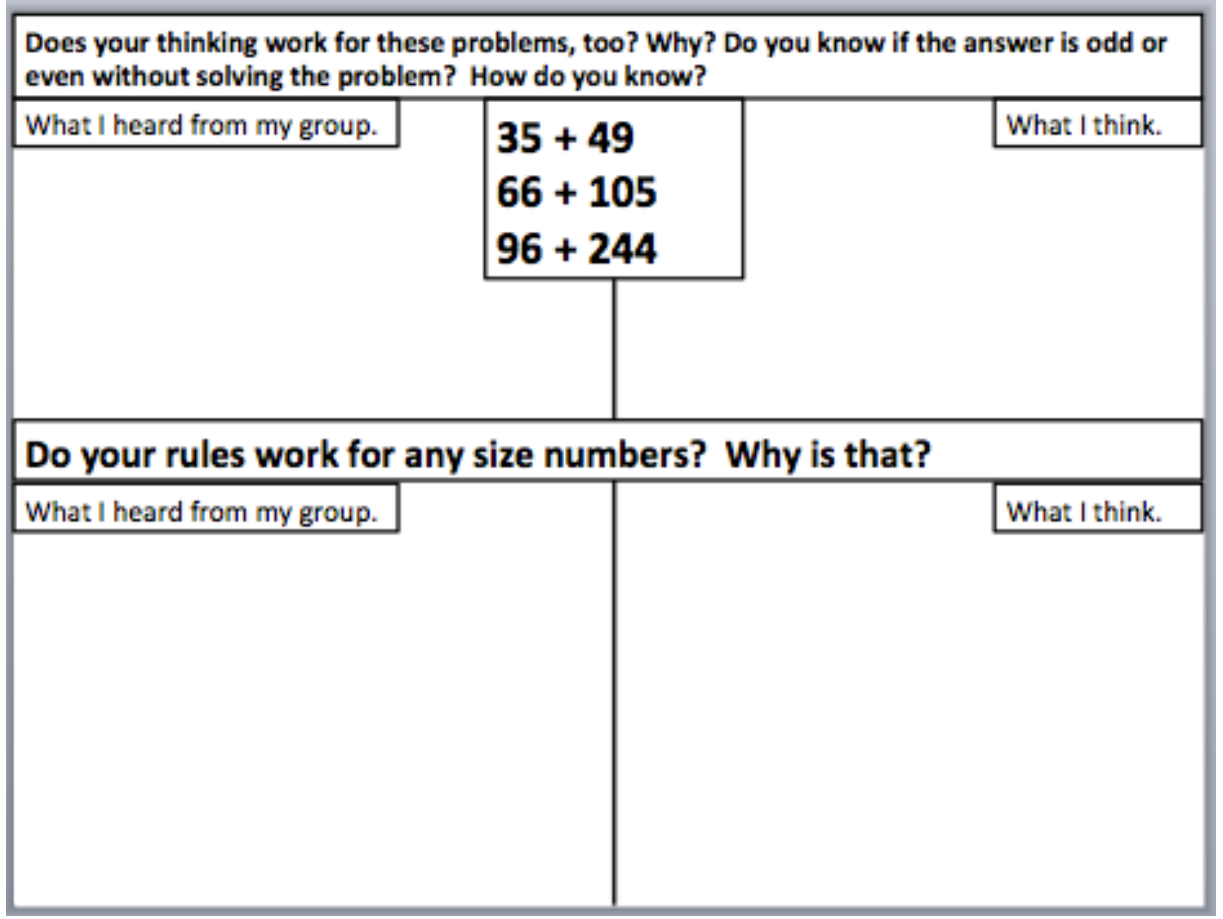

Figure 4.7. Odd and evens task from Mr. Nelson's student thinking assignment.

According to the Instructional Quality Assessment (IQA) rubric, this task would be considered at the highest level for Potential of the Task because "the task has the potential to engage students in exploring and understanding the nature of mathematical concepts, procedures, and/or relationships." (Boston \& Wolf, 2006)

As he rehearsed teacher noticing, Mr. Nelson, reflected in his assignment about one marker of success for the Odds and Evens Task.

My first reflection is on the level of engagement for the task. It is clear that the work that I have been doing around discussing and engaging in critical thought of mathematics is paying dividends. The majority of the students have written responses for each task that represent real reflection. (M123, Winter 2017, Student Thinking Assignment) 
Reflecting about the enactment of the task in figure 4.7 with his students, Mr. Nelson noted that his use of discourse routines and meaning making structures have started to pay off in his classroom. His evidence for the payoff was that students provided authentic reflections. He points to engagement in the task as a step forward for his students.

Although this may seem a small success, I also interpret it as a step towards acceptance of student reasoning, no matter the quality of that reasoning, and marking it as a strength.

Moreover, from Mr. Nelson's vantage point providing tasks with potential such as task in Figure 4.7 along with teaching explicit discourse routines and structures represented an important shift in his instructional practice. "Two or three years ago, [my

lessons] would have been much more lecture based, while still having some opportunities to turn and talk and able to do some activities." (Interview, Spring 2017) Mr. Nelson saw his instructional practice as being in a state of transition but shifting from a lecture-based lessons to open-ended tasks illustrated an important point in that transition. Mr. Nelson's responses on the teaching survey are evidence that he was tentative about his preparedness to use research-based instructional practices to support his students to learn math in principled ways. Indeed, the tentative feeling and evaluative stance was consistent with the scores of his rehearsals of teaching noticing.

\section{Mr. Nelson's Teacher Noticing}

Looking at the chart below, Mr. Nelson's pattern of teacher noticing seemed to fluctuate from assignment to assignment. The graph below was generally described in Ms. Jones findings and analysis. Generally, his teacher noticing rehearsals were characteristic of a level 1 or 2 , baseline or a mixed level. This means that his noticing of 
student thinking was often very general and evaluative or focused on his own pedagogical moves.

\section{Mr. Nelson's Noticing Scores by Rehearsal}

Noticing What

Noticing How

Responding to Noticing

4

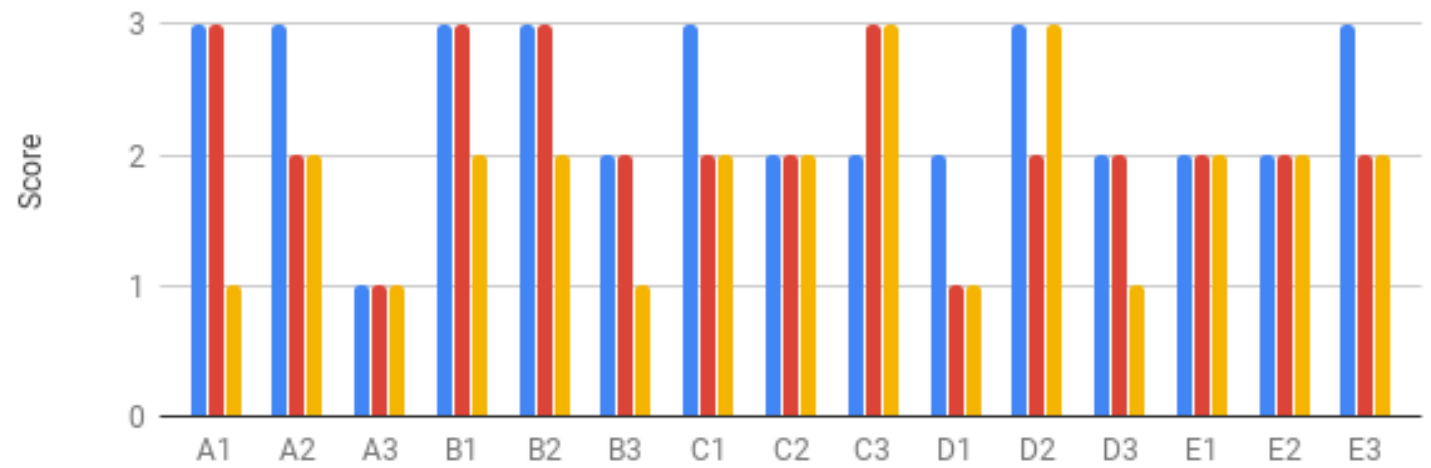

Course and Rehearsal Number

Figure 4.8: Mr. Nelson's teacher noticing graph.

This is evident in data points A3, B3, C2, D3 and most of the rest of the student thinking exercises. When his attention was trained on general class behavior or pedagogy, how he noticed tended to be evaluative and lacked interpretation. My interpretation is that when his focus is not on specific student thinking it less likely to interpret specific student thinking. His responses to student thinking also followed this trend. He either had no next steps recorded or they were focused on what the students needed generally to improve their thinking and reasoning skills.

Mr. Nelson often noted that the behavior of class was so challenging that he chose to only work with a small group of students to rehearse teacher noticing. These rehearsals 
were scored at higher levels of what he noticed. Rehearsals of teacher noticing in small groups allowed Mr. Nelson to notice specific thinking. For example, in rehearsal A1, he posed the problem 146 divided by 13 to a small group of students. He was able to focus in on one student's thinking.

During the interview $\mathrm{J}$ began by describing the strategy that he would use. When I asked him to show me how he would solve it, he furiously went to work. He began with a series of long addition problems with a core of $13+13$. Midway through his computation, he must have had a calculation error because he did not arrive at the correct quotient. Whenever asked about his thinking, he would state that he was adding one value to another. He concluded the process by counting the number of times that he had added the value 13 and received a remainder.

I learned a lot about J's thinking. For his understanding of division, he needed to group the divisor into as many groups as needed to arrive at the dividend. For him division was an inverse operation for multiplication and his multiplication strategy was repeated addition. This leads me to conclude that he is still not seeing multiplication as an operation. He has adapted the one strategy that he feels comfortable with and is actively applying it to more complex operations. (BST, Student Thinking Assignment \#1, Spring 2015)

Mr. Nelson noticed this specific student's thinking and was able to watch his process all the way through which allowed him to describe the thinking in great detail. In this rehearsal of student thinking, Mr. Nelson did not take an evaluative stance, instead he interpreted what the student understands about division as connected to repeated addition and noted that he was not seeing the multiplicative nature of the operation.

Activities of teaching as sources for teacher noticing. One significant interpretation I make is that Mr. Nelson's teacher noticing was more likely to be trained on specific students' thinking and lead to specific interpretations of their understanding when he was interviewing students. Interviewing students is a teacher activity that often includes the conferring practice. As is shown in figure 4.8, this was not a common part 
of Mr. Nelson's rehearsals, but when he did engage in conferring with students, how he noticed was more likely to take on an interpretive stance toward the student's thinking.

It is also interesting to note that Mr. Nelson often analyzed student work as source for student thinking. When Mr. Nelson used only the student work to analyze his students' thinking, his attention may have focused on specific students' thinking but he tended to take on an evaluative stance. (see rehearsal C1 in figure 4.7). I do not suggest that this means the activity of analyzing student work is a poor source for interpreting student thinking. I interpret this to mean analyzing only student work may limit interpretations of student understanding because the student is not present to add explanation to their work. One interpretation may be that the students in Mr. Nelson's class may not know how to show their reasoning on paper. Another interpretation may be that the student work he analyzed was so fraught with mistakes that it was hard to avoid evaluation.

In the next paragraph, I turn to an example of Mr. Nelson's rehearsal of teacher noticing in which he used student work as well as student monitoring as a source of 
student thinking.

\section{Mr. Nelson's Activity of Teaching When Noticing Occurred}

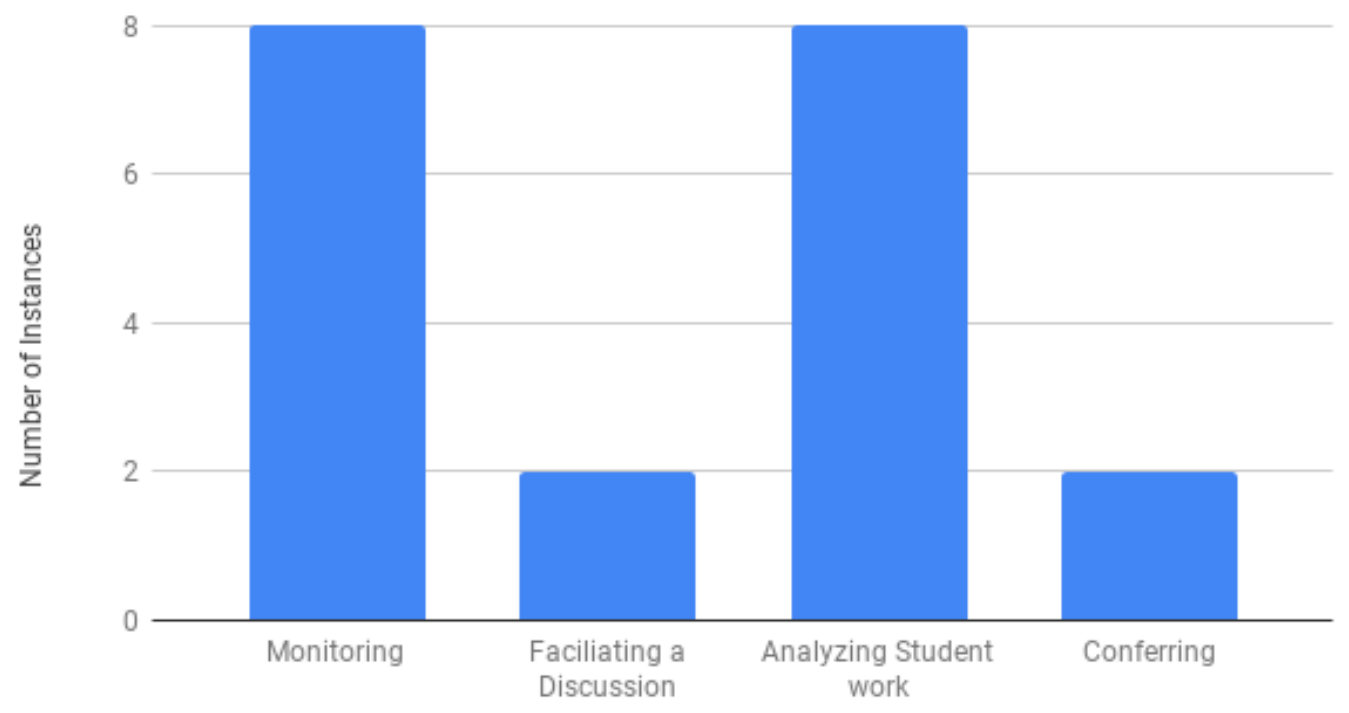

Figure 4.9: Sources of Mr. Nelson's teacher noticing.

Example of Mr. Nelson's Teacher Noticing. The following example of Mr.

Nelson's rehearsal of teacher noticing came from the Patterns, Functions and Change

course. The task students were asked to complete was a linear function pattern involving two different growth factors. The task is included below.

Big EZ, the banana slug, challenged Flash (another banana slug) to a $60 \mathrm{~cm}$ race. Because Big EZ is much larger, he offered to give Flash a $10 \mathrm{~cm}$ head start. Flash agreed and the race began. After 5 seconds, Big EZ had crawled 6 $\mathrm{cm}$, and Flash had crawled $4 \mathrm{~cm}$. If they continue at this rate, who do you predict will win the race? Why?

Figure 4.10. Linear function task from Mr. Nelson's student thinking assignment.

The task was given to a small group of five students. Mr. Nelson asked the students to create a model to show the banana slug race. It is important to note that the 
original problem was about crayfish. Mr. Nelson believed that many of his students may not have had experiences with crayfish. He reported that he changed the context of the problem to one which may have been more relatable for his students. Aguirre and her colleagues (2017) refer to this equity-based practice as drawing on multiple resources of knowledge by connecting to experiences in students' communities.

The mathematical concepts embedded in this problem are complex. To solve the problem a student must attend to both time and distance. In addition, the student must pay attention to different starting points and separate rates of change for each creature. If the student decides to represent both creatures on the same number line, they have to consider the time and distance and decide how to represent the intervals for both banana slugs on the same line. It is easy to see why the task may have been challenging to interpret each students' thinking with so many variables to consider.

The following is Mr. Nelson's written description of two of his students work. It is unclear from the description whether or not questions were asked to probe for student thinking, so it is possible that this Mr. Nelson's reflections were based on the student work alone.

M struggled to represent the race. He wanted to represent the race to scale but continually ran out of space. He has intervals of time marked off, but he does not label the distance traveled for each time interval. 


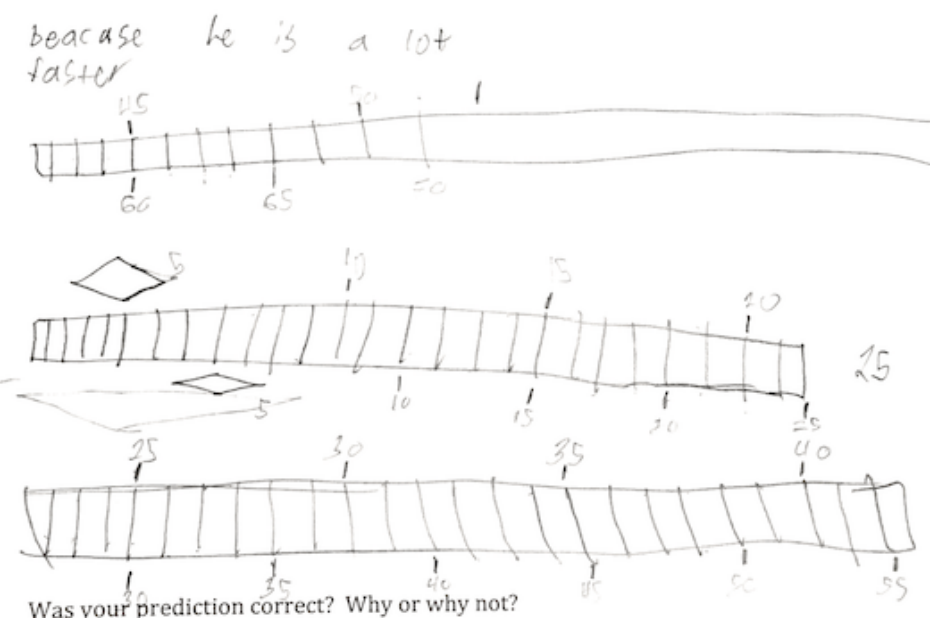

E mapped the race with a numberline based strategy. I continually pressed her throughout the lesson to add detail, so her model contains both the time and distance.

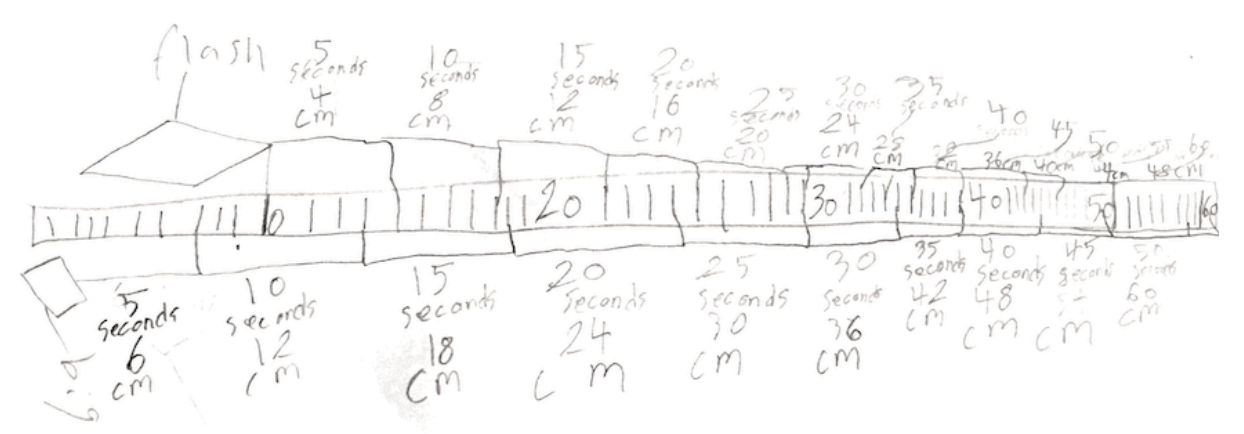

$\mathrm{K}$ focused her efforts on the art work of her model. Although she was working throughout the lesson, it is difficult to really understand her model. (PFC, Fall 2016, Student Thinking Assignment). 


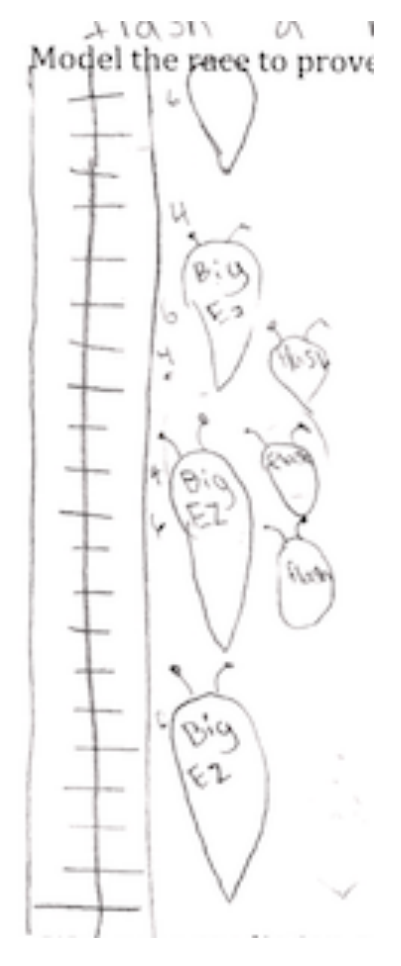

Mr. Nelson's mixed level reflection is focused on a description of what his students are doing to model the problem, rather than what these actions yield in terms of student understanding of the pattern. The evaluations of student thinking he offers seem to be related to student struggles.

There are a few ways to think about Mr. Nelson's evaluative stance when he notices student thinking. One interpretation may be that he was not be clear what mathematical ideas to focus on in the task. Should the mathematical focus be the representation of each slugs' progress in the model? Should it be about the constant growth of each slug? Another interpretation might be that he does not yet recognize the potential of conferring with students along the way to determine their understanding of the mathematics. 
Mr. Nelson reflected that he asked students to make a T-table next, then he quickly modeled a graph of their growth. This makes me think that he may have felt that the students needed to get to the "end of the lesson sequence" to then learn about what they understand. A further interpretation could be that Mr. Nelson was not clear what constitutes students understanding of linear functions. He may think the students' actions, rather than their thinking, as they engage in the task show or do not show understanding. He may not yet understand that students' actions represent thinking which reveals understanding.

It is also possible that the complexity of Mr. Nelson's situated context precluded him from being able to listen to students long enough to make interpretations. Perhaps the interruption of behavior issues made focused and extended levels of teacher noticing an unreachable aim at this point.

\section{Summary of EaMML Impact for Mr. Nelson}

Mr. Nelson's story of change is one of unwavering belief in a few ideas embedded the EaMML project. First, students need to explore sensemaking experiences in mathematics. Second, teaching the standard algorithm and other rote procedures too early without attention to sensemaking mathematical experiences inhibits students' ability to reason, and stunts their flexibility with numbers and third understanding the mathematics is critical to teaching mathematics. Despite the fact that Mr. Nelson struggled to fully realize these beliefs in his classroom practice, his convictions remained resolute. Mr. Nelson's personal formative mathematics experience is a likely contributing 
factor to his convictions and willingness keep homing in on more effective instructional practices.

\section{Limitations of the Study}

As I described in chapter 3 one limitation of this study may be that the data sources were heavily weighted with teacher reflection. The teacher survey, documents of practice and participant interview all represented participant reflections of their practice. I argue that my social constructivist research paradigm and case study approach warranted more participant reflections. If construction of knowledge operates in social spaces then is folded into individual scheme, reflections need to be analyzed in order to draw out significant learning, shifts and beliefs and explored and valued instructional practices. I mitigated this limitation by including the SR interview and the EaMML observation data. In addition, my research questions tended to focus on what could be answered from a participant's perspective.

Another limitation was my own lens as a mathematics teacher. My assumptions about what instructional beliefs and practices constitute effective mathematics teaching are a part my research lens. This is evident through my reflection journal I kept throughout the process of this project.

Today I am working on coding Mr. Nelson's interview. As I code, I have this nagging feeling of judgement about his continued complaint. So much of his interview is about how hard his students have been during the year, so he reflects and laments the struggle. Inside the lamenting, I think I see the steadfast clutching to beliefs about how students should be learning mathematics using reasoning and sensemaking habits. This is a promising feeling. Although he feels this lack of success in his class, he is not reflecting that "this method doesn't work for these kids" or they just need to be told what to do". Instead, he is continuing to reflect beliefs about the importance of mathematizing and recognizing the logic in 
others' thinking. He also seems to be able to interpret the understanding in student thinking and he is not reverting to taking over the thinking. What makes Mr. Nelson continue to hold these ideas when other research suggests that this experience may cause a teacher to revert back to old habits? (Dissertation Reflection Journal, March 2019)

This reflection represents many moments of doubt about my subjective lens as a researcher. I worried that my interpretations were judgements. The journal helped me keep this limitation forefront as I was interpreting the data. In addition, using the systematic process of the thematic networks analysis helped me to allow the data to emerge and reflect back and forth from the data to the themes. 


\section{Chapter 5: Discussion and Conclusion}

\section{Research Problem}

The challenge mathematics teachers face today with enacting reform-oriented instruction encompasses many complex layers of knowledge development. Teacher understanding of principled mathematics is necessary, but not sufficient. Teachers also need to develop the pedagogical content knowledge that allows them to connect students' ways of thinking and knowing to the learning of the mathematics. To add a further layer, students have ideas about mathematics that are varied and arise from their own socially constructed meaning making capacities. Teachers have to negotiate the mathematical understanding across the class to support all students in their mathematics learning. Teachers need tools determine how their students are making sense of the mathematics and how to respond to their students' understandings.

\section{Purpose of the Study}

The purpose of this case study is the describe how three teachers navigated these challenges and what knowledge gained as they engaged in the EaMML PD project. The theoretical assumption of the project is that students' mathematical thinking is rich in opportunities for teachers to connect to students' innate meaning making abilities and to explore the principles of the mathematics. As a researcher, I wanted to learn how this theoretical assumption played out in terms of teachers' beliefs as well as their articulated and enacted instructional practice.

\section{Research Questions and Methods}


There were three research questions I wanted to answer. First, in what ways does being involved in a reform-oriented PD project that is focused on integrating mathematics content and pedagogy development and students' mathematical thinking impacting teachers' a) instruction and b) beliefs about mathematics teaching, or c) their view of themselves as a teacher of mathematics? Second, which activities, tools or frameworks from the PD elements do teachers point to as the most impactful in terms of their work in the classroom? Third, how do teachers notice students' mathematical thinking and in which tasks of teaching is teacher noticing - whether strong or weakmost apparent?

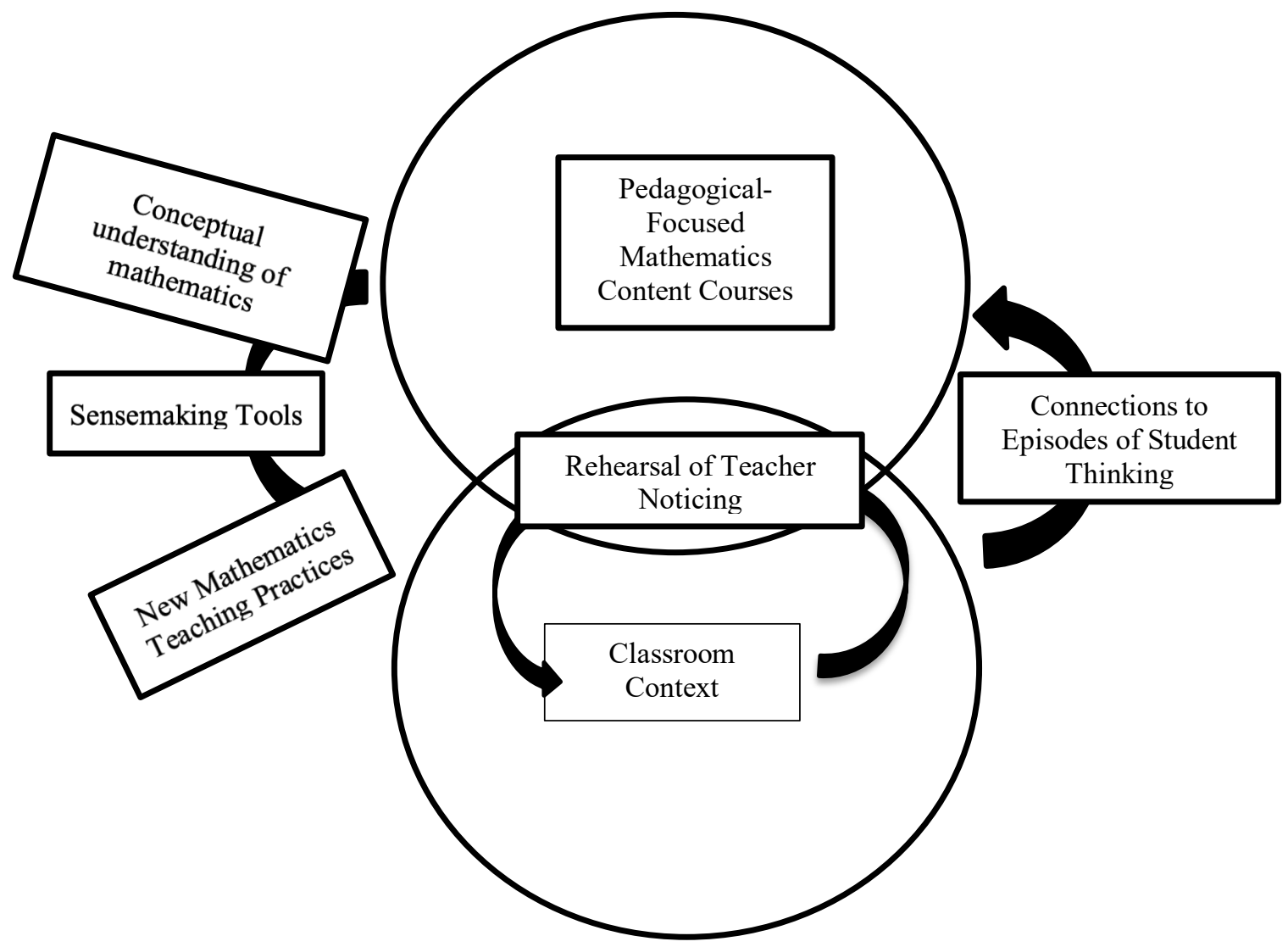

Figure 5.1. Interpretive framework illustrating the intersection between the theoretical framework, EaMML project $\mathrm{PD}$ elements and the case study research findings. 
I collected data from five content courses and two leadership courses offered over 3 years of the EaMML project. Data was also collected from one SR interview. Using a thematic networks analysis, I coded the data then drew out a few themes inductively. I also used the learning to notice framework to analyze 43 student thinking assignments from the three participants. The interpretive framework below summarizes the themes that emerged from the data.

\section{Summary of Findings.}

The content-focused pedagogy courses impacted the teachers' thinking and understanding of conceptual mathematics that makes a difference for Kindergarten through grade 8 students. In addition, the ways in which teachers made better sense of the mathematics themselves became new tools for sensemaking that they brought into their classrooms to try out with their students. The situated context of each individual classroom informed which tools and mathematics teaching practices teachers tried. Student thinking assignments from the course, provided participants the opportunity to rehearse teacher noticing of students' mathematical thinking. Again, context mattered in terms of what teachers noticed. Teachers that demonstrated the most focused or extended teacher noticing were able to attend to specific students' thinking and interpret student understanding based on the mathematics of the tasks.

In this study I do not intend to suggest that the data can be interpreted to evaluate the larger EaMML context or PD in general. Instead the descriptions of these participants 
provide illustrations of the impacts of a PD model grounded in the research about students' mathematical thinking.

\section{Situated in the Larger Context}

In this section, I return to the theoretical framework of this study. I examine the themes and findings in relation to the theoretical framework. First, I discuss the learning in and from practice and how it may or may not have supported these three teachers to shift their practice in the classroom. Next, I analyze the nature of pedagogical content knowledge and how teachers developing PCK was implemented in classroom practice. Finally, I argue the importance of the practice of teacher noticing to sustaining the impacts of professional development.

Learning in and from practice. Ball and Cohen (1999) argue that in order for teachers to navigate this complex paradigm shift in teaching mathematics, they must learn in and from their own situated practice. The EaMML content-focused pedagogy courses allowed teachers to examine students' mathematical thinking outside the busyness of the classroom, first through the examination of written and video episodes of student thinking and later through student thinking assignments.

Examining written and video episodes of student thinking. The learning from practice outside of their classroom clearly impacted the three participants, albeit in different ways. Each of the teachers from this study noted specific student thinking that was surprising, inspiring, or complex from the cases of student thinking. In the case of Mr. Wells, the student thinking episodes he examined in the EaMML course sessions caused him to examine the low expectations he held of his own students. 
In addition, teachers often tried out specific tasks they were inspired by and then referred to their own students' thinking in relation to the children in the video or written case studies. Finally, the exploration of mathematics concepts allowed the teachers to develop new anchors into what conceptual understanding of mathematics looks like in the classroom.

Exploring conceptual understanding as a learner. It was evident that the teachers connected to specific tools or mathematics teaching practices that allowed them to make sense of the mathematics content in more conceptual ways. Each participant brought the tools or mathematics teaching practices that seemed to support their own understanding to the classroom to enact with students as they engaged in rehearsals of teacher noticing. Mr. Wells noted a profound reflection that his own way of successfully navigating mathematics as a student did not necessarily result in understanding mathematics in principled ways. His work in the MIL courses supported him to deepen his conceptual understanding of the mathematics he had originally understood procedurally. In a similar manner, his classroom practice shifted from a model of teacher directed explanation of how to do the mathematics and subsequent student practice, to facilitated discursive experiences in which open tasks were explored, students shared ideas and other students were asked to respond to those ideas.

Rehearsals of teacher noticing. The rehearsals of teacher noticing provided a context for the teachers to practice eliciting, interpreting and responding to the student thinking in their own classrooms, then reflecting back their experiences in subsequent course sessions. How the teachers interpreted the student thinking in their classrooms was 
shaped by the situated context of their workplace. Mr. Nelson, a $5^{\text {th }}$ grade teacher, was very impacted by the challenges in his classroom, as well as the challenges in his building. In his view, a systemic overreliance on standard algorithms and procedures in his building hindered the thinking abilities of his students. Attention to these issues was an obstacle for Mr. Nelson's ability to interpret student thinking in specific ways.

What is not explicitly clear in the data from this study is the extent to which teachers brought their new revelations about conceptual understanding of mathematics into their classrooms practice. I do not mean to suggest that teachers did not do lean on new conceptual understanding anchors in their instruction, but I believe that different measures or prompts would be needed in this study in order to parse out how teachers understanding of content played out in reflected upon or observable classroom instruction.

Pedagogical content knowledge (PCK). In this study, learning in and from practice opened the doors to developing new pedagogical content knowledge. One theme that emerged from the data was that teachers derived new meaning making tools used in the courses and tried them out in their classrooms. The findings in this study demonstrated the teachers offered manipulatives to students to use in thinking about the mathematics and considered new representations that would support students in the conceptual understanding. They practiced routines for discussions and questioning that pressed students to talk about their mathematical thinking. This type of knowledge is referred to as knowledge of content and students in Ball et al.'s (2008) elaboration of PCK. 
Ms. Jones noted the critical importance of understanding and listening to student thinking in order to be able to anticipate what students will do and say for instructional planning. Mr. Nelson developed a PD for colleagues in his school community centered on the number and operations strand. The purpose was to highlight the importance of understanding the progression of students' thinking in mathematics. Ball et al. (2008) categorizes this knowledge as specialized content knowledge.

One example of PCK that stood out in this case study was the instances in which teachers discussed student thinking in the written and video case studies and then noticed their own students engaging in this same thinking. This phenomenon suggests to me the potential for teachers engaging in this type of PD model to seed networks of knowledge of content and students and specialized content knowledge that are then further developed if teachers continue to listen and learn from their own students. In order to allow these seeds to root, a critical aspect of teacher noticing is maintaining a curious stance toward noticing student's thinking as evidence of student learning rather than student's mimicry or correct use of procedures.

Teacher noticing. The process of teacher noticing is at the heart of a teacher's ability to navigate complex classrooms with varied learners making sense of mathematics. According to Sherin (2011) teacher noticing is an active and cyclical process with teachers as actors in the process. What teachers make sense of, in terms of their noticing of students' thinking in a mathematics lesson, determines what direction they choose to take the lesson. The new direction becomes a playing field for the teacher to navigate. What they make sense of in the new playing field determines what student 
thinking teachers select to share and what they choose to ignore. Van Es (2011) argues that teacher noticing is critical for teachers to determine the extent that a mathematics teaching practice is impacting student learning. They need to know what counts as evidence of student learning in relation to conceptual understanding of the mathematics and the teacher pedagogy they are implementing. Mathematics understanding in more heteronomous classroom environments are linked to performance of procedures and demonstration of fact knowledge. Thus, what counts as evidence is often binary. Correct processes and answers determine understanding. In contrast, conceptual understanding is a nuanced web of relationships linking procedures, meanings of operations and flexible ways of using numbers (Hiebert, 1997). Conceptual understanding is not binary and is better thought of as developing understanding or a mental state of shifting understanding (Carpenter \& Lehrer, 1999). What counts as evidence of understanding from this frame is multifaceted. Teachers might interpret student thinking in terms of where they land on a trajectory of concept development. Alternatively, teachers might interpret how students understand the meanings of the operations they are using. A different approach may be interpreting students' flexibility as they approach problems or manipulate numbers, etc.

Jacobs et al. (2010), built upon the work of van Es and others by extending teacher noticing to include attending to, interpreting and responding to student's mathematical thinking and arguing that "teachers must attend to these three skills in an integrated way almost simultaneously, while they are making in-the-moment decisions." (Jacobs, et al., pg. 192) 
The three teachers in the case study illustrated different levels of teacher noticing using the adapted learning to notice framework. This suggests that what teachers chose to take up from the professional development and enact in their classroom instruction was varied.

The sample size of this study limits any generalizing link from the courses to the shifts in instruction but using the framework to examine the student thinking exercises over time could provide facilitators a lens into the classroom practice and how the practice integrates student thinking, principled teaching and learning, and teacher moves. For instance, Ms. Jones practice of noticing illustrated a picture of specific descriptions of student thinking that are consistent with a focused or extended level of teacher noticing. She often responded to student thinking by enacting teacher moves such as pairing students to move them forward in their continuum of number sense, asking questions to learn more about the students thinking or extend the student thinking or bringing student ideas to the attention of the whole class.

Mr. Wells' noticing practice shifted over the span of the courses from more mixed level teacher noticing to a focused level. His early rehearsals of student thinking showed that he took a binary view described above to determining his student's mathematics understanding. His discussions in the assignments centered on the teacher moves he used to help his students understand what to do. Later, Mr. Wells' interpretations of student thinking connected to the mathematics standards progressions. Teacher moves included posing questions to students about how they knew their answer worked, or how they 
knew their answer was correct. He described asking questions of the whole group of students and having the students respond to their peers.

Mr. Nelsons' practice of teacher noticing fluctuated depending on the activity in which he was noticing. When he was interviewing his students, Mr. Nelson was more likely to notice specific students' thinking and interpret the thinking. When he was posing a problem and collecting student work to analyze, his teacher noticing tended to be more general and evaluative. His situated context was a self-described barrier to supporting students to use their own sensemaking capacity. There are few reasons we might attribute to Mr. Nelson's struggle to shift his mathematics teaching practices. Mr. Nelson was the teacher in the case study teaching mathematics to the oldest students in the study, and at the same time he was also the teacher who reported feeling the weakest in terms of mathematics content knowledge. The mathematics content at $5^{\text {th }}$ grade becomes significantly more challenging for students and teachers. It is likely that this factor was one the reasons he struggled to help his students to reason non-algorithmically about mathematics. This factor may also have contributed to his mixed teacher noticing levels. In addition, Mr. Nelson often reported being distracted by classroom management issues which blocked him from paying attention to his students' mathematical thinking in meaningful ways.

Limitations of the study from an equity-based lens. In this study there were missed opportunities for focusing on equity as a researcher. In addition, there may have also been as missed opportunities for participants to foreground equity in their diverse classrooms. The participants and I represented a different racial and class background from the 
students in the respective classroom communities. Our positionality was surely a factor in the ways in which we focused on explicit conceptual understanding teaching practices more robustly than equity-based practices. However, Aguirre at al. (2017) argue that the conceptual understanding versus equity-based practice approach in research represents a false dichotomy. Mathematical education researchers (MERS) need to address these issues as both/and or intertwined. The participants in the EaMML project and the current case study examined frameworks that addressed equity-based teaching practices. It is clear that they were using teaching practices that connected to those frameworks. A recent focus in the MERS literature suggests that attention to student thinking and deepening conceptual understanding promotes the building of students' mathematical identities, positions students as mathematical authorities, draws upon the multiple mathematical competencies available in the learning community, and focuses on students' own informal language and reasoning over mathematics correctness allowing all students to make sense and participate in the mathematics community. (Aguirre, et al. 2017; Aguirre, Mayfield-Ingram, 2013; Moschkovich, 2013)

I acknowledge that the theoretical frameworks I chose in this study obscured opportunities to learn if the participants attended to other equity-based practices in their classrooms. For example, the participants may have drawn from the community funds of knowledge (Aguirre et. al., 2013) of their students and connected to their students' home lives more robustly, but my research choices did not yield this information. 


\section{Implications}

This case study describes the impacts that three participants involved one PD project suggested made a difference in their beliefs and practice. The power of a small, in depth, case study is the possibilities that are illuminated for the larger community. In this section, I detail the implications for further research, PD facilitators and the teaching community.

Further research possibilities. The information gained from this study, could lead to other further research that contribute to the field of mathematics teacher education. In this section, I focus my discussion on research specific to teacher noticing of students' mathematical understanding in relation to conceptual understanding of mathematics and teachers' developing PCK.

Using the adapted learning to notice framework. Using this framework was helpful as a researcher seeking to determine whether certain aspects of the PD trickled into classroom practice. It would be interesting to use the framework as part of a larger scale study and look for themes related to growth in teacher noticing. It could be also used to code student thinking exercises across different PD projects with similar practicebased designs (i.e., those that include Math Labs, Math Studios, or Lesson Study) to see if similarities or differences emerge. Assuming a similar PD design, it might also be helpful to conduct observations of PD participants' classroom practice before and after the PD to learn about teacher noticing and shifts in teacher noticing.

One aspect of the adapted learning to notice framework that seemed insufficient for learning about the teacher noticing practice relates to teacher moves that suggest an 
interpretation was made but was not overt. I observed examples of what I might term implicit interpretations of student thinking through explicit teacher moves that support the student. For example, a teacher described a student's thinking then made a move to pair the student with another student, or suggested a new representation or model, but never commented on their actual interpretation of student thinking that prompted such a suggestion. Although the interpretation is not explicit, the teacher move seems to be undergirded by an interpretation. Jacobs et al. (2010) have expanded the teacher noticing research to include eliciting, supporting, and extending teacher moves in response to student thinking. It could be useful to capture these moves to expand the framework.

Sustaining Instructional Shifts. An alternative line of research would be to follow up the current study with these three participants to see what they point to as impacts from the PD that are sustained in their work. More broadly, include in PD designs followup observations in classrooms to learn what participants continue to implement related to the PD.

Implications for PD facilitators. This study has implications for PD providers using similar PD approaches.

Using the adapted learning to notice framework. The adapted learning to notice Framework could be useful in examining teachers verbal and written discussions around student thinking as a formative assessment of how teachers are taking in and making sense of the content. The framework could be used as a tool for facilitators to frame their feedback to press participants to connect more to specific students' thinking or to connect their interpretations of the mathematics. Alternatively, a feedback protocol could be 
developed for participants to use when sharing student thinking exercises with other participants. For example, one participant receives a copy of a partner's student thinking assignment and listens to their partner share then listens for and underlines the noticing of specific student thinking and interpretations based on the mathematical concepts.

Explicating Teacher Interpretation of Student Mathematical Thinking. It might be helpful in PD sessions to make explicit what an interpretation connected to the mathematics sounds like. In the MIL content courses this could be done before examining the written and video episodes of student thinking. This may support teachers to recognize what an interpretation could sound like so they can rehearse their own interpretations as they examine the cases.

Implications for teaching community. The implications I see for teaching communities center around practical inquiry into students' mathematical thinking. Teachers in my own situated context use a reform-oriented curriculum, but they often express frustration that the student strategies suggested in the materials are creative, but not useful. My wondering about this is whether the teachers understand the conceptual underpinnings of the math and how the strategies make those underpinnings visible. As generalists, teachers will not always choose to use their PD funds and time to focus on mathematics, so it is critical that school leaders design ways to implement job embedded mathematics PD that supports deepening conceptual understanding in mathematics. The participants in this study lauded examining the cases of student thinking as impactful. This suggests a couple of ways cases of student thinking could be harnessed at the practitioner level. 
Sharing examples of student reasoning. Students' authentic mathematical thinking has a powerful impact on teachers' beliefs about what students can do. Interesting student reasoning could be collected from each teacher and displayed by grade level. Faculty might then examine student understanding across the grades and reflect on the connections they see. They could further use the thinking as a springboard to reflect on their expectations of students.

Connecting conceptual understanding to student thinking. One implication at the practitioner level is to raise teacher awareness to use the adapted learning to notice Framework to raise awareness about what we could notice as we monitor and confer with our students. Below are a couple of ways this could be implemented at the teacher practitioner level.

To rehearse interpreting student thinking, engage teachers across grade levels in doing the mathematics together connected to a strand that grows through the grades. Then examine samples of student thinking from different grade levels and interpret the student thinking examples in relationship to the specific conceptual understanding. Another suggestion is to conduct interviews of student thinking to bring to staff meetings to interpret and calibrate interpretations of developing student mathematics understanding connected to progressions or trajectories of student understanding.

Using the: This is a protocol I created. It is specific to unit overview planning. A grade level team would start by (a) examining background mathematics in the curriculum materials (b) connecting the strategies and student thinking posed by the materials to the 
mathematics (c) predict what students might say or do and how that might connect to the student's conceptual understanding. 


\section{References}

An, S., Kulm, G., \& Wu, Z. (2004). The pedagogical content knowledge of middle school, mathematics teachers in China and the US. Journal of Mathematics Teacher Education, 7(2), 145-172. doi: 10.1023/B:JMTE.0000021943.35739.1c

Aguirre, J., Herbel-Eisenmann, B., Celedón-Pattichis, S. , Civil, M. Wilkerson,T., Stephan, M., Pape, S. \& Clements, D. (2017). Equity within mathematics education research as a political act: Moving from choice to intentional collective professional responsibility. Journal for Research in Mathematics Education, 48(2), 124-147. doi:10.5951/jresematheduc.48.2.0124

Aguirre, J., Mayfield-Ingram, K. \& Martin, D. (2013). The impact of identity in K-8 mathematics: Rethinking equity-based practices. Reston, VA: National Council of Teachers of Mathematics.

Aguirre, J. M., Turner, E. E., Bartell, T. G., Kalinec-Craig, C., Foote, M. Q., Roth McDuffie, A., \& Drake, C. (2013). Making connections in practice: How prospective elementary teachers connect to children's mathematical thinking and community funds of knowledge in mathematics instruction. Journal of Teacher Education, 64(2), 178-192.

Attride-Stirling, J. (2001). Thematic networks: an analytic tool for qualitative research. Qualitative Research, 1(3), 385-405. doi:

$10.1177 / 146879410100100307$

Campbell, P. F., \& Malkus, N. N. (2011). The impact of elementary mathematics 
coaches on student achievement. The Elementary School Journal, 111(3), 430-454. doi: $10.1086 / 657654$

Ball, D., \& Cohen, D. (1999). Developing practice, developing practitioners: Toward a practice-based theory of professional education. In L. Darling-Hammond and G. Sykes (Eds.), Teaching as the learning profession (pp.3-31). San Francisco, CA: Jossey-Bass.

Ball, D. L., Sleep, L., Boerst, T. A., \& Bass, H. (2009). Combining the development of practice and the practice of development in teacher education. The Elementary School Journal, 109(5), 458-474. doi: 10.1086/596996

Ball, D. L., Thames, M. H., \& Phelps, G. (2008). Content knowledge for teaching: What makes it special? Journal of Teacher Education, 59(5), 389-407. doi: $10.1177 / 0022487108324554$

Banilower, E. R., Boyd, S. E., Pasley, J. D., \& Weiss, I. R. (2006). Lessons from a decade of mathematics and science reform: A Capstone report for the local systemic change through Teacher Enhancement Initiative. North Carolina: Horizon Research

Battista, M. T. (1994). Teacher beliefs and the reform movement in mathematics education. Phi Delta Kappan, 75(6), 462-470. Retrieved from http://www.jstor.org/stable/20405142

Battista, M. T., Fey, J. T., King, K. D., Larson, M., Reed, J., Smith, M. S., ... \& Sutton, J. T. (2007). Connecting research and practice at NCTM. Journal for Research in Mathematics Education, 38(2),108-114. doi: 10.2307/30034951 
Bell, C. A., Wilson, S. M., Higgins, T., \& McCoach, D. B. (2010). Measuring the effects of professional development on teacher knowledge: The case of developing mathematical ideas. Journal for Research in Mathematics Education, 41(5), 479512. Retrieved from http://www.jstor.org/stable/41110411

Boaler, J. (2009). The elephant in the classroom: Helping children to learn and love maths. London, England: Souvenir Press.

Bobis, J., Clarke, B., Clarke, D., Thomas, G., Wright, B., Young-Loveridge, J., \& Gould, P. (2005). Supporting teachers in the development of young children's mathematical thinking: Three large scale cases. Mathematics Education Research Journal, 16(3), 27-57. doi 10.1007/BF03217400

Borko, H. (2004). Professional development and teacher learning: Mapping the terrain. Educational Researcher, 33(8), 3-15. doi: 10.3102/0013189X033008003

Borko, H., Jacobs, J., Eiteljorg, E., \& Pittman, M. E. (2008). Video as a tool for fostering productive discussions in mathematics professional development. Teaching and Teacher Education, 24(2), 417-436. doi: 10.1016/j.tate.2006.11.012

Boston, M. (2012). Assessing instructional quality in mathematics. The Elementary School Journal, 113(1), 76-104. doi: 10.1086/666387

Boston, M. D., \& Wolf, M. K. (2006). Assessing academic rigor in mathematics instruction: The development of Instructional Quality Assessment Toolkit (CSE Tech. Rep. No. 672). Los Angeles: University of California, National California, National Center for Research on Evaluation, Standards, and Student Testing (CRESST). 
Carpenter, T. P., Fennema, E., Peterson, P. L., Chiang, C. P., \& Loef, M. (1989).

Using

knowledge of children's mathematics thinking in classroom teaching: An experimental study. American Educational Research Journal, 26(4), 499-531. doi: 10.3102/00028312026004499

Clark, V. L. P., \& Creswell, J. W. (2010). Understanding research: A consumer's guide. Upper Saddle River, NJ: Merrill.

Creswell, J. W. (2012). Qualitative inquiry and research design: Choosing among five approaches. London, England: Sage Publications.

Darling-Hammond, L., \& McLaughlin, M. W. (1995). Policies that support professional development in an era of reform. Phi Delta Kappan, 76(8), 597-604.

Darling-Hammond, L., \& Sykes, G. (1999). Teaching as the learning profession: Handbook of policy and practice. San Francisco, CA: Jossey-Bass.

Darling-Hammond, L., Wei, R. C., Andree, A., Richardson, N., \& Orphanos, S. (2009). Professional learning in the learning profession. Washington, DC: National Staff Development Council.

Denscombe, M. (2008). Communities of practice a research paradigm for the mixed methods approach. Journal of Mixed Methods Research, 2(3), 270-283. doi: $10.1177 / 1558689808316807$

Desimone, L. M., Porter, A. C., Garet, M. S., Yoon, K. S., \& Birman, B. F. (2002). Effects of professional development on teachers' instruction: Results from a 
three-year longitudinal study. Educational Evaluation and Policy Analysis,

24(2), 81-112. doi: 10.3102/01623737024002081

Desimone, L. M. (2009). Improving impact studies of teachers' professional development: Toward better conceptualizations and measures. Educational Researcher, 38(3), 181-199. doi: 10.3102/0013189X08331140

Dweck, C. S. (2010). Mind-sets. Principal Leadership, 10(5), 26-29. Retrieved from http://www.eosdn.on.ca

Ellis, M. W., \& Berry III, R. Q. (2005). The Paradigm shift in mathematics education: Explanations and implications of reforming conceptions of teaching and learning. Mathematics Educator, 15(1), 7-17. doi: 17648378

Fennema, E., Carpenter, T. P., Franke, M. L., Levi, L., Jacobs, V. R., \& Empson, S. B. (1996). A longitudinal study of learning to use children's thinking in mathematics instruction. Journal for Research in Mathematics Education, 27(4), 403-434. doi: $10.2307 / 749875$

Franke, M. L., Carpenter, T. P., Levi, L., \& Fennema, E. (2001). Capturing teachers’ generative change: A follow-up study of professional development in mathematics. American Educational Research Journal, 38(3), 653-689. doi: $10.3102 / 0013189 X 033008003$

Franke, M. L., Carpenter, T., Fennema, E., Ansell, E., \& Behrend, J. (1998). Understanding teachers' self-sustaining, generative change in the context of professional development. Teaching and Teacher Education, 14(1), 67-80. Doi 10.1016/S0742-051X(97)00061-9 
Franke, M. L., \& Kazemi, E. (2001). Learning to teach mathematics: Focus on student thinking. Theory into Practice, 40(2), 102-109. doi:

$0.1207 / \mathrm{s} 15430421 \mathrm{tip} 4002 \_4$

Fuson, K. C., Smith, S. T., \& Lo Cicero, A. M. (1997). Supporting Latino first graders' ten-structured thinking in urban classrooms. Journal for Research in Mathematics Education, 28(6), 738-766. doi: 10.2307/749640

George, A. L., \& Bennett, A. (2005). Case studies and theory development in the social sciences. Cambridge, MA: MIT Press.

Ginsburg, H. (1989). Children's arithmetic: How they learn it and how you teach it. (Rev. Ed.) Austin, Texas: Pro-Ed.

Guba, E., \& Lincoln, Y. (2005). Paradigmatic controversies, contradictions, and emerging confluences. In N. Denzin \& Y. Lincoln (Eds.), Handbook of qualitative research, (pp. 191-215). Thousand Oaks, CA: Sage.

Gutstein, E., Lipman, P., Hernandez, P., \& de los Reyes, R. (1997). Culturally relevant mathematics teaching in a Mexican American context. Journal for Research in Mathematics Education, 28(6), 709-737. doi: 10.2307/749639

Guttierez, R. (2007). A “Gap-gazing” fetish in math education? Problematizing research on the achievement gap. Journal of Research in Mathematics Education, 39(4), 357-364. Retrieved from http://www.jstor.org/stable/40539302

Guttierez, R. (2009). Embracing the inherent tensions in teaching mathematics from an equity stance. Democracy and Education, 18(3), 9-16. 
Heibert, J., Carpenter, T. P., Fennema, E., Fuson, K., Human, P, Murray, H... \& Wearne, D. (1997). Making sense: Teaching and learning mathematics with understanding. Portsmouth NH: Heinemann.

Hill, H. C. (2009). Fixing teacher professional development. Phi Delta Kappan, 90(7), 470-476. Retrieved from http://www.jstor.org/stable/20446155

Hill, H. C., Blunk, M. L., Charalambous, C. Y., Lewis, J. M., Phelps, G. C., Sleep, L., \& Ball, D. L. (2008). Mathematical knowledge for teaching and the mathematical quality of instruction: An exploratory study. Cognition and Instruction, 26(4), 430-511. doi:10.1080/07370000802177235

Hill, H. C., Rowan, B., \& Ball, D. L. (2005). Effects of teachers' mathematical knowledge for teaching on student achievement. American Educational Research Journal, 42(2), 371-406.

Hufferd-Ackles, K., Fuson, K. C., \& Sherin, M. G. (2004). Describing levels and components of a math-talk learning community. Journal for Research in Mathematics Education, 35(2), 81-116. doi: 10.2307/30034933

Jacobs, V. R., Lamb, L. L., Philipp, R. A. \& Schappelle, B.P. (2011) Deciding how to respond on the basis of children's understandings. In M. Sherin, V. Jacobs, \& R. Philipp, (Eds.) Mathematics teacher noticing: Seeing through teachers' eyes (pp. 97-116). New York, NY: Routledge.

Jacobs, V. R., Lamb, L. L. \& Philipp, R. A. (2010). Professional noticing of children's mathematical thinking. Journal for Research in Mathematics Education, 41(2), 169-202. Retrieved from http://www.jstor.org/stable/20720130 
Johnson, R. B., \& Onwuegbuzie, A. J. (2004). Mixed methods research: A research paradigm whose time has come. Educational Researcher, 33(7), 14-26. doi: 10.3102/0013189X033007014

Kamii, C. (1984). Autonomy: The aim of education envisioned by Piaget. Phi Delta Kappan, 65(6), 410-415. Retrieved from http://www.jstor.org/stable/20387059

Kamii, C., \& Housman, L. B. (2000). Young children reinvent arithmetic: Implications of Piaget's theory. New York: Teachers College Press.

Kazemi, E., \& Franke, M. L. (2004). Teacher learning in mathematics: Using student work to promote collective inquiry. Journal of Mathematics Teacher Education, 7(3), 203-235. doi 10.1023/B:JMTE.0000033084.26326.19

Ladson-Billings, G. (2009). Just what is critical race theory and what's it doing in a nice field like education? International journal of qualitative studies in education, 11(1), 7-24.

Lampert, M. (2009). Learning teaching in, from, and for practice: What do we mean?. Journal of Teacher Education, 61(1-2), 21-34. doi: $10.1177 / 0022487109347321$

Lampert, M., Beasley, H., Ghousseini, H. Kazemi, E. \& Franke, M., (2010). Using designed instructional activities to enable novices to manage ambitious mathematics teaching. In M. Stein \& L. Kucanpost (Eds). Instructional Explanations in the Disciplines, (pp. 129-41). New York, NY: Springer.

Lave, J., \& Wenger, E. (1998). Communities of practice. New York: Cambridge University Press. 
Lincoln, Y. S. \& Guba, E.G. (1985). Naturalistic Inquiry. Beverly Hills, CA: Sage.

Little, J.W. (1993). Teachers' professional development in a climate of educational Reform. Educational Evaluation and Policy Analysis, 15(2), 129-151. doi:10.3102/01623737015002129.

Loucks-Horsley, S., \& Matsumoto, C. (1999). Research on professional development for teachers of mathematics and science: The state of the scene. School Science and Mathematics, 99(5), 258-271. doi: 10.1111/j.1949-8594.1999.tb17484.x

Lyle, J. (2003). Stimulated Recall: A report on its use in naturalistic research. British Educational Research Journal., 29(6), 861-878.

Mason, J, (2011). Noticing: Roots \& branches. In M. Sherin, V. Jacobs, \& R.Philipp (Eds.) Mathematics teacher noticing: Seeing through teachers' eyes, (pp. 35-50). New York: Routledge.

Merriam, S. B. (1998). Qualitative research and case study applications in education. San Francisco, CA: Jossey-Bass.

Morgan, D. L. (2007). Paradigms lost and pragmatism regained methodological implications of combining qualitative and quantitative methods. Journal of Mixed Methods Research, 1(1), 48-76. doi: 10.1177/2345678906292462

Moschkovich, J. (2013). Principles and guidelines for equitable mathematics teaching practices and materials for English language learners. Journal of Urban Mathematics Education, 6(1), 45-57.

Moses, R. \& Cobb, C. (2001). Radical equations: Math literacy and civil rights. Boston, MA: Beacon Press. 
National Commission on Excellence in Education. (1983). A nation at risk: The imperative for educational reform. Washington, DC: U. S. Department of Education.

National Governors Association (2010). Common core state standards.

National Council of Teachers of Mathematics. (1989). Curriculum and

evaluation standards for school mathematics. Reston, VA: NCTM.

National Council of Teachers of Mathematics. (2000). Principles and standards of school mathematics. Reston, VA: NCTM.

National Council of Teachers of Mathematics. (2000). Principles to actions. Reston, VA: NCTM.

Parise, L. M., \& Spillane, J. P. (2010). Teacher learning and instructional change: How formal and on-the-job learning opportunities predict change in elementary school teachers' practice. The Elementary School Journal, 110(3), 323-346. doi: $10.1086 / 648981$

Polya, G. (1945). How to solve it. Princeton, NJ: Princeton University Press.

Prawat, R. S. (1992). Teachers beliefs about teaching and learning: A constructivist perspective. American Journal of Education, 100(3), 354-395.

Rigelman, N., Lewis, C., Gray, M., McQueen, A., \& Prigodich, K. (2018, April). Let's talk about professional development models that work. Paper presented at the National Council of Teachers of Mathematics Annual Research Conference, Washington, DC. 
Rosebery, A. S., \& Puttick, G. M. (1998). Teacher professional development as situated sensemaking: A case study in science education. Science Education, 82(6), 649- 677. doi 10.1002/(SICI)1098-237X(199811)82:6<649::AID-SCE2>3.0.CO;2-H RMC (2017). East Metro Mathematics Leadership Project. Portland, OR: RMC Research Corporation.

Schoenfeld, A.H. (2004). The math wars. Educational Policy, 18(1), 253-286. doi: $10.1177 / 0895904803260042$

Sherin, M. G., Jacobs, V. R., \& Phillip, R.A. (2011). Situating the study of teacher noticing. In M. Sherin, V. Jacobs \& R. Philipp. (Eds.) Mathematics teacher noticing: Seeing through teachers' eyes (3-13). New York: Routledge.

Shulman, L. S. (1986). Those who understand: Knowledge growth in teaching. Educational Researcher, 15(2), 4-14. doi: 10.3102/0013189X015002004

Smith, M. S. (2001). Practice based professional development for teachers of mathematics. Reston, VA: NCTM.

Spillane, J. P. (1999) External reform initiatives and teachers' efforts to reconstruct their practice: The mediating role of teachers' zones of enactment. Journal of Curriculum Studies, 31(2), 143-175. doi:10.1080/002202799183205

Stein, M. K., Smith, M. S., \& Silver, E. A. (1999). The development of professional developers: Learning to assist teachers in new settings in new ways. Harvard Educational Review, 69(3), 237-270. doi 131.252.96.28 
Swafford, J. O., Jones, G. A., \& Thornton, C. A. (1997). Increased knowledge in geometry and instructional practice. Journal for Research in Mathematics Education, 28(4), 467-483. doi: 10.2307/749683

Taylor, L. \& Parsons, J. (2011). Improving Student Engagement. Current Issues in Education, 14(1). Retrieved from http://cie.asu.edu/

Thomas, G. (2011). A typology for the case study in social science following a review of definition, discourse, and structure. Qualitative Inquiry, 17(6), 511-521. doi: $10.1177 / 1077800411409884$

Turnuklu, E. B., \& Yesildere, S. (2007). The Pedagogical content knowledge in mathematics: Pre-service primary mathematics teachers' perspectives in Turkey. Issues in the Undergraduate Mathematics Preparation of School Teachers, 1, 1-13. Retrieved from www.k-12prep.math.ttu.edu

Van Es, E. (2011). A framework for learning to notice student thinking. In M. Sherin, V. Jacobs \& R. Phillip (Eds.) Mathematics teacher noticing: Seeing through teachers' eyes, (pp.134-151). New York: Routledge.

Van Es, E. A., \& Sherin, M. G. (2008). Mathematics teachers "learning to notice" in the context of a video club. Teaching and Teacher Education, 24(2), 244-276. doi: $10.1016 /$ j.tate 2006.11 .005

Wager, A. A. (2014). Noticing Children's Participation: Insights into teacher positionality toward equitable mathematics pedagogy. Journal for Research in Mathematics Education, 45(3), 312-350. doi: 10.5951/jresematheduc.45.3.0312 
Whitcomb, J., Borko, H., \& Liston, D. (2009). Growing talent. Journal of Teacher Education, 60(3), 207-212. doi: 10.1177/0022487109337280

Williams, D., \& Coles, L. (2007). Teachers' approaches to finding and using research evidence: an information literacy perspective. Educational Research, 49(2), 185206. doi:10.1080/00131880701369719

Wilson, P. H., Mojica, G. F., \& Confrey, J. (2013). Learning trajectories in teacher education: Supporting teachers' understandings of students' mathematical thinking. The Journal of Mathematical Behavior, 32(2), 103-121. doi:10.1007/s11858-014-0598-7

Yackel, E. \& Cobb, P. (1996), Sociomathematical norms, argumentation and autonomy in mathematics. Journal for Research in Mathematics Education, 27(4), 458-477. Retrieved from http://www.jstor.org/stable/749877.

Yin, R. K. (2014).Case study research: Design and methods. Beverly Hills, CA: Sage. 


\section{Appendix A}

\section{East Metro Mathematics Leadership Project Logic Model}

Exhibit 2: East Metro Mathematics Leadership Project Logic Model

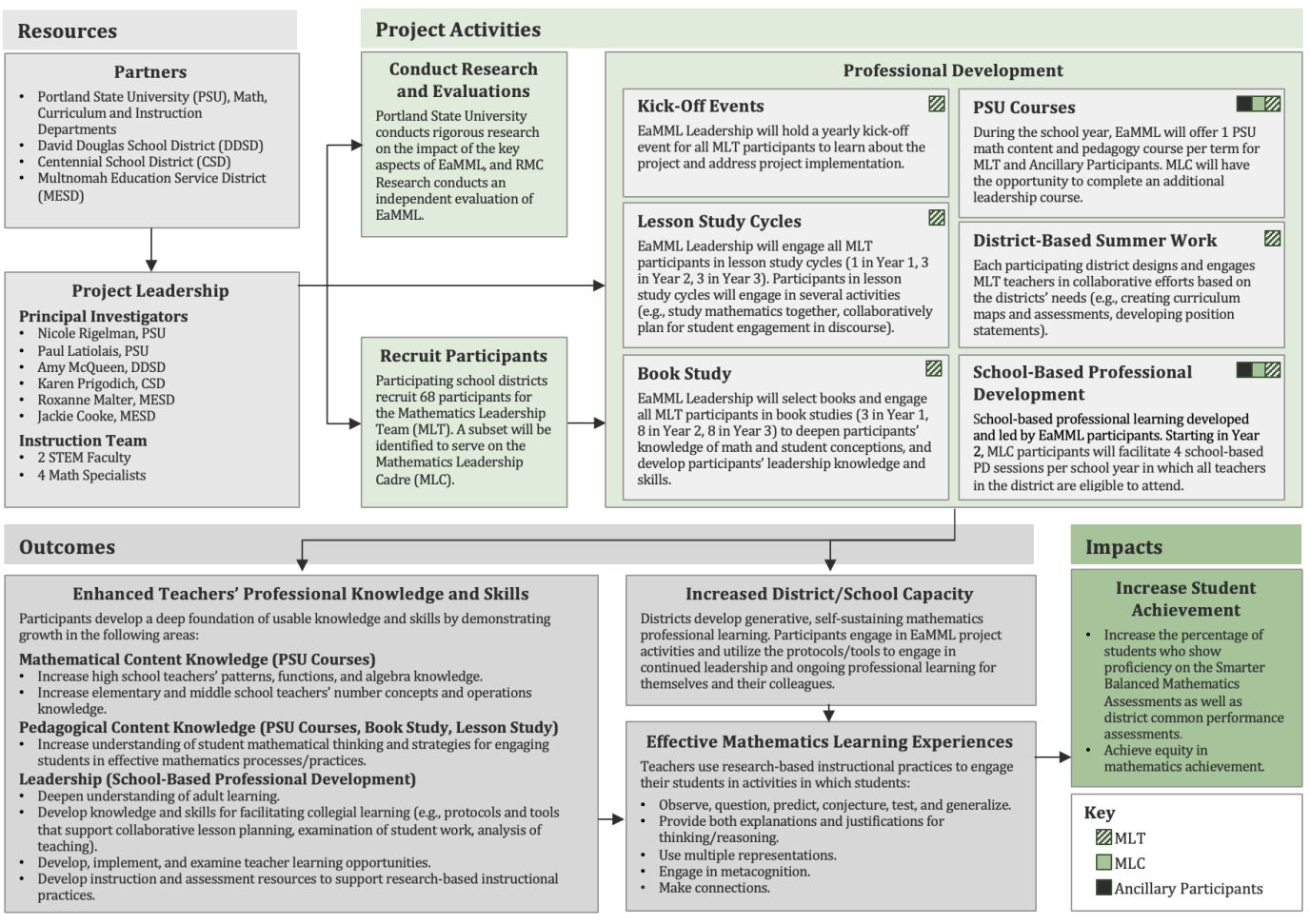




\section{Appendix B}

\section{Dissertation Recruitment Presentation}

Teachers' Learning in the Context of Students' Mathematical Thinking

A Doctoral Dissertation Study Participant Recruitment Mary Duden

\section{Mary Duden, EdD Candidate}

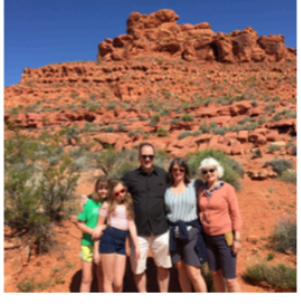

\section{Purpose of the Research}

- To research the 'so what?'.

What do teachers gain from this professional development (PD) approach?

- To include teacher voices in the process of evaluating a PD model.

- The study will be a case study with only 5-7 participants in order to allow for a broader illustration the impact of the PD on what you think, believe and enact in your mathematics instruction.

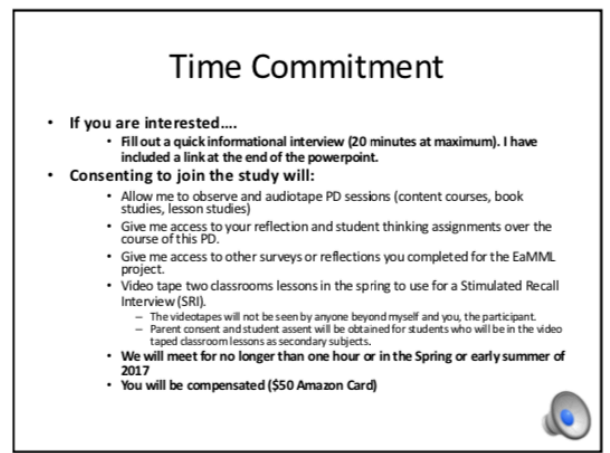




\section{Confidentiality and Security}

- Consent Form

- All transcripts will be de-identified and pseudonyms will be used.

- Audio tape and Video tape data will be stored in a

locked safe in my home office.

- Transcripts and reflections or surveys will be saved in a Google folder that is password protected and only accessible by me the researcher.

- No data that identifies you will be shared with evaluators from your school district.

\section{Risks and Benefits}

Risks...

- You may feel some discomfort.

Benefits...

- Voice is included in an evaluation of the impact of

a professional development model.

- Contribute new thoughts and ideas or confirm

existing ideas to the larger Professional

Development research field as well as the

mathematics teaching research field.

- Reflection supports growth in teaching

mathematics.

- Compensation with a \$50 Amazon card.

\section{Informed Consent}

- You have the right to say No.

- There will be no impact on your relationship with the EaMML Grant Leadership Team or your district administrators if you choose to say no.

\section{What's Next?}

- If you are interested, fill out the online Google Interview. You can connect to that interview here:https://docs.google.com/forms/d/e/1FAlpQLLfflzv2YCzi asZhGINwC2G5FeVxmAT6msek9V8mASC2Y7i8h7w/viewform

- Questions? Email me at dudenm@pdx.edu.

- Please fill out the survey. 


\section{Appendix C}

\section{Initial Recruitment Survey}
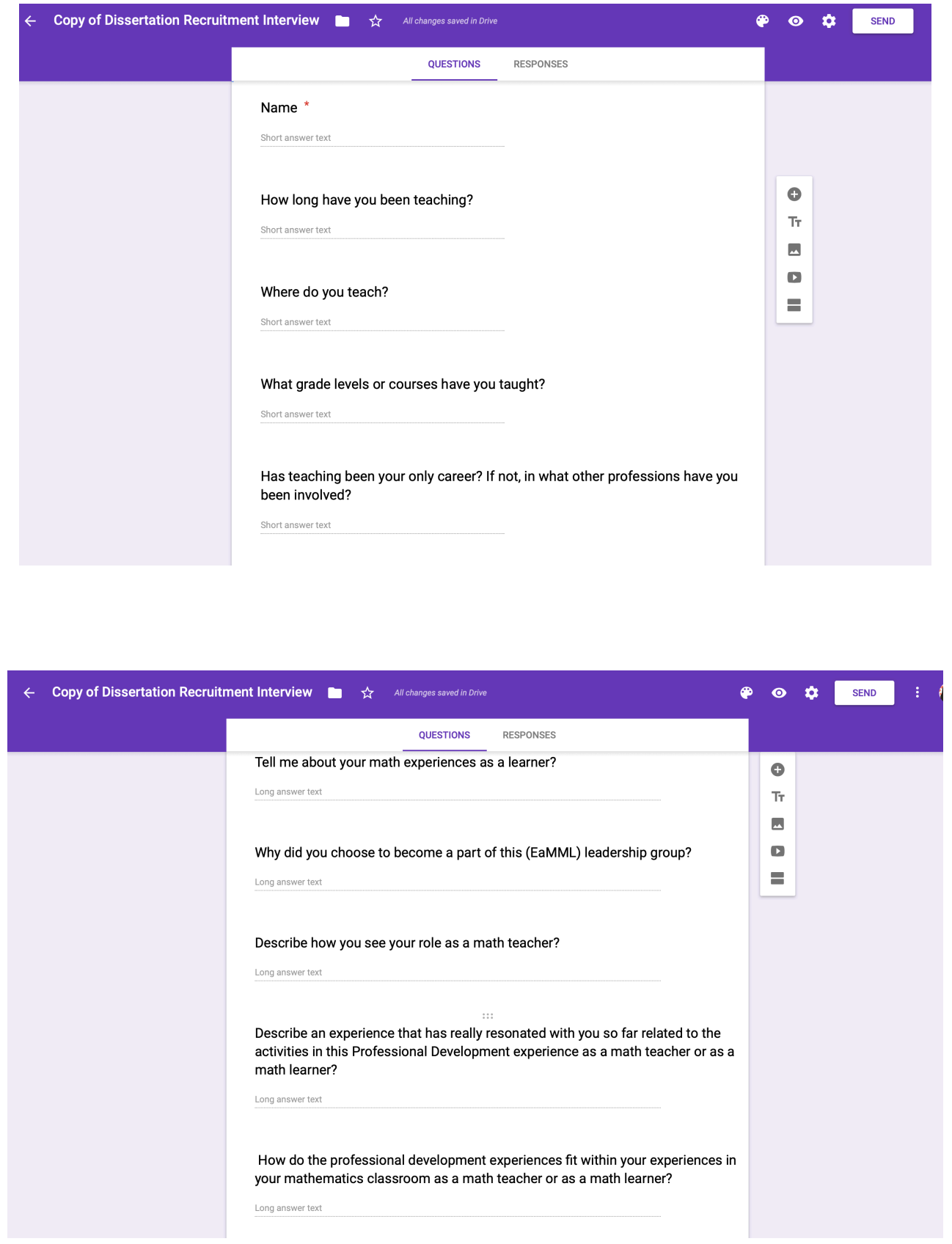

\section{Appendix D}


You are being asked to participate in a research project. Researchers are required to provide a consent form to inform you about the study, to convey that participation is voluntary, to explain risks and benefits of participation, and to empower you to make an informed decision. You should feel free to ask the researchers any questions you may have.

\section{Title: Teacher Learning in the Context of Students' Mathematical Thinking}

\section{Researcher: Mary Duden, Portland State University, dudenm@pdx.edu}

You are invited to participate in a research study about professional development (PD) for mathematics instruction. Mary Duden, an EdD candidate from Portland State University, will conduct this study. Your participation in the study is completely voluntary. Please take as much time as you need to read this invitation and decide whether you are interested in taking part in the study.

\section{PURPOSE OF RESEARCH:}

You are being asked to participate in a research study of teachers' integration of mathematical practices that center students' mathematical thinking. This study is embedded in the East Metro Mathematics Leadership (EaMML) grant a Mathematics and Science Partnership grant with the purpose of supporting increased school district capacity to "generate self-sustaining mathematics professional learning."

You have been asked to be a part of this study because you are a part of the EaMML participant group. From this study, the researcher hopes to learn the ways in which your ideas about mathematics instruction and enactment of mathematics instruction have changed due to the PD activities you are involved with as a part of the grant. This study is a qualitative case study and as such the researcher will primarily use observational techniques.

In the entire study, 5-7 people are being asked to participate in the case study research process. The total time commitment for participation in this study will be about 30 minutes for an initial demographics survey and one hour each during interviews in the spring of 2016 and 2017. All other research instruments such as classroom audio transcripts and observational tools are tools used during the PD sessions and will not require extra time from the participants.

\section{WHAT YOU WILL DO:}

In this study, you will be observed in one or more of the PD sessions related to the 
EaMML grant. This may include the math content and pedagogy courses, lesson studies, book studies or kick off events. For this case study, you will only be asked to do minimal work outside of the work required by the PD activities you are already involved. You will be asked to complete an initial demographic survey with the researcher in the winter of 2016. This survey will take no more than $\mathbf{3 0}$ minutes. In addition, you will also be asked to conduct an interview with the researcher in the spring of 2016 and 2017. Each of these interviews will be no more than 60 minutes each.

The case study research will be conducted in three phases.

Phase 1 will take place early in the winter of 2016. In this phase, the researcher will meet with project leaders from the Centennial School District and David Douglas School District to obtain consent to conduct this study with their school districts. The researcher will then propose the study to participants of the EaMML grant and recruit 5-7 participants.

Phase 2 will take place later in the winter of 2016. During this phase the observation of PD activities will be conducted.

The researcher requests access to assignments or reflections collected during PD activities in order to get a full picture of your experiences and thinking during PD activities. In addition, the researcher requests access to archived course assignments and grant documentation. Information from these documents will lend to learning about shifts in your thinking over time as a result of PD activities.

I agree to allow access to archived course assignments and grant documents collected prior to this research study.

\section{Yes No Initials}

Phase 3 will take place after in the spring of 2016 and 2017. During this phase, the researcher will conduct a Stimulated Recall Interview (SR). An SR interview is an interview technique that allows the participant to use an instance of classroom instruction as a context to reflect upon your mathematics teaching practice. In preparation for the spring SR interviews, the researcher will videotape two classroom mathematics lessons. During the mathematics lesson videotaping sessions, you are asked to carry out math lessons as you would regularly on a daily basis. You will not be asked to do any preparation outside of preparation that you regularly conduct. The researcher will obtain the proper consent documents for video in a classroom.

The subsequent interview will take place shortly after the final mathematics lesson and will last no more than an hour. 
In addition to the reflection of practice portion of the interview, the researcher will provide you with written description of researcher interpretations that have surfaced during the analysis of data from the PD activities and the interview. This will give you, as the participant, an opportunity to offer your own interpretations of the data.

In order to collect robust data, the researcher may audiotape professional development sessions and interviews. This will ensure that when your words or explanations are reported in the case study they will be reported accurately.

The tapes will be transcribed and then stored in a locked fireproof vault in the researcher's home office until August of 2020. At this point all data will be destroyed. Transcribed data will be stored online through a data coding system. As I stated above, there will be no link to participant information.

In addition, the researcher will collect videotaped data of participant classroom instruction no more than four times during the study period. Videotaped data will be used solely for reflection purposes during the spring interviews. The videotaped data will not be seen or shared by any other parties. The videotaped data will be stored in the researchers home office in a locked cabinet. The videotapes will be destroyed by August of 2020. The researcher will obtain the necessary consent documents for videotaping classroom instruction.

I agree to allow videotaping of the no more than four mathematics lessons.

Yes No Initials

I agree to allow audiotaping of the interview and PD activities.

Yes No Initials

\section{POTENTIAL BENEFITS}

Although, you will not directly benefit from your participation in this study, your participation in this study may contribute to the understanding of how PD can support teachers as they learn effective practices to support students in increasing their engagement and conceptual understanding of mathematics.

\section{POTENTIAL RISKS}

There are no anticipated risks to your involvement in this study. The researcher has no affiliation with the evaluators of your practices in the David Douglas and Centennial School District so there would be no evaluative aspects related to your reflections. In addition, the data connected to you will be coded with a pseudonym. If there is any discomfort related to questions the researcher might ask, you may ask that the question be skipped. 
5. PRIVACY AND CONFIDENTIALITY: The data for this project is being collected anonymously. Outside of the study, nobody else will be able to link data to you. In the descriptions of the case study a pseudonym will be used for detail relevant to your data.

The data for this project will be kept confidential. Transcripts, reflections and PD assignment copies will be kept on a password protected Google drive account or a locked cabinet in the researcher's home office. The data from the transcripts will be coded using an online computer data coding system. The coded data will have no personal information included that could link you to the transcripts. All conversations with you will be conducted privately, either in a location such as a coffee shop, or online using Google hangout or Skype. Observation sessions will be focused on the larger group.

Information about you will be kept confidential to the maximum extent allowable by law. The data related to larger themes that arise may accessible by the leadership team from the larger EaMML grant and the institutional review board (IRB) at Portland State University. The results of this study may be published or presented at professional meetings, but the identities of all research subjects will remain confidential and your participation will remain anonymous.

\section{YOUR RIGHTS TO PARTICIPATE OR SAY NO}

Participation in this research project is completely voluntary. You have the right to say no. You may change your mind at any time and withdraw from the case study portion of the study.

You may choose not to answer specific questions or to stop participating at any time. Choosing not to participate or withdrawing from this study will have no adverse effect on your participation in the EaMML grant. You will be told of any significant findings that develop during the course of the study that may influence your willingness to continue to participate in the research.

\section{COSTS AND COMPENSATION FOR BEING IN THE STUDY:}

There are no costs to you as a result of participating in this study. You will be compensated for your time in the study. You will receive a \$50 Amazon gift card. In addition, the researcher would like to compensate you for your time with support in your classroom.

Researcher support could take on any of the following forms:

- Make copies or prep for upcoming lessons

- Work with students that may need more support (enrichment and intervention) 
- Enact a lesson in your classroom in order to free you up to conduct other activities

- Support your work in planning a lesson

\section{CONFLICT OF INTEREST}

The researcher was involved in co-teaching the content and pedagogy courses of the EaMML grant over the past year and a half. The researcher, however, will not play a role in the facilitation of the courses moving forward. The involvement does not mean that the researcher expects you to act or say particular things. The researcher is interested in how you are interacting with your students' mathematical thinking.

11. CONTACT INFORMATION FOR QUESTIONS AND CONCERNS If you have concerns or questions about this study, such as scientific issues, how to do any part of it, or to report an injury, please contact the researcher:

Mary Duden dudenm@pdx.edu 971-404-5228 OR

Nicole Rigelman rigelman@pdx.edu 503-725-4699:sEp:

If you have questions or concerns about your role and rights as a research participant, would like to obtain information or offer input, or would like to register a complaint about this study, you may contact, anonymously if you wish, the PSU Institutional Review Board Office of Research Integrity Address: 1600 4th Ave., Market Center Building, Ste. 620 Portland, OR 97201 Phone: (503) 725-2227 or 1 (877) 480-4400.

Your signature below means that you voluntarily agree to participate in this research study.

Signature: Date: 


\title{
Appendix E
}

\author{
Parent Permission to Videotape
}

Teacher Learning in the Context of Students' Mathematical Thinking

Your child is invited to participate in a research study conducted by Mary Duden from Portland State University, Graduate School of Education. The researcher hopes to learn what teachers are learning about their students' mathematical thinking through professional development (PD) and how it impacts their mathematics instruction. This research study is conducted in partial fulfillment of a doctoral degree in Curriculum and Instruction through Portland State University. Your child will be involved only minimally in the study as the students in the mathematics lessons that will be video-taped for the teacher to watch later.

If you decide to let your child participate, he/she will be videotaped twice during classroom mathematics lessons in the spring. These videos will only be shared with the classroom teacher. They will not be shared publicly. While participating in this study, it is possible your child may experience the discomfort of being videotaped. The researcher will minimize the discomfort, by positioning the videotape on the larger class rather than individual students. Your child may not receive any direct benefit from taking part in this study, but the study may help to increase knowledge of mathematics teaching, which may help others in the future.

Any information that is obtained in connection with this study and that can be linked to your child or identify your child will be kept confidential. Any writing included in the dissertation paper or presentations about the classroom episodes that include your child will be kept confidential. Pseudonyms will be used in any written episodes describing what students' say and do in the lesson. The transcripts of the classroom lessons will be kept confidential and will be stored in a password protected Google drive folder.

Your child's participation is voluntary. He/she does not have to take part in this study, and it will not affect his/her relationship with [name of the teacher]. You may also withdraw your permission for your child to participate from this study at any time without affecting his/her relationship with [name of the teacher]. Likewise, your child may withdraw his/her assent at any time without affecting his/her [relationship] with [name of the teacher].

If you have questions or concerns about your child's participation in this study, contact Mary Duden at 1666 SE Linn St. Portland, Oregon 97202, 971-404-5228. If you have concerns about your child's rights as a research subject, please contact the PSU Office of Research Integrity, Market Center Building Ste. 620, Portland State University, (503) 725-2227. 
Your signature indicates that you have read and understand the above information and agree to let your child take part in this study. The researcher should provide you with a copy of this form for your own records.

Participant Signature

Participant Printed Name
Date

$\overline{\text { Date }}$

Investigator Printed Name

You will receive a copy of this consent form for your records. 


\section{Appendix F}

\section{Portfolio Reflection Assignment \\ DMI: Exploring Measurement Concepts (M123)}

\section{Homework: Final Portfolio Review}

As the Measuring Space in One, Two, and Three Dimensions seminar ends, look back over your portfolio. It should contain your writing for each seminar assignment plus the facilitator's responses to your work. Examine this collection and then write about each of the following:

Pick one area of math you worked on in this seminar. Explain what you learned.

1. Pick one issue about student learning that you were thinking about during the seminar. Explain what you learned.

2. Likely there are issues, mathematical or pedagogical, that came up for you during the seminar that still puzzle you. Pick one issue that is still "alive" for you. Explain what it is and describe your current thinking about it.

3. Choose two of the standards for mathematics practice and explain what you learned about them over the course of the seminar.

4. What worked for you in this seminar?

5. What would you suggest being changed about the seminar? 


\title{
Appendix G
}

\author{
]Example of Student Thinking Assignment
}

\section{Sixth Homework}

\section{Reading assignment: Casebook chapter 6}

Read chapter 6 in the casebook for Measuring Space in One, Two, and Three Dimensions, including both the introductory text and cases 23 to 26 . Also, go back to chapter 1 and reread Beverly's case 5 ("Which box is bigger? Which box holds more?"), which also relates to volume of boxes.

\section{Portfolio assignment: Student thinking on volume}

Pose a question related to volume to your students. You might give them a task directly from a case or adapt one of those tasks. In your report, include your question, how your students responded to it, and what you make of your students' responses. Reflect on any of the mathematical practice standards you noted. Please provide specific examples of what your students said and did. Include actual quotations or samples of their written work. Examining the work of a few students in-depth is more helpful than including the responses of every student. Conclude with your analysis of their work or thinking.

\section{Math assignment: Rectangular solids}

Find some cubes and build a rectangular solid. Now build a second solid that doubles all the edges of the first. What happens to the area of each face? What happens to the surface area of the solid? What happens to the volume? What do you think would happen if you tripled the length of each edge?

Bring your questions and ideas about this exercise to the next class. 


\section{Appendix H}

\section{Focus Questions for Written Episodes of Students' Mathematical Thinking}

\section{Focus Questions: Chapter 1}

1. In some of the cases, we see children looking at a two-dimensional shape, such as a footprint or a rug surface, and trying to answer the question, "How big is it?" When we examine their work, we see that the individual children are actually measuring different things about the two-dimensional object. Similar issues arise when the children talk about the size of a three-dimensional object, such as a box.

a. Consider a 2-D object. What can we measure? Identify different measurable aspects of 2-D objects.

b. Consider a 3-D object. What can we measure? Identify different measurable aspects of 3-D objects.

2. In Barbara's case 2, line 100, she asks her students, "What does it mean to measure your foot?" Through their actions, several students offer their ideas. Looking at Ellen's work and her explanation, what does it mean to Ellen to measure her foot? What does it mean to Maletu? What does it mean to Rocky?

3. In Isabelle's case 3, what is the same and what is different about Keith's, Fiona's, and Lauren's suggestions for measuring the rug?

4. In Beverly's case 5, line 485, Melinda declares that the two boxes hold the same amount. What is right about Melinda's idea? What is not right?

5. Look over your work on questions 1-4. How does the work of these students expand and illustrate your understanding of practices 3,5 , and 7 ?

\section{Appendix I}




\section{Example of MIL Mathematics Activity}

\section{Math assignment: Crazy Cakes*}

Divide each of the "strange cakes" below into two parts with equal area. The two parts need not be congruent.
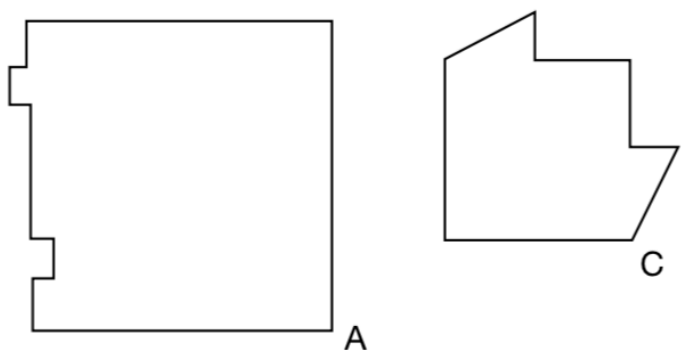

A
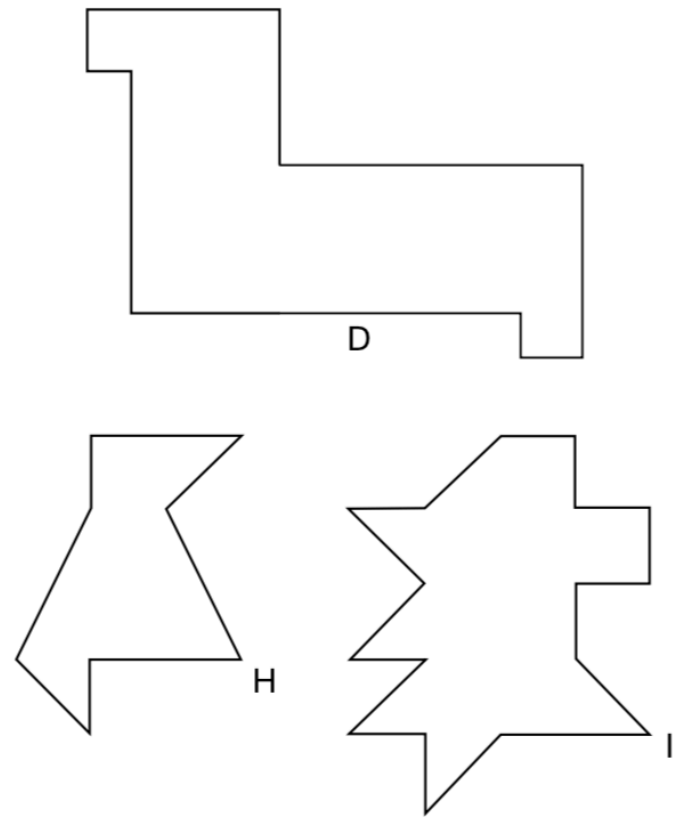

*Lettering is discontinuous because these are just five of the nine figures (A through I) that appear on the "Crazy Cakes for Two" student sheet from C. Tierney, M. Ogonowski, A. Rubin, and S.J. Russell, Different Shapes, Equal Pieces, a grade 4 unit of Investigations in Number, Data, and Space (Glenview, Ill: Pearson Education, 2017). Used by permission of Pearson Education, Inc. All rights reserved. 


\section{Appendix J}

Case Study Participant Interview

Opening Question: Tell me about how the lessons you chose went? How did you feel about them?

\section{Part I: Stimulated Recall Interview Prompts}

(Choose from these prompts)

- What decision were you facing?

- What were you thinking? What did you notice?

- What did you learn about your students' thinking?

- If you made a decision, why did you make that decision?

\section{Part II: Targeted Questions}

1. How is your teaching the same or different from when you started the EaMML project?

2. What are some activities that had the greatest impact in your learning?

Follow Up Question: Would the PD have the same impact if the coursework involved didn't have the student thinking portion?

3. What further support do you think is needed to sustain this work for the district?

4. What further support do you need? 


\section{Appendix K}

\section{Instructional Quality Assessment (IQA) Classroom Observation Tool (Boston \&Wolf, 2014)}

\begin{tabular}{c|}
\hline $\begin{array}{c}\text { Instructional Quality Assessment } \\
\text { Classroom Observation Tool }\end{array}$ \\
\hline
\end{tabular}

COVER PAGE - COMPLETE FOR EACH LESSON AND ATTACH TO FIELD NOTES, COPY OF INSTRUCTIONAL TASK, AND SCORE SHEET

Background Information

Date of observation:

Start Time:

District:

Grade:
Observer:

End Time:

School:

Day 1 or Day 2

Classroom Context

Total number of students in the classroom:

Boys Girls

Sketch of seating arrangement(s):

Mathematical Topic of the Lesson:

Field Notes (attach).

IQA Mathematics Lesson Observation Rubrics and Checklists, Melissa Boston $\mathbb{C} 2012$

For permission to use, contact Melissa Boston, bostonm@duq.edu, 412-396-6109 


\section{Part 1: Documents Needed During the Observation}

\section{Accountable Talk Function Reference List}

Most of these moves will be made by the teacher, but in some cases, students might make them. In recording the actual moves, note $T$ for Teacher move, $S$ for Student move.

\section{Accountability to the Learning Community}

- Keeping everyone together so they can follow complex thinking "What did she just say?"

"Can you repeat what Juan said in your own words?"

- Getting students to relate to one another's ideas "Jay just said....and Susan, you're saying..."

"Who wants to add on to what Ana just said?"

"Who agrees and who disagrees with what Ana just said?"

"How does what you're saying relate to what Juan just said?"

"I agree with Sue, but I disagree with you, because..."

"I agree with Fulano because..."

- Revoicing/Recapping

"Can you repeat what Juan said in your own words?"

"So what I'm hearing you say is..."

- Marking

"That's a really important point."

"Jenna said something really interesting. We need to think about that."

\section{Accountability to Knowledge and Rigorous Thinking}

- Pressing for accuracy

"Where could we find more information about that?"

"Are we sure about that? How can we know for sure?"

"What evidence is there?"

"How do you know?"

"How did you get 50 ?"

- Building on prior knowledge / recalling prior knowledge

"How does this connect with what we did last week?"

"Do you remember when we talked about slope?"

- Pressing for reasoning

"What made you say that?"

"Why do you think that?"

"Can you explain that?"

"Why do you disagree?"

"Say more about that."

"What do you mean?"

IQA Mathematics Lesson Observation Rubrics and Checklists, Melissa Boston (C2012

For permission to use, contact Melissa Boston, bostonm@duq.edu, 412-396-6109 
Academic Rigor 2: Implementation Lesson Checklist:

\begin{tabular}{|c|c|c|}
\hline$\uparrow$ & $\begin{array}{l}\text { The Lesson provided opportunities } \\
\text { for students to engage in high-level } \\
\text { thinking: }\end{array}$ & $\begin{array}{l}\text { The Lesson DID NOT provide opportunities } \\
\text { for students to engage in } \\
\text { high-level thinking: }\end{array}$ \\
\hline & $\begin{array}{l}\text { Students } \\
\text { engaged with the task in a way that } \\
\text { addressed the teacher's goals for high-level } \\
\text { thinking and reasoning. } \\
\circ \text { communicated mathematically with peers. } \\
\text { had appropriate prior knowledge to engage } \\
\text { with the task. } \\
\text { had opportunities to serve as mathematical } \\
\text { authority in classroom } \\
\text { had access to resources that supported their } \\
\text { engagement with the task. } \\
\text { Teacher } \\
\text { supported students to engage with the high- } \\
\text { level demands of the task while } \\
\text { maintaining the challenge of the task } \\
\text { provided sufficient time to grapple with the } \\
\text { demanding aspects of the task and for } \\
\text { expanded thinking and reasoning. } \\
\text { held students accountable for high-level } \\
\text { products and processes. } \\
\text { provided consistent presses for explanation } \\
\text { and meaning. } \\
\text { provided students with sufficient modeling } \\
\text { of high-level performance on the task. } \\
\text { provided encouragement for students to } \\
\text { make conceptual connections. }\end{array}$ & $\begin{array}{l}\text { The task } \\
\text { expectations were not clear enough to promote } \\
\text { students' engagement with the high-level demands } \\
\text { of the task. } \\
\text { was not complex enough to sustain student } \\
\text { engagement in high-level thinking. } \\
\text { was too complex to sustain student engagement in } \\
\text { high-level thinking (i.e., students did not have the } \\
\text { prior knowledge necessary to engage with the task at } \\
\text { a high level). } \\
\text { The teacher } \\
\text { Allowed classroom management problems to } \\
\text { interfere with students' opportunities to engage in } \\
\text { high-level thinking. } \\
\text { provided a set procedure for solving the task } \\
\text { shifted the focus to procedural aspects of the task or } \\
\text { on correctness of the answer rather than on meaning } \\
\text { and understanding. } \\
\text { Gave feedback, modeling, or examples that were too } \\
\text { directive or did not leave any complex thinking for } \\
\text { the student. } \\
\text { Did not press students or hold them accountable for } \\
\text { high-level products and processes or for explanations } \\
\text { and meaning. } \\
\text { Did not give students enough time to deeply engage } \\
\text { with the task or to complete the task to the extent } \\
\text { that was expected. } \\
\text { Did not provide students access to resources } \\
\text { necessary to engage with the task at a high level. }\end{array}$ \\
\hline \multicolumn{3}{|c|}{$\begin{array}{l}\text { The Discussion provides opportunities for students to engage with the high-level demands of the task. } \\
\text { Students: }\end{array}$} \\
\hline \multicolumn{3}{|c|}{$\begin{array}{l}\text { use multiple strategies and make explicit connections or comparisons between these strategies, or explain why } \\
\text { they choose one strategy over another. } \\
\text { use or discuss multiple representations and make connections between different representations or between the } \\
\text { representation and their strategy, underlying mathematical ideas, and/or the context of the problem } \\
\text { identify patterns or make conjectures, predictions, or estimates that are well grounded in underlying } \\
\text { mathematical concepts or evidence. } \\
\text { generate evidence to test their conjectures. Students use this evidence to generalize mathematical relationships, } \\
\text { properties, formulas, or procedures. }\end{array}$} \\
\hline
\end{tabular}

IQA Mathematics Lesson Observation Rubrics and Checklists, Melissa Boston (C2012

For permission to use, contact Melissa Boston, bostonm@duq.edu, 412-396-6109 


\begin{tabular}{|c|c|c|}
\hline Question Type & Description & Examples \\
\hline Probing & $\begin{array}{l}\text { - Clarifies student thinking } \\
\text { Enables students to } \\
\text { elaborate their own } \\
\text { thinking for their own } \\
\text { benefit and for the class }\end{array}$ & $\begin{array}{l}\text { - "How did you get that answer?" } \\
\text { - "Why did you use that scale for your graph?" } \\
\text { - "Why did you use that formula to solve the } \\
\text { - " "Explem?" }\end{array}$ \\
\hline $\begin{array}{l}\text { Exploring } \\
\text { mathematical } \\
\text { meanings and } \\
\text { relationships }\end{array}$ & $\begin{array}{l}\text { Points to underlying } \\
\text { mathematical } \\
\text { relationships and } \\
\text { meanings } \\
\text { - Makes links between } \\
\text { mathematical ideas }\end{array}$ & $\begin{array}{l}\text { - "What does 'n' represent in terms of the } \\
\text { - "How does the 'x' in your table related to the ' } x \text { ' } \\
\text { - in your graph?" } \\
\text { "How would your expression work for any } \\
\text { "function?" } \\
\text { "What is staying the same in your equation? Why } \\
\text { is it staying the same?" }\end{array}$ \\
\hline $\begin{array}{l}\text { Generating } \\
\text { discussion }\end{array}$ & $\begin{array}{l}\text { Enables other members } \\
\text { of class to contribute and } \\
\text { comment on ideas under } \\
\text { discussion }\end{array}$ & $\begin{array}{l}\text { - "Explain to me what John was saying." } \\
\text { - "What else did you notice about the graph of the } \\
\text { - "Wabola?" } \\
\text { agree?" }\end{array}$ \\
\hline $\begin{array}{l}\text { Procedural or } \\
\text { factual }\end{array}$ & $\begin{array}{l}\text { Elicits a mathematical } \\
\text { fact or procedure } \\
\text { - Requires a yes/no or } \\
\text { single response answer. } \\
\text { - Requires the recall of a } \\
\text { memorized fact or } \\
\text { procedure }\end{array}$ & $\begin{array}{l}\text { - "What is the square root of } 4 \text { ?" } \\
\text { - "What is a co-efficient?" } \\
\text { - "What is } 3 \times 5 \text { ? } \\
\text { - "Does this picture show } 1 / 2 \text { or } 1 / 4 \text { ?" }\end{array}$ \\
\hline $\begin{array}{l}\text { Other } \\
\text { mathematical }\end{array}$ & $\begin{array}{l}\text { Related to teaching and } \\
\text { learning mathematics but } \\
\text { do not request } \\
\text { mathematical procedures } \\
\text { or factual knowledge, } \\
\text { probe students' thinking, } \\
\text { press for explanations, or } \\
\text { generate discussion. }\end{array}$ & $\begin{array}{l}\text { - "How could you use this in the real world?" } \\
\text { - 'Which problem was the most difficult?" }\end{array}$ \\
\hline $\begin{array}{l}\text { Non- } \\
\text { mathematical }\end{array}$ & $\begin{array}{l}\text { - Does not relate to } \\
\text { teaching and learning } \\
\text { mathematics }\end{array}$ & $\begin{array}{l}\text { - "Why didn't you use graph paper?" } \\
\text { - "Who has ever seen a caterpillar?" }\end{array}$ \\
\hline
\end{tabular}

Adapted from Boaler \& Humphries (2005).

IQA Mathematics Lesson Observation Rubrics and Checklists, Melissa Boston (C2012

For permission to use, contact Melissa Boston, bostonm@duq.edu, 412-396-6109 
Part 2: IQA Mathematics Rubrics

\section{Accountable Talk}

Consider talk from the whole-group discussion only.

I. How effectively did the lesson-talk build Accountability to the Learning Community?

Participation in the Learning Community

Was there widespread participation in teacher-facilitated discussion?

\begin{tabular}{|c|l|}
\hline \multicolumn{2}{|l|}{ Rubric 1: Participation } \\
\hline $\mathbf{4}$ & Over $75 \%$ of the students participated throughout the discussion. \\
\hline $\mathbf{3}$ & $50-75 \%$ of the students participated in the discussion. \\
\hline $\mathbf{2}$ & $25-50 \%$ of the students participated in the discussion. \\
\hline $\mathbf{1}$ & Less than $25 \%$ of the students participated in the discussion. \\
\hline $\mathbf{0}$ & None of the students participated in the discussion. \\
\hline N/A & Reason: \\
\hline
\end{tabular}

Number of students in class

Number of students who participated

IQA Mathematics Lesson Observation Rubrics and Checklists, Melissa Boston (C2012 
Teacher's Linking Contributions

Does the teacher support students in connecting ideas and positions to build coherence in the discussion?

\begin{tabular}{|c|l|}
\hline \multicolumn{2}{|l|}{ Rubric 2: Teacher's Linking } \\
\hline $\mathbf{4}$ & $\begin{array}{l}\text { The teacher consistently (at least 3 times) connects (or provides opportunities for students to connect) } \\
\text { speakers' contributions to each other and shows (or provides opportunities for students to show) how } \\
\text { ideas/positions shared during the discussion relate to each other. }\end{array}$ \\
\hline $\mathbf{3}$ & $\begin{array}{l}\text { At least twice during the lesson the teacher connects (or provides opportunities for students to connect) } \\
\text { speakers' contributions to each other and shows (or provides opportunities for students to show) how } \\
\text { ideas/positions relate to each other. }\end{array}$ \\
\hline $\mathbf{2}$ & $\begin{array}{l}\text { At one or more points during the discussion, the teacher links speakers' contributions to each other, but } \\
\text { does not show how ideas/positions relate to each other (weak links). No follow-up questions are asked } \\
\text { ORters contributions } \\
\text { OR only one strong effort is made to connect speakers' contributions to each other (1 strong link). }\end{array}$ \\
\hline $\mathbf{1}$ & Teacher does not make any effort to link or revoice speakers' contributions. \\
\hline $\mathbf{0}$ & No class discussion OR Class discussion was not related to mathematics. \\
\hline N/A & Reason: \\
\hline
\end{tabular}

Students' Linking Contributions Do student's contributions link to and build on each other?

\begin{tabular}{|c|c|}
\hline \multicolumn{2}{|c|}{ Rubric 3: Students' Linking } \\
\hline 4 & $\begin{array}{l}\text { The students consistently connect their contributions to each other and show how ideas/positions shared } \\
\text { during the discussion relate to each other. (e.g. I agree with Jay because...") }\end{array}$ \\
\hline 3 & $\begin{array}{l}\text { At least twice during the lesson the students to connect their contributions to each other and show how } \\
\text { ideas/positions shared during the discussion relate to each other. (e.g. I agree with Jay because...") }\end{array}$ \\
\hline 2 & $\begin{array}{l}\text { At one or more points during the discussion, the students link students' contributions to each other, but } \\
\text { do not show how ideas/positions relate to each other. (e.g., "I disagree with Ana.") } \\
\text { OR only one strong effort is made to connect their contributions with each other. }\end{array}$ \\
\hline 1 & Students do not make any effort to link or revoice students' contributions. \\
\hline $\mathbf{0}$ & No class discussion OR Class discussion was not related to mathematics. \\
\hline N/A & Reason: \\
\hline
\end{tabular}

IQA Mathematics Lesson Observation Rubrics and Checklists, Melissa Boston (C2012

For permission to use, contact Melissa Boston, bostonm@duq.edu, 412-396-6109 
Teacher's Linking Contributions

Does the teacher support students in connecting ideas and positions to build coherence in the discussion?

\begin{tabular}{|c|l|}
\hline \multicolumn{2}{|l|}{ Rubric 2: Teacher's Linking } \\
\hline $\mathbf{4}$ & $\begin{array}{l}\text { The teacher consistently (at least 3 times) connects (or provides opportunities for students to connect) } \\
\text { speakers' contributions to each other and shows (or provides opportunities for students to show) how } \\
\text { ideas/positions shared during the discussion relate to each other. }\end{array}$ \\
\hline $\mathbf{3}$ & $\begin{array}{l}\text { At least twice during the lesson the teacher connects (or provides opportunities for students to connect) } \\
\text { speakers' contributions to each other and shows (or provides opportunities for students to show) how } \\
\text { ideas/positions relate to each other. }\end{array}$ \\
\hline $\mathbf{2}$ & $\begin{array}{l}\text { At one or more points during the discussion, the teacher links speakers' contributions to each other, but } \\
\text { does not show how ideas/positions relate to each other (weak links). No follow-up questions are asked } \\
\text { ORters contributions } \\
\text { OR only one strong effort is made to connect speakers' contributions to each other (1 strong link). }\end{array}$ \\
\hline $\mathbf{1}$ & Teacher does not make any effort to link or revoice speakers' contributions. \\
\hline $\mathbf{0}$ & No class discussion OR Class discussion was not related to mathematics. \\
\hline N/A & Reason: \\
\hline
\end{tabular}

Students' Linking Contributions Do student's contributions link to and build on each other?

\begin{tabular}{|c|c|}
\hline \multicolumn{2}{|c|}{ Rubric 3: Students' Linking } \\
\hline 4 & $\begin{array}{l}\text { The students consistently connect their contributions to each other and show how ideas/positions shared } \\
\text { during the discussion relate to each other. (e.g. I agree with Jay because...") }\end{array}$ \\
\hline 3 & $\begin{array}{l}\text { At least twice during the lesson the students to connect their contributions to each other and show how } \\
\text { ideas/positions shared during the discussion relate to each other. (e.g. I agree with Jay because...") }\end{array}$ \\
\hline 2 & $\begin{array}{l}\text { At one or more points during the discussion, the students link students' contributions to each other, but } \\
\text { do not show how ideas/positions relate to each other. (e.g., "I disagree with Ana.") } \\
\text { OR only one strong effort is made to connect their contributions with each other. }\end{array}$ \\
\hline 1 & Students do not make any effort to link or revoice students' contributions. \\
\hline $\mathbf{0}$ & No class discussion OR Class discussion was not related to mathematics. \\
\hline N/A & Reason: \\
\hline
\end{tabular}

IQA Mathematics Lesson Observation Rubrics and Checklists, Melissa Boston (C2012

For permission to use, contact Melissa Boston, bostonm@duq.edu, 412-396-6109 
II. How effectively did the lesson-talk build Accountability to Knowledge and Rigorous Thinking?

Asking: Were students pressed to support their contributions with evidence and/or reasoning?

\begin{tabular}{|c|l|}
\hline \multicolumn{2}{|l|}{ Rubric 4: Asking (Teachers' Press) } \\
\hline $\mathbf{4}$ & $\begin{array}{l}\text { The teacher consistently (almost always) asks students to provide evidence for their contributions (i.e., } \\
\text { press for conceptual explanations) or to explain their reasoning. (There are few, if any instances of } \\
\text { missed press, where the teacher needed to press and did not.) }\end{array}$ \\
\hline $\mathbf{3}$ & $\begin{array}{l}\text { Once or twice during the lesson the teacher asks students to provide evidence for their contributions } \\
\text { (i.e., press for conceptual explanations) or to explain their reasoning. (The teacher sometimes presses } \\
\text { for explanations, but there are instances of missed press.) }\end{array}$ \\
\hline $\mathbf{2}$ & $\begin{array}{l}\text { Most of the press is for computational or procedural explanations or memorized knowledge } \\
\text { OR There are one or more superficial, trivial efforts, or formulaic efforts to ask students to provide } \\
\text { evidence for their contributions or to explain their reasoning (i.e., asking everyone, "How did you get } \\
\text { that?"). }\end{array}$ \\
\hline $\mathbf{1}$ & $\begin{array}{l}\text { There are no efforts to ask students to provide evidence for their contributions, AND } \\
\text { there are no efforts to ask students to explain their thinking. }\end{array}$ \\
\hline $\mathbf{0}$ & Class discussion was not related to mathematics OR No class discussion \\
\hline N/A & Reason: \\
\hline
\end{tabular}

Providing: Did students support their contributions with evidence and/or reasoning? (This evidence must be appropriate to the content area-i.e., evidence from the text; citing an example, referring to prior classroom experience.)

\begin{tabular}{|c|l|}
\hline \multicolumn{2}{|c|}{ Rubric 5: Providing (Students' Responses) } \\
\hline $\mathbf{4}$ & $\begin{array}{l}\text { Students consistently provide evidence for their claims, OR students explain their thinking using } \\
\text { reasoning in ways appropriate to the discipline (i.e. conceptual explanations). }\end{array}$ \\
\hline $\mathbf{3}$ & $\begin{array}{l}\text { Once or twice during the lesson students provide evidence for their claims, OR students explain their } \\
\text { thinking, using reasoning in ways appropriate to the discipline (i.e. conceptual explanations). }\end{array}$ \\
\hline $\mathbf{2}$ & $\begin{array}{l}\text { Students provide explanations that are computational, procedural or memorized knowledge, } \\
\text { OR What little evidence or reasoning students provide is offered to back up claims is inaccurate, } \\
\text { incomplete, or vague. }\end{array}$ \\
\hline $\mathbf{1}$ & Speakers do not back up their claims, OR do not explain the reasoning behind their claims. \\
\hline $\mathbf{0}$ & Class discussion was not related to mathematics OR No class discussion \\
\hline N/A & Reason: \\
\hline
\end{tabular}

IQA Mathematics Lesson Observation Rubrics and Checklists, Melissa Boston (C2012 


\section{Academic Rigor}

\section{RUBRIC 1: Potential of the Task}

Did the task have potential to engage students in rigorous thinking about challenging content?

\begin{tabular}{|c|c|}
\hline 4 & $\begin{array}{l}\text { The task has the potential to engage students in exploring and understanding the nature of mathematical } \\
\text { concepts, procedures, and/or relationships, such as: } \\
\text { - Doing mathematics: using complex and non-algorithmic thinking (i.e., there is not a predictable, well-rehearsed } \\
\text { approach or pathway explicitly suggested by the task, task instructions, or a worked-out example); OR } \\
\text { - Procedures with connections: applying a broad general procedure that remains closely connected to mathematical } \\
\text { concepts. } \\
\text { The task must explicitly prompt for evidence of students' reasoning and understanding. } \\
\text { For example, the task MAY require students to: } \\
\text { - solve a genuine, challenging problem for which students' reasoning is evident in their work on the task; } \\
\text { - develop an explanation for why formulas or procedures work; } \\
\text { - identify patterns and form and justify generalizations based on these patterns; } \\
\text { - make conjectures and support conclusions with mathematical evidence; } \\
\text { - make explicit connections between representations, strategies, or mathematical concepts and procedures. } \\
\text { - follow a prescribed procedure in order to explain/illustrate a mathematical concept, process, or relationship. }\end{array}$ \\
\hline 3 & $\begin{array}{l}\text { The task has the potential to engage students in complex thinking or in creating meaning for mathematical } \\
\text { concepts, procedures, and/or relationships. However, the task does not warrant a " } 4 \text { " because: } \\
\text { - the task does not explicitly prompt for evidence of students' reasoning and understanding. } \\
\text { - students may be asked to engage in doing mathematics or procedures with connections, but the underlying } \\
\text { mathematics in the task is not appropriate for the specific group of students (i.e., too easy or too hard to } \\
\text { promote engagement with high-level cognitive demands); } \\
\text { - } \text { students may need to identify patterns but are not pressed for generalizations or justification; } \\
\text { - students may be asked to use multiple strategies or representations but the task does not explicitly prompt } \\
\text { students to develop connections between them; } \\
\text { students may be asked to make conjectures but are not asked to provide mathematical evidence or explanations } \\
\text { to support conclusions }\end{array}$ \\
\hline 2 & $\begin{array}{l}\text { The potential of the task is limited to engaging students in using a procedure that is either specifically called for or its } \\
\text { use is evident based on prior instruction, experience, or placement of the task. There is little ambiguity about what } \\
\text { needs to be done and how to do it. The task does not require students to make connections to the concepts or } \\
\text { meaning underlying the procedure being used. Focus of the task appears to be on producing correct answers } \\
\text { rather than developing mathematical understanding (e.g., applying a specific problem solving strategy, } \\
\text { practicing a computational algorithm). } \\
\text { OR There is evidence that the mathematical content of the task is at least } 2 \text { grade-levels below the grade of the } \\
\text { students in the class. }\end{array}$ \\
\hline 1 & $\begin{array}{l}\text { The potential of the task is limited to engaging students in memorizing or reproducing facts, rules, formulae, } \\
\text { or definitions. The task does not require students to make connections to the concepts or meaning that underlie } \\
\text { the facts, rules, formulae, or definitions being memorized or reproduced. }\end{array}$ \\
\hline $\mathbf{0}$ & The task requires no mathematical activity. \\
\hline $\mathbf{N} / \mathbf{A}$ & Students did not engage in a task. \\
\hline
\end{tabular}

\section{ATTACH OR DESCRIBE THE TASK.}

IQA Mathematics Lesson Observation Rubrics and Checklists, Melissa Boston (C2012

For permission to use, contact Melissa Boston, bostonm@duq.edu, 412-396-6109 
RUBRIC 2: Implementation of the Task

At what level did the teacher guide students to engage with the task in implementation?

\begin{tabular}{|c|c|}
\hline 4 & $\begin{array}{l}\text { Students engaged in exploring and understanding the nature of mathematical concepts, procedures, and/or } \\
\text { relationships, such as: } \\
\text { - Doing mathematics: using complex and non-algorithmic thinking (i.e., there is not a predictable, well-rehearsed } \\
\text { approach or pathway explicitly suggested by the task, task instructions, or a worked-out example); OR } \\
\text { - Procedures with connections: applying a broad general procedure that remains closely connected to mathematical } \\
\text { concepts. } \\
\text { There is explicit evidence of students' reasoning and understanding. } \\
\text { For example, students may have: } \\
\text { - solved a genuine, challenging problem for which students' reasoning is evident in their work on the task; } \\
\text { - developed an explanation for why formulas or procedures work; } \\
\text { - identified patterns, formed and justified generalizations based on these patterns; } \\
\text { - made conjectures and supported conclusions with mathematical evidence; } \\
\text { - made explicit connections between representations, strategies, or mathematical concepts and procedures. } \\
\text { - followed a prescribed procedure in order to explain/illustrate a mathematical concept, process, or relationship. }\end{array}$ \\
\hline 3 & $\begin{array}{l}\text { Students engaged in complex thinking or in creating meaning for mathematical concepts, procedures, and/or } \\
\text { relationships. However, the implementation does not warrant a "4" because: } \\
\text { - there is no explicit evidence of students' reasoning and understanding. } \\
\text { - } \quad \text { students engaged in doing mathematics or procedures with connections, but the underlying mathematics in the } \\
\text { task was not appropriate for the specific group of students (i.e., too easy or too hard to sustain engagement } \\
\text { with high-level cognitive demands); } \\
\text { - } \quad \text { students identified patterns but did not make generalizations; } \\
\text { - } \text { students used multiple strategies or representations but connections between different } \\
\text { - } \text { strategies/representations were not explicitly evident; } \\
\text { students made conjectures but did not provide mathematical evidence or explanations to support conclusions }\end{array}$ \\
\hline 2 & $\begin{array}{l}\text { Students engaged in using a procedure that was either specifically called for or its use was evident based on prior } \\
\text { instruction, experience, or placement of the task. There was little ambiguity about what needed to be done and } \\
\text { how to do it. Students did not make connections to the concepts or meaning underlying the procedure being used. } \\
\text { Focus of the implementation appears to be on producing correct answers rather than developing } \\
\text { mathematical understanding (e.g., applying a specific problem solving strategy, practicing a computational } \\
\text { algorithm). } \\
\text { OR There is evidence that the mathematical content of the task is at least } 2 \text { grade-levels below the grade of the } \\
\text { students in the class. }\end{array}$ \\
\hline 1 & $\begin{array}{l}\text { Students engage in memorizing or reproducing facts, rules, formulae, or definitions. Students do not make } \\
\text { connections to the concepts or meaning that underlie the facts, rules, formulae, or definitions being } \\
\text { memorized or reproduced. }\end{array}$ \\
\hline 0 & The students did not engage in mathematical activity. \\
\hline $\mathbf{N} / \mathbf{A}$ & The students did not engage with a mathematical task. \\
\hline
\end{tabular}

IQA Mathematics Lesson Observation Rubrics and Checklists, Melissa Boston $\subset 2012$

For permission to use, contact Melissa Boston, bostonm@duq.edu, 412-396-6109 


\section{RUBRIC 3: Student Discussion Following Task}

To what extent did students show their work and explain their thinking about the important mathematical content?

\begin{tabular}{|c|c|}
\hline 4 & $\begin{array}{l}\text { Students show/describe written work for solving a task and/or engage in a discussion of the important } \\
\text { mathematical ideas in the task. During the discussion, students provide complete and thorough } \\
\text { explanations of why their strategy, idea, or procedure is valid; students explain why their strategy works } \\
\text { and/or is appropriate for the problem; students make connections to the underlying mathematical ideas } \\
\text { (e.g., "I divided because we needed equal groups"). } \\
\text { OR } \\
\text { Students show/discuss more than one strategy or representation for solving the task, provide explanations } \\
\text { of why the different strategies/representations were used to solve the task, and/or make connections } \\
\text { between strategies or representations. [Thorough presentation and discussion across strategies or } \\
\text { representation.] }\end{array}$ \\
\hline 3 & $\begin{array}{l}\text { Students show/describe written work for solving a task and/or engage in a discussion of the important } \\
\text { mathematical ideas in the task. During the discussion, students provide explanations of why their strategy, } \\
\text { idea, or procedure is valid and/or students begin to make connections BUT the explanations and } \\
\text { connections are not complete and thorough (e.g., student responses often require extended press from the } \\
\text { teacher, are incomplete, lack precision, or fall short making explicit connections). } \\
\text { OR } \\
\text { Students show/discuss more than one strategy or representation for solving the task, and provide } \\
\text { explanations of how the different strategies/representations were used to solve the task but do not make } \\
\text { connections between different strategies or representations. [Thorough presentation and/or discussion of } \\
\text { individual strategies or representations, but no talk or questioning across different strategies)] }\end{array}$ \\
\hline 2 & $\begin{array}{l}\text { Students show/describe written work for solving the task (e.g., the steps for a multiplication problem, } \\
\text { finding an average, or solving an equation; what they did first, second, etc) but do not engage in a } \\
\text { discussion of why their strategies, procedures, or mathematical ideas work; do not make connection to } \\
\text { mathematical concepts. [Procedural explanations only] } \\
\text { OR Students show/discuss only one strategy or representation for solving the task, } \\
\text { OR Students make presentations of their work with no questioning or prompting from the teacher (to the } \\
\text { presenters or to the class) to explain the mathematical work, make connections, etc. [Presentations with } \\
\text { no discussion] }\end{array}$ \\
\hline 1 & $\begin{array}{l}\text { Students provide brief or one-word answers (e.g., fill in blanks); } \\
\text { OR } \\
\text { Student's responses are non-mathematical. }\end{array}$ \\
\hline $\mathbf{0}$ & There was no discussion of the task. \\
\hline N/A & Reason: \\
\hline
\end{tabular}

IQA Mathematics Lesson Observation Rubrics and Checklists, Melissa Boston (C2012

For permission to use, contact Melissa Boston, bostonm@duq.edu, 412-396-6109 
Rigor of Teachers' Questions

\begin{tabular}{|c|l|}
\hline \multicolumn{2}{|c|}{ Rubric AR-Q: Questioning } \\
\hline $\mathbf{4}$ & $\begin{array}{l}\text { The teacher consistently asks academically relevant questions that provide opportunities for students to } \\
\text { elaborate and explain their mathematical work and thinking (probing, generating discussion), identify } \\
\text { and describe the important mathematical ideas in the lesson, or make connections between ideas, } \\
\text { representations, or strategies (exploring mathematical meanings and relationships). }\end{array}$ \\
\hline $\mathbf{3}$ & $\begin{array}{l}\text { At least } 2 \text { times during the lesson, the teacher asks academically relevant questions (probing, } \\
\text { generating discussion, exploring mathematical meanings and relationships). }\end{array}$ \\
\hline $\mathbf{2}$ & $\begin{array}{l}\text { There are one or more superficial, trivial, or formulaic efforts to ask academically relevant questions } \\
\text { probing, generating discussion, exploring mathematical meanings and relationships) (i.e., every } \\
\text { student is asked the same question or set of questions) or to ask students to explain their reasoning; } \\
\text { OR only one (1) strong effort is made to ask academically relevant questions. }\end{array}$ \\
\hline $\mathbf{1}$ & $\begin{array}{l}\text { The teacher asks procedural or factual questions that elicit mathematical facts or procedure or require } \\
\text { brief, single word responses. }\end{array}$ \\
\hline $\mathbf{0}$ & $\begin{array}{l}\text { The teacher did not ask questions during the lesson, or the teacher's questions were not relevant to the } \\
\text { mathematics in the lesson. }\end{array}$ \\
\hline Reason:
\end{tabular}

IQA Mathematics Lesson Observation Rubrics and Checklists, Melissa Boston (C2012

For permission to use, contact Melissa Boston, bostonm@duq.edu, 412-396-6109 
Under Development: Mathematical Residue Rubric

Extent to which the whole-group discussion builds new, important mathematical ideas

4 The discussion following students' work on the task surfaces the important mathematical ideas, concepts, or connections embedded in the task and serves to extend or solidify students' understanding of the main mathematical goals/ideas/concepts of the lesson. The discussion leaves behind important mathematical residue.

3 During the discussion following students' work on the task, the important mathematical ideas, concepts, or connections begin to surface, are wrestled with by students, but are not pursued in depth or have not materialized/solidified by the close of the lesson. The lesson is beginning to amount to something mathematically but the mathematics is only partially developed; perhaps due to time or student readiness.

2 During the discussion following students' work on the task, the important mathematical ideas, concepts, or connections in the task are explained or made explicit by the teacher primarily (i.e., the teacher is telling students what connections should have been made; students take notes or provide brief answers but do not make meaningful mathematical contributions to the discussion, students make superficial contributions that are taken over by the teacher).

The discussion is mathematical, but does not address the concepts, ideas, or connections embedded in the task (random or not consistent with the mathematical goal) OR the discussion is about mathematics that is not relevant/important for the group of students.

1 Important mathematical ideas do not surface during the discussion following students' work on the task. There is no apparent mathematical goal; the discussion does not focus on developing (or building up) students' understanding of the important mathematical ideas. The discussion was about non-mathematical aspects of the task and did not leave behind mathematical residue.

$0 \quad$ There was no discussion following the task.

IQA Mathematics Lesson Observation Rubrics and Checklists, Melissa Boston (C2012 
Part 3: Scoring Sheet

COMPLETE A SCORING SHEET FOR EACH OBSERVATION. CONNECT TO COVER SHEET.

Observer:

Lesson Code:

Academic Rigor

\begin{tabular}{|l|l|l|}
\hline Dimension & Rater 1 & Rater 2 \\
\hline Rubric 1: Potential of the Task & & \\
\hline Rubric 2: Implementation of the Task & & \\
\hline $\begin{array}{l}\text { Rubric 3: Student Discussion Following the } \\
\text { Task }\end{array}$ & & \\
\hline Rubric AR-Q: Questioning & & \\
\hline Rubric AR-X: Mathematical Residue & & \\
\hline
\end{tabular}

Accountable Talk

\begin{tabular}{|l|l|l|}
\hline Dimension & Rater 1 & Rater 2 \\
\hline Rubric AT1: Participation & & \\
\hline Rubric AT2: Teacher's Linking & & \\
\hline Rubric AT3: Students' Linking & & \\
\hline Rubric AT4: Asking (Teacher Press) & & \\
\hline Rubric AT5: Providing (Student Responses) & & \\
\hline
\end{tabular}

IQA Mathematics Lesson Observation Rubrics and Checklists, Melissa Boston (C2012

For permission to use, contact Melissa Boston, bostonm@duq.edu, 412-396-6109 


\section{Appendix L}

\section{Learning to Notice Framework}

Van Es, E. (2011). A framework for learning to notice student thinking. In M.G. Sherin, V.R. Jacobs \& R.A. Phillip (Eds.) Mathematics teacher noticing: Seeing through teachers' eyes, (pp.134-151). New York: Routledge.

\begin{tabular}{|c|c|c|c|c|}
\hline & Baseline (1) & Mixed (2) & Focused (3) & $\begin{array}{l}\text { Extended } \\
\text { (4) }\end{array}$ \\
\hline \multirow[t]{2}{*}{$\begin{array}{l}\text { What Teacher's } \\
\text { Notice }\end{array}$} & $\begin{array}{l}\text { Attend to whole } \\
\text { class } \\
\text { environment, } \\
\text { behavior and } \\
\text { learning and to } \\
\text { teacher } \\
\text { pedagogy. }\end{array}$ & $\begin{array}{l}\text { Primarily attend } \\
\text { to teacher } \\
\text { pedagogy }\end{array}$ & $\begin{array}{l}\text { Attend to } \\
\text { particular } \\
\text { student's' } \\
\text { mathematical } \\
\text { thinking. }\end{array}$ & $\begin{array}{l}\text { Attend to } \\
\text { the } \\
\text { relationship } \\
\text { between } \\
\text { particular } \\
\text { students' } \\
\text { mathematica } \\
1 \text { thinking } \\
\text { and between } \\
\text { teaching } \\
\text { strategies } \\
\text { and student } \\
\text { mathematica } \\
1 \text { thinking. }\end{array}$ \\
\hline & & $\begin{array}{l}\text { Begin to attend } \\
\text { to particular } \\
\text { students' } \\
\text { mathematical } \\
\text { thinking }\end{array}$ & & \\
\hline \multirow[t]{2}{*}{$\begin{array}{l}\text { How Teachers } \\
\text { Notice }\end{array}$} & $\begin{array}{l}\text { Form general } \\
\text { impressions of } \\
\text { what occurred }\end{array}$ & $\begin{array}{l}\text { Form general } \\
\text { impressions } \\
\text { highlight } \\
\text { noteworthy } \\
\text { events }\end{array}$ & $\begin{array}{l}\text { Highlight } \\
\text { noteworthy } \\
\text { events }\end{array}$ & $\begin{array}{l}\text { Highlight } \\
\text { noteworthy } \\
\text { events }\end{array}$ \\
\hline & $\begin{array}{l}\text { Provide } \\
\text { descriptive and } \\
\text { evaluative } \\
\text { comments }\end{array}$ & $\begin{array}{l}\text { Provide } \\
\text { primarily } \\
\text { evaluative with } \\
\text { some } \\
\text { interpretive } \\
\text { comments }\end{array}$ & $\begin{array}{l}\text { Provide } \\
\text { interpretive } \\
\text { comments }\end{array}$ & $\begin{array}{l}\text { Provide } \\
\text { interpretive } \\
\text { comments }\end{array}$ \\
\hline
\end{tabular}




\begin{tabular}{|l|l|l|l|l|}
\hline & $\begin{array}{l}\text { Provide little or } \\
\text { no evidence to } \\
\text { support analysis }\end{array}$ & $\begin{array}{l}\text { Begin to refer to } \\
\text { specific events } \\
\text { and interactions } \\
\text { as evidence }\end{array}$ & $\begin{array}{l}\text { Refer to specific } \\
\text { events and } \\
\text { interactions as } \\
\text { evidence }\end{array}$ & $\begin{array}{l}\text { Refer to } \\
\text { specific } \\
\text { events and } \\
\text { interactions } \\
\text { as evidence }\end{array}$ \\
\hline & & & $\begin{array}{l}\text { Elaborate on } \\
\text { events and } \\
\text { interactions }\end{array}$ & $\begin{array}{l}\text { Elaborate on } \\
\text { events and } \\
\text { interactions }\end{array}$ \\
\hline & & & $\begin{array}{l}\text { Make } \\
\text { connections } \\
\text { between } \\
\text { events and } \\
\text { principles of } \\
\text { teaching and } \\
\text { learning }\end{array}$ \\
\hline & & & $\begin{array}{l}\text { On the basis } \\
\text { of } \\
\text { interpretatio } \\
\text { ns propose } \\
\text { alternative } \\
\text { pedagogical } \\
\text { solutions }\end{array}$ \\
\hline
\end{tabular}




\section{Appendix M}

\section{Permission to Adapt and Reprint the Learning to Notice Framework}

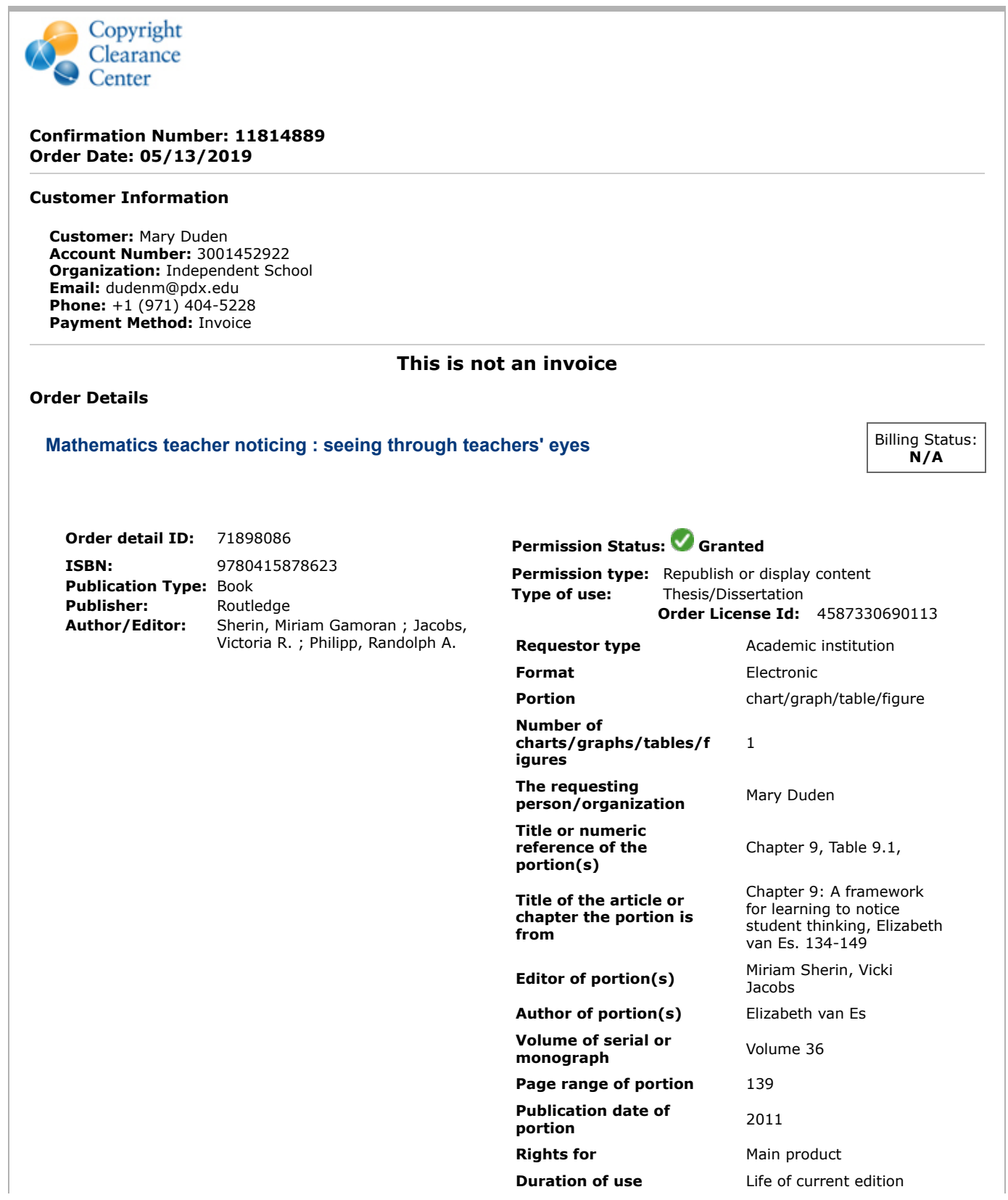

